\title{
EXPERIMENTAL TESTS OF PERTURBATIVE QCD
}

G. Altare1li

CERN - Geneva

\section{CONTENT}

1. - INTRODUCTION

2. - EXPERIMENTAL DETERMINATIONS OF $\alpha_{\mathbf{s}}$

2.1 - Total Hadronic Cross-Section in $\mathrm{e}^{+} \mathrm{e}^{-}$Annihilation

2.2 - Scaling Violations in Deep Inelastic Leptoproduction

2.3 - Quarkonium Decays

$2.4-\mathrm{e}^{+} \mathrm{e}^{-} \rightarrow$ Jets

2.5 - other Processes

2.6 - Summary and Conclusion on $\alpha_{s}$

3. - THE QCD THEORY OF HARD PROCESSES

3.1 - Jets in $\mathrm{e}^{+} \mathrm{e}^{-}$annihilation

3.2 - Deep Inelastic Leptoproduction and the Nucleon Parton Densities

3.3 - Drell-Yan Processes and W/Z Production

3.4 - Hard Processes in $(\vec{p})$ Collisions

4. - CONCLUSIONS

To be published in

Annual Review of Nuclear and Particle Science

Vol. 39 (1989) 


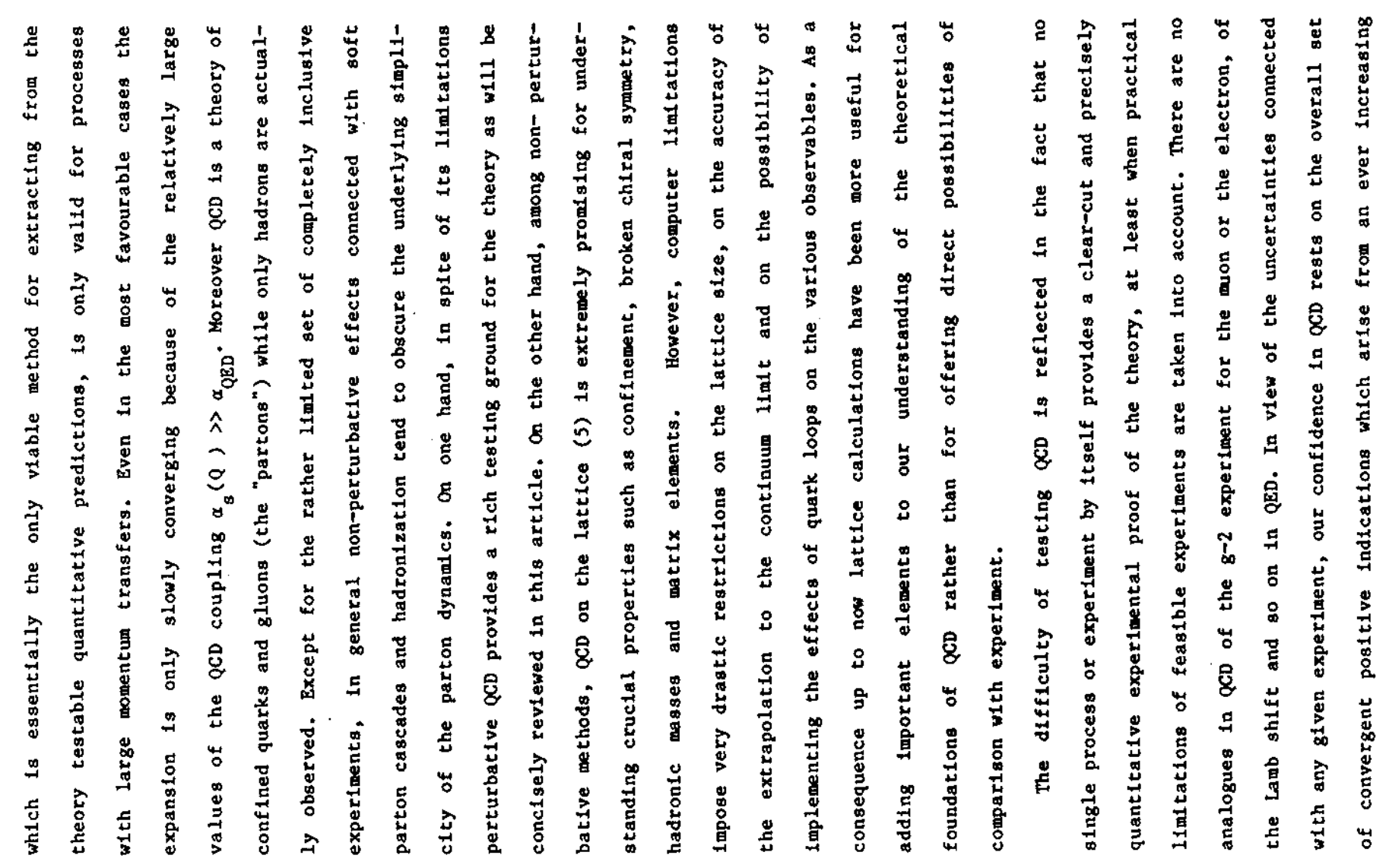

$$
\text { (1) }
$$




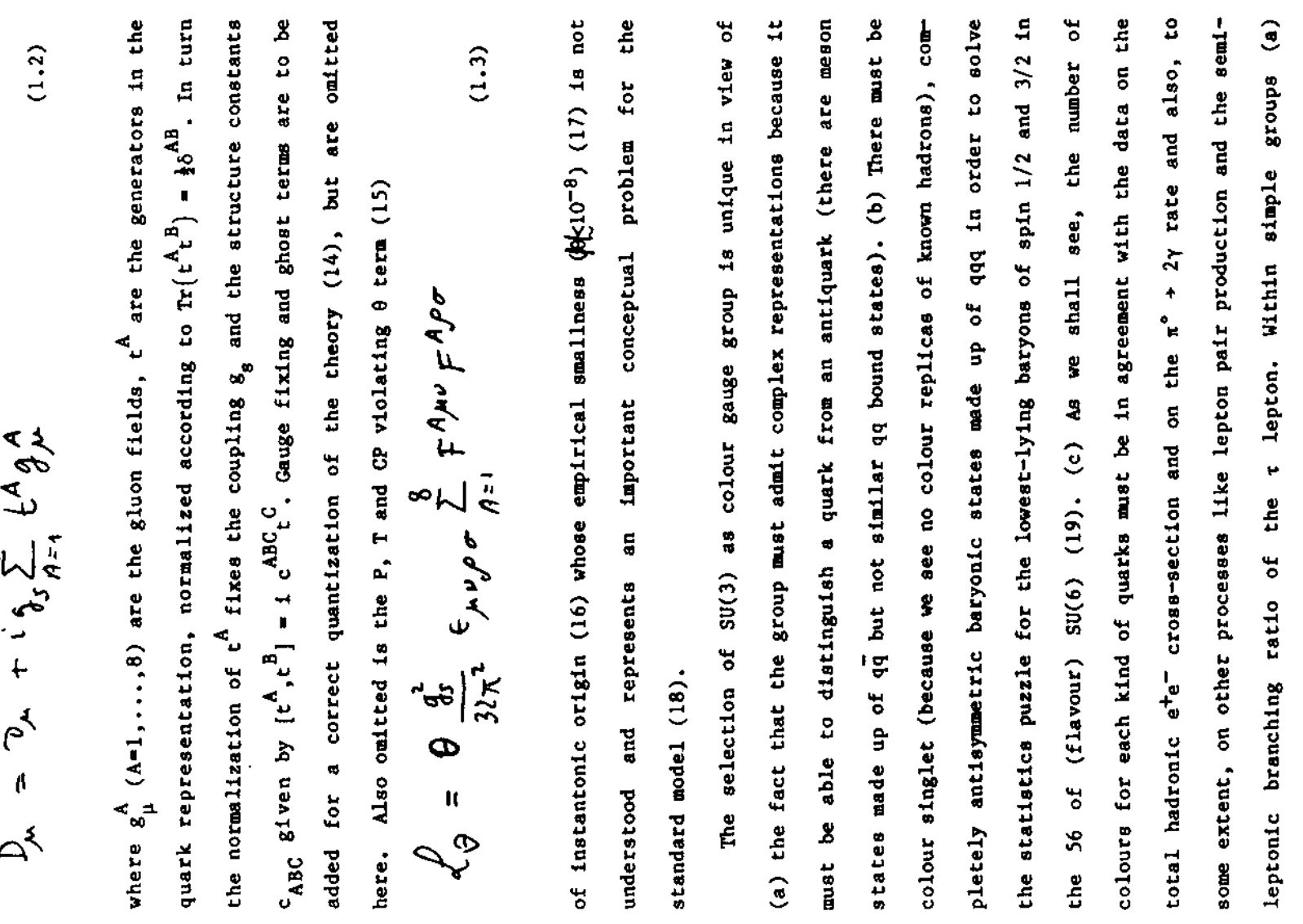

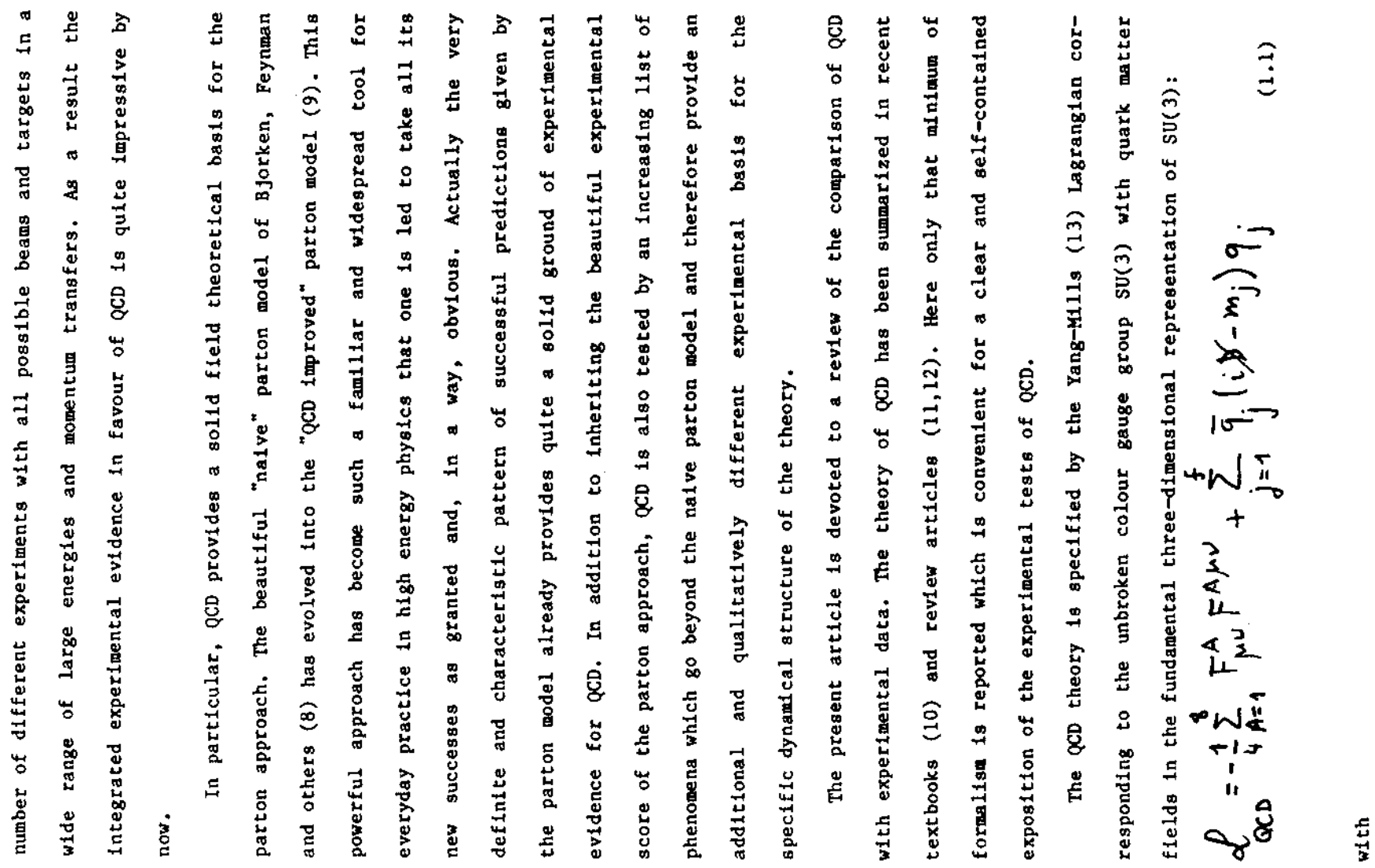



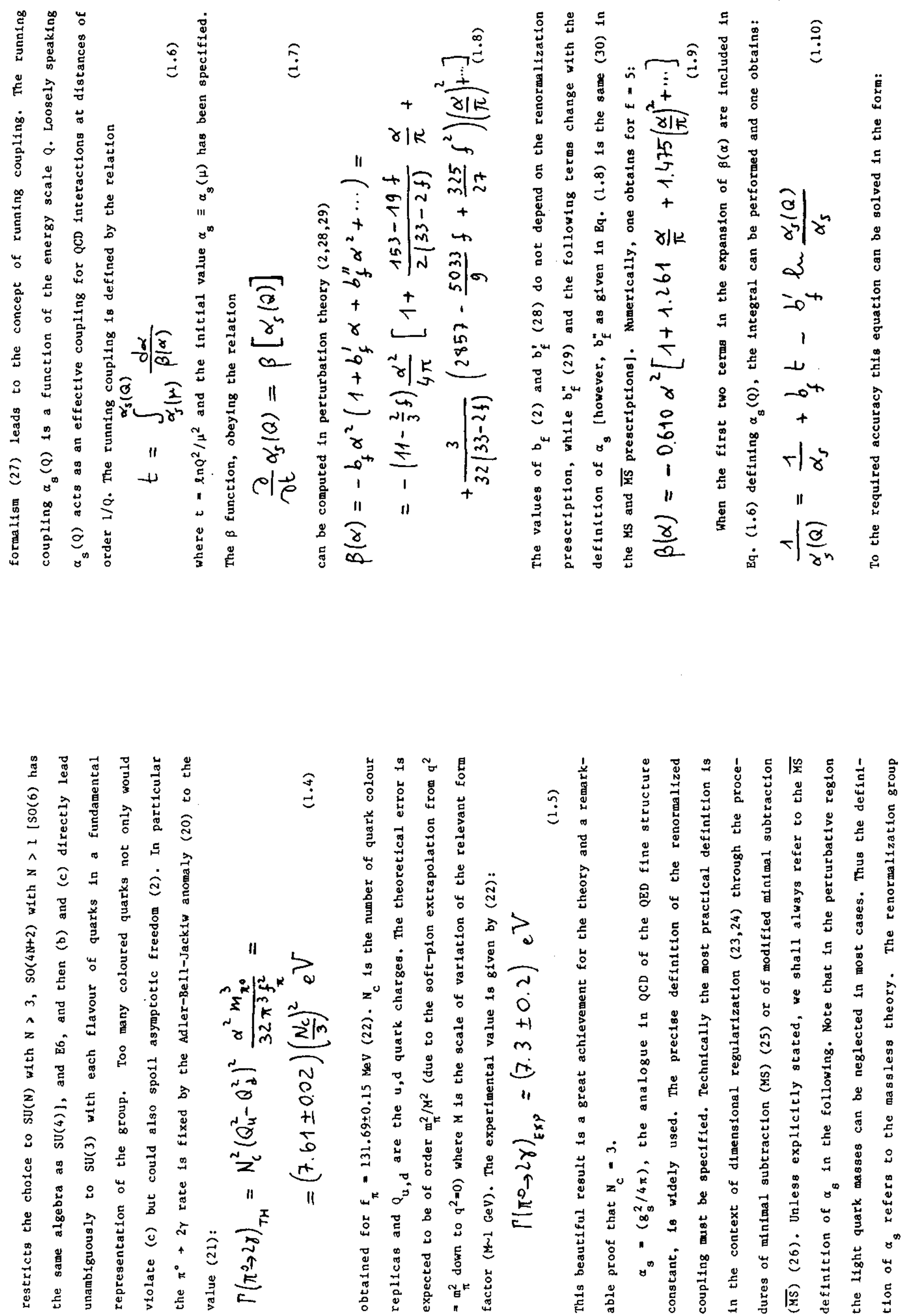


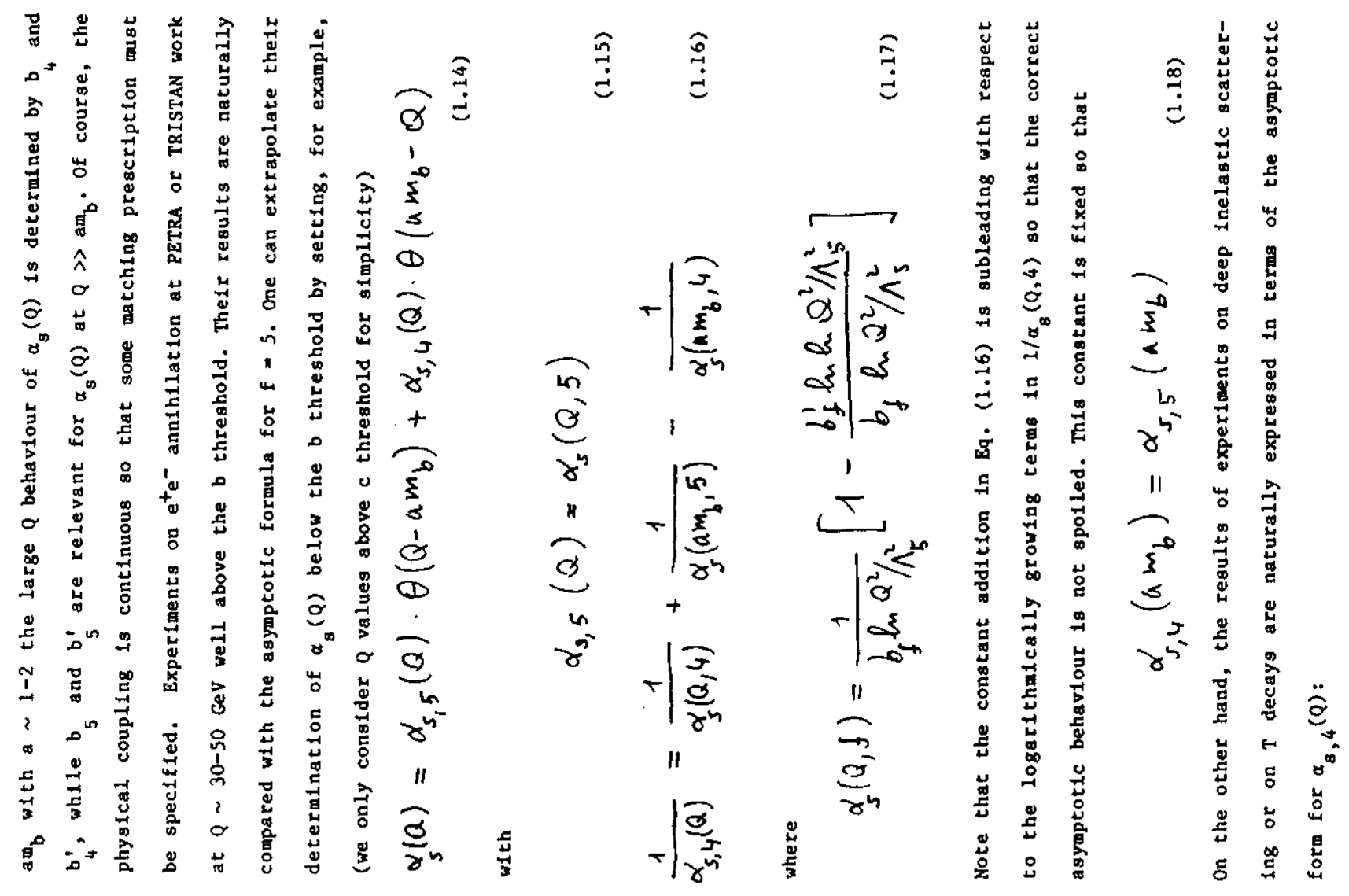

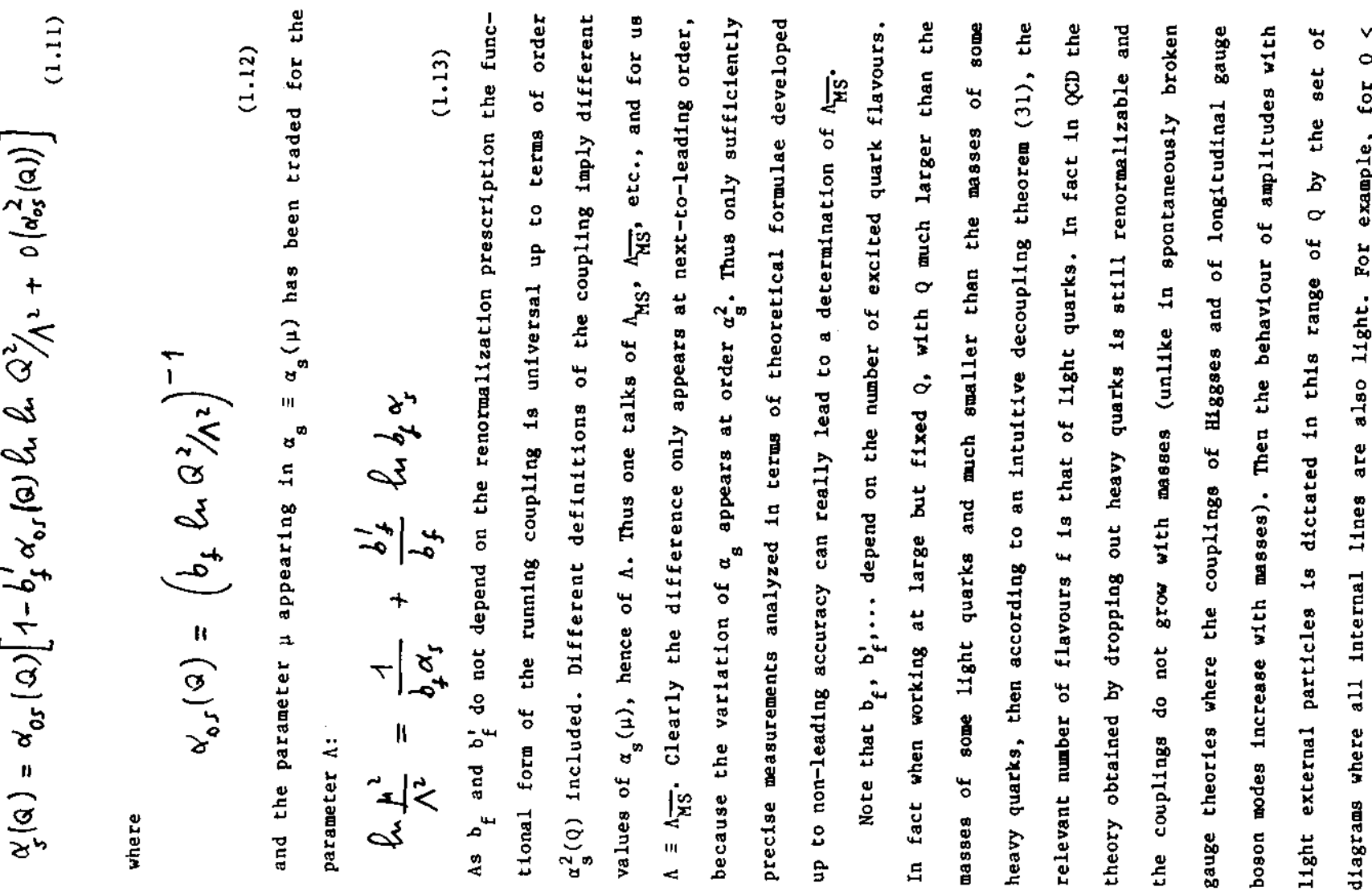



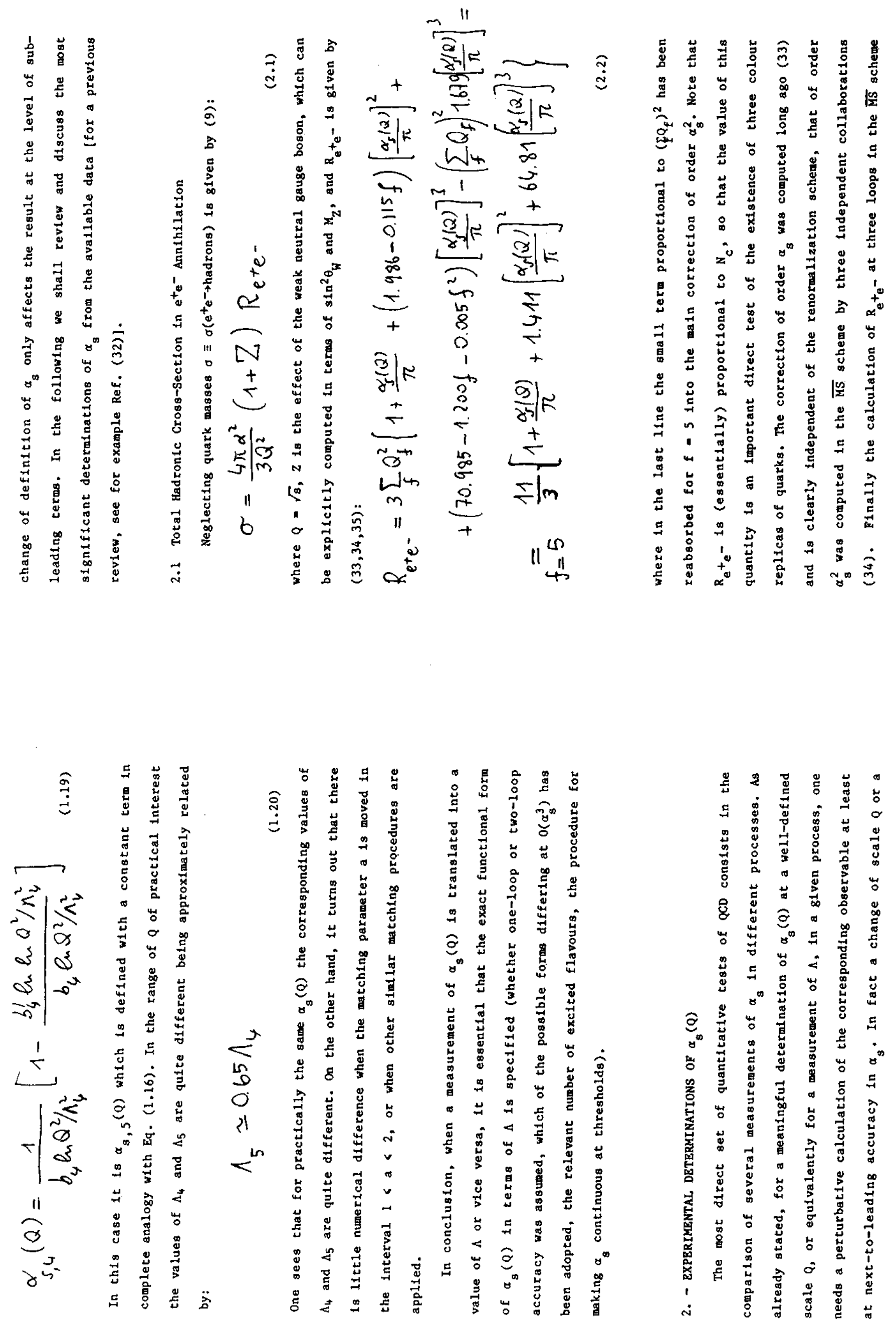

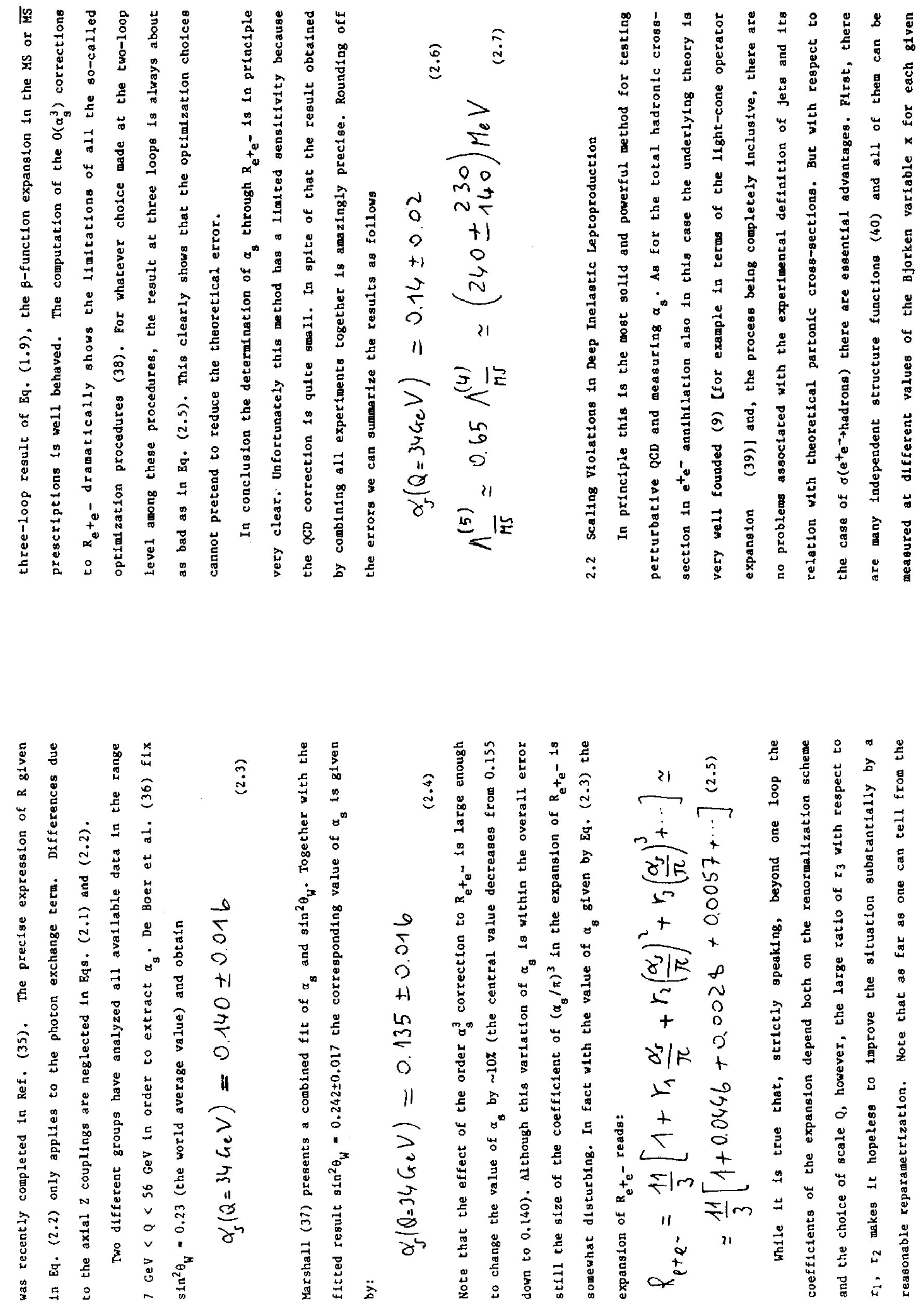


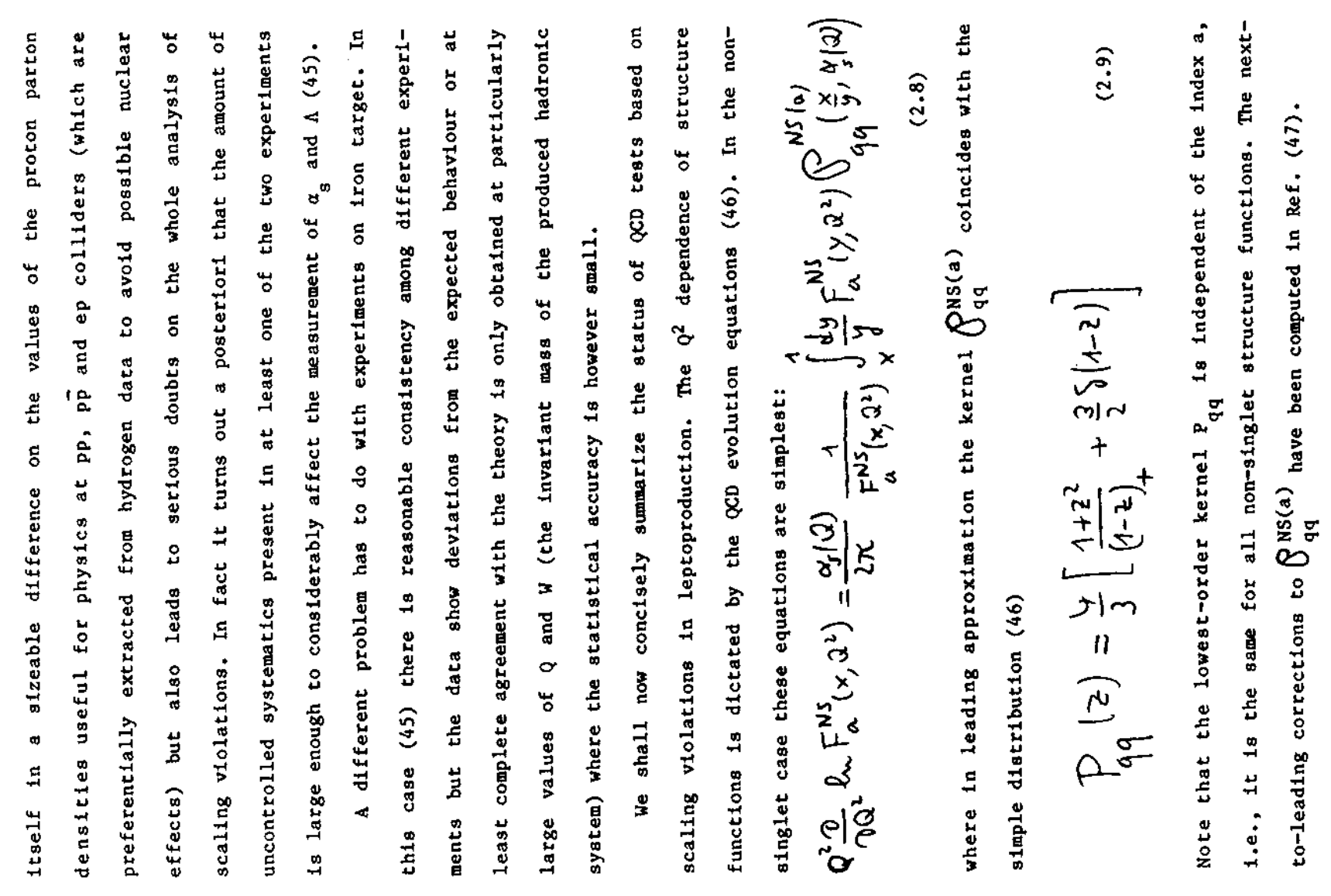

$$
\text { (3) }
$$




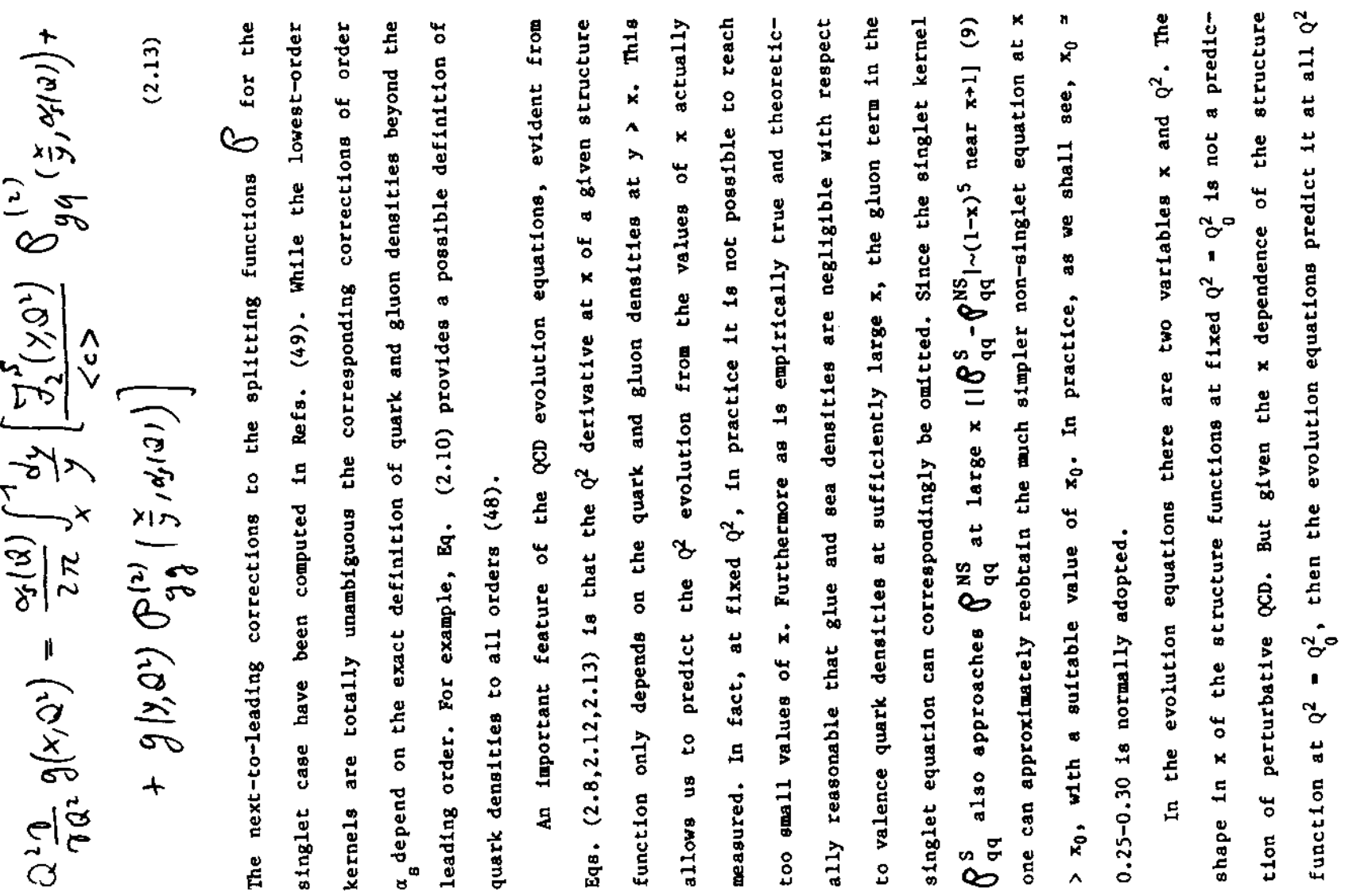

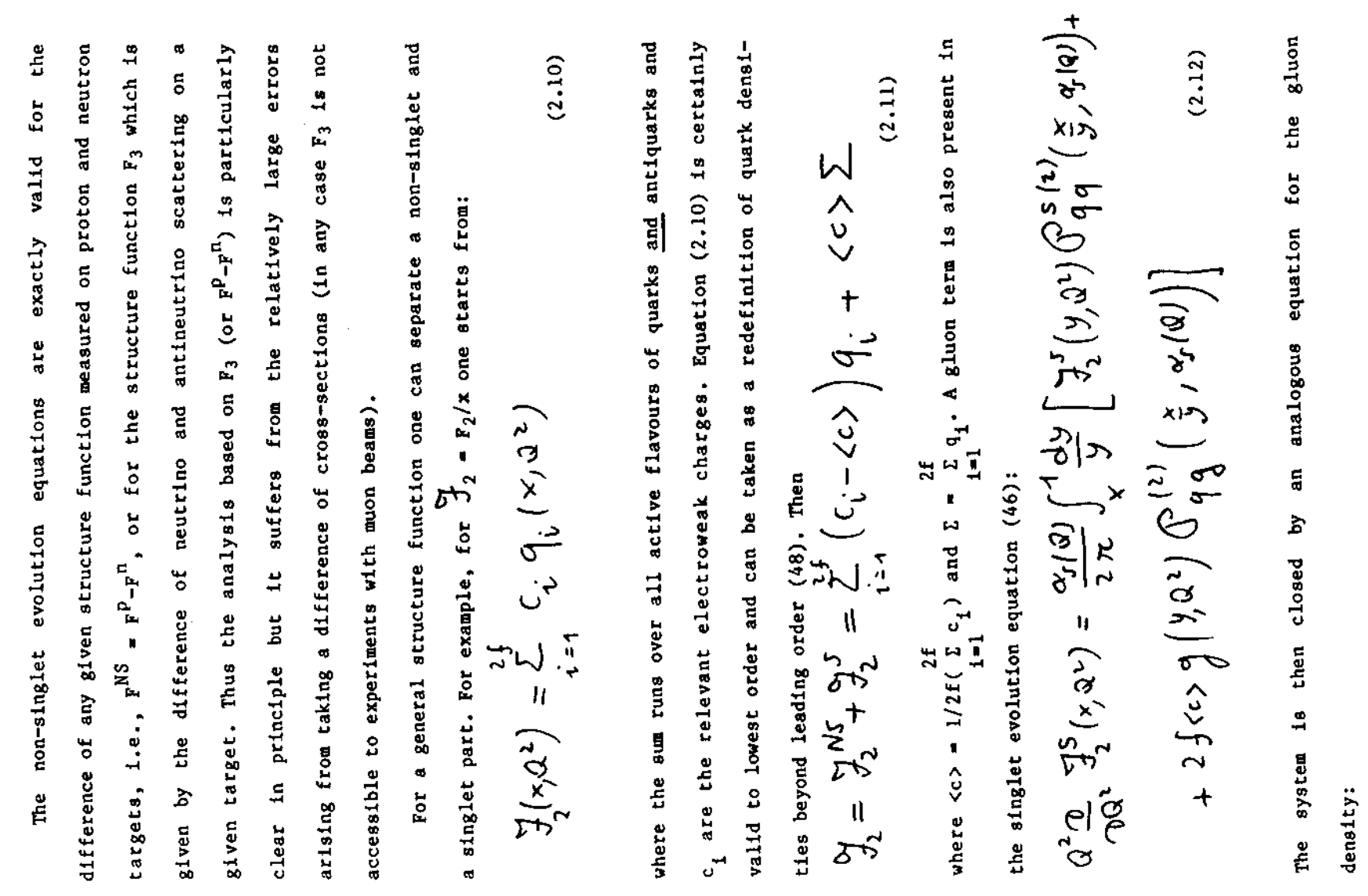


ऽ

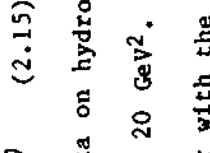

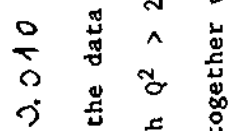

H

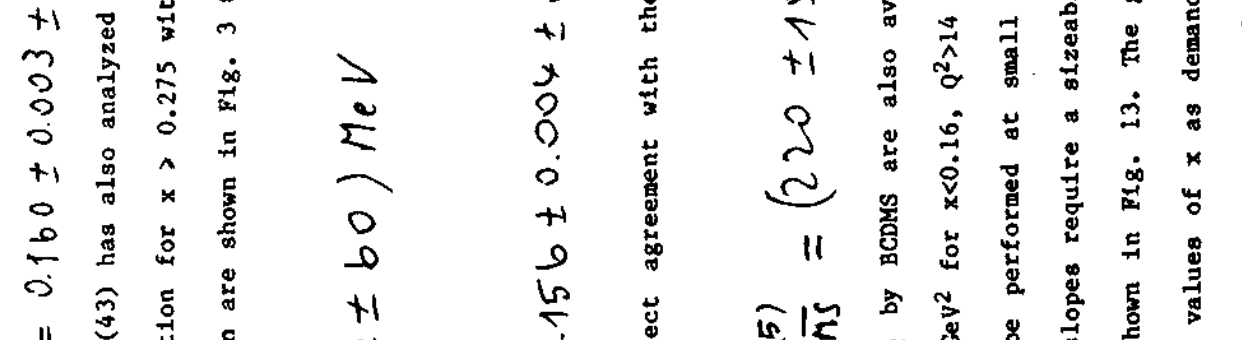

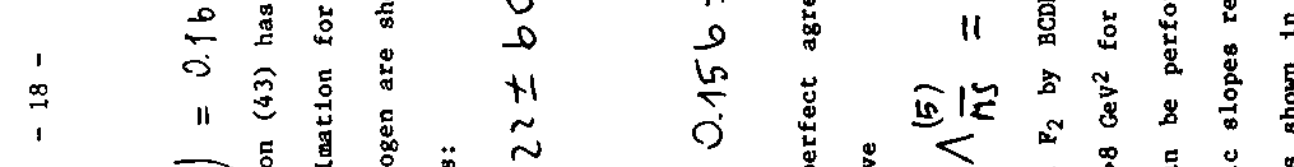

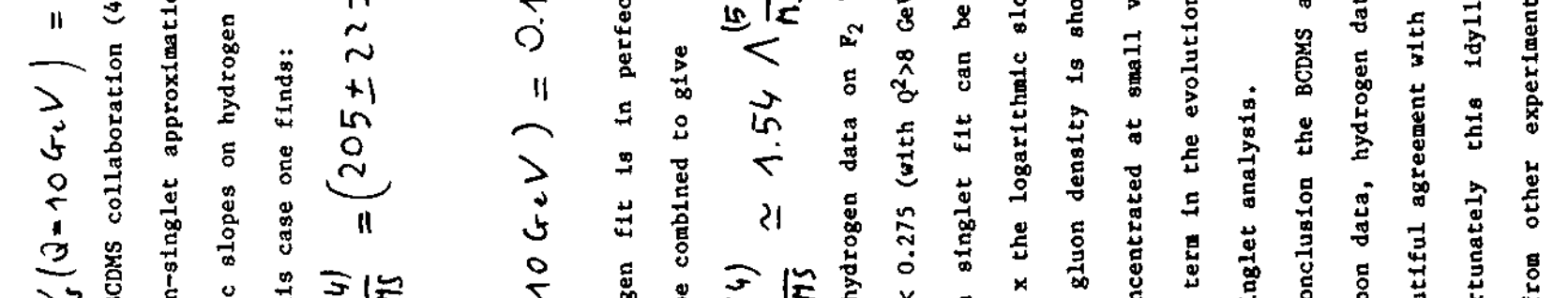

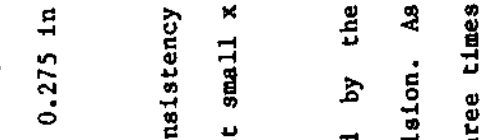

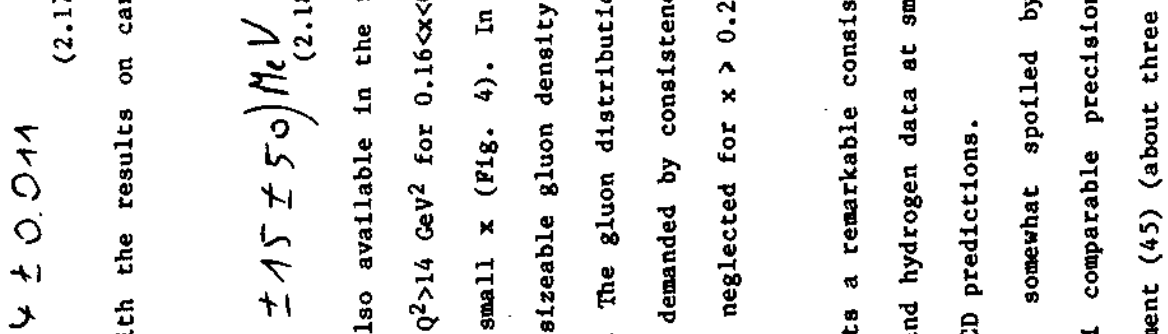

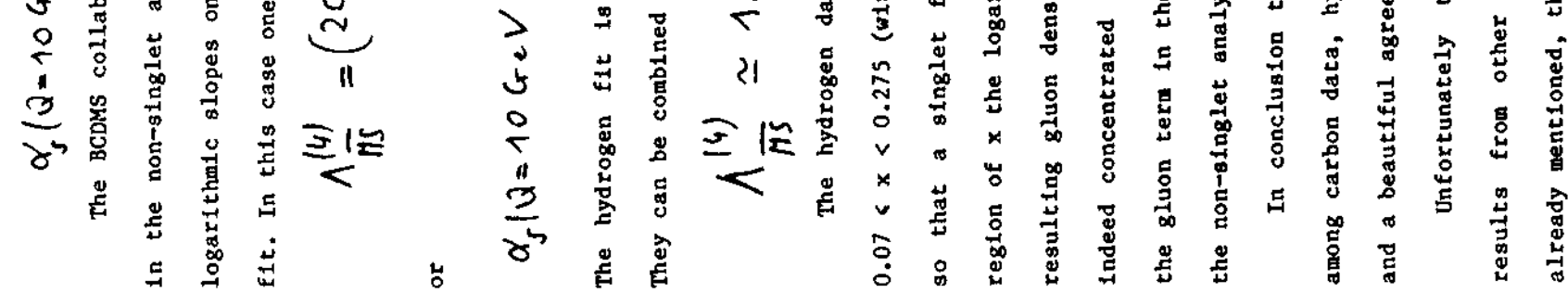

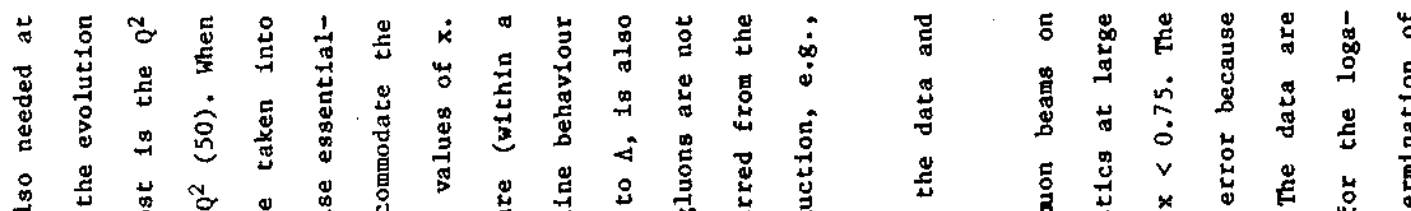

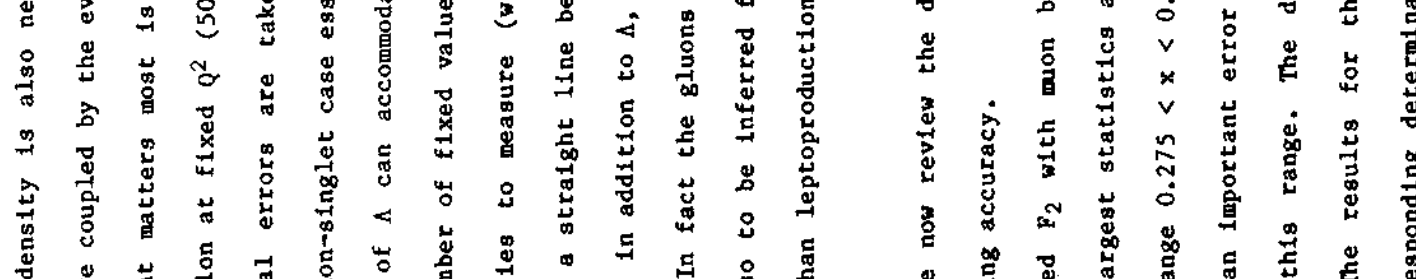

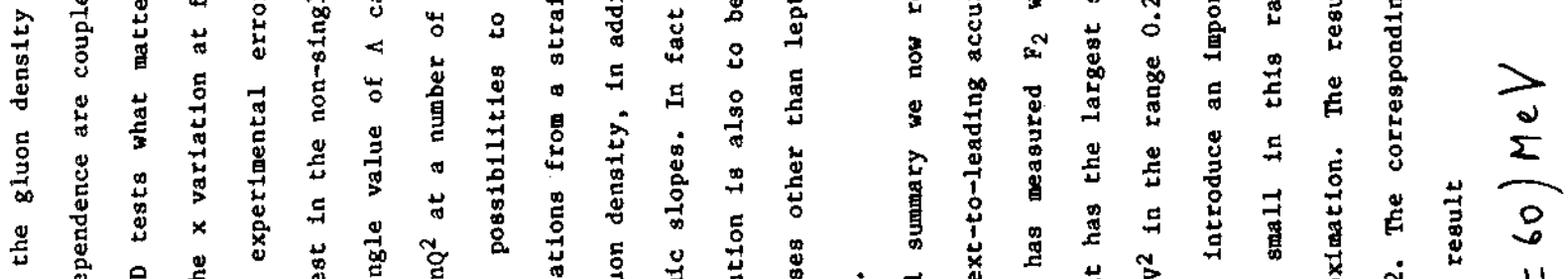

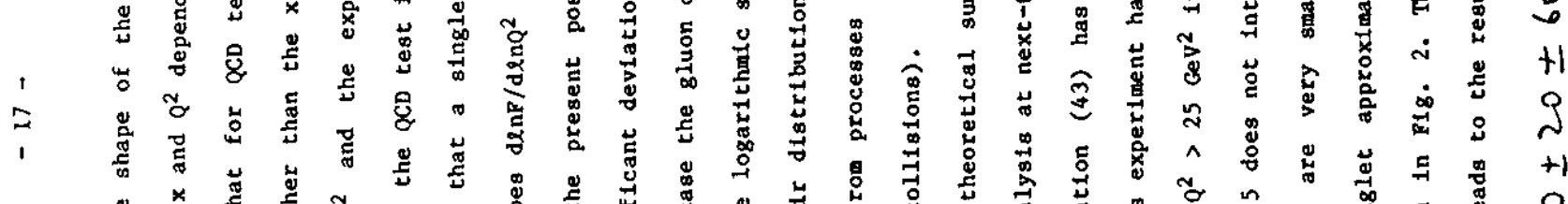

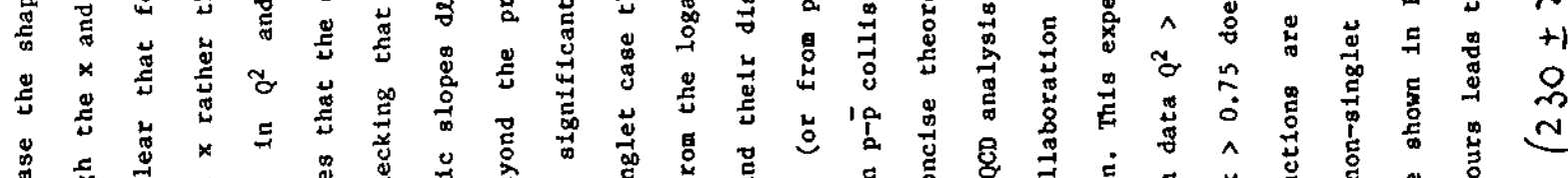

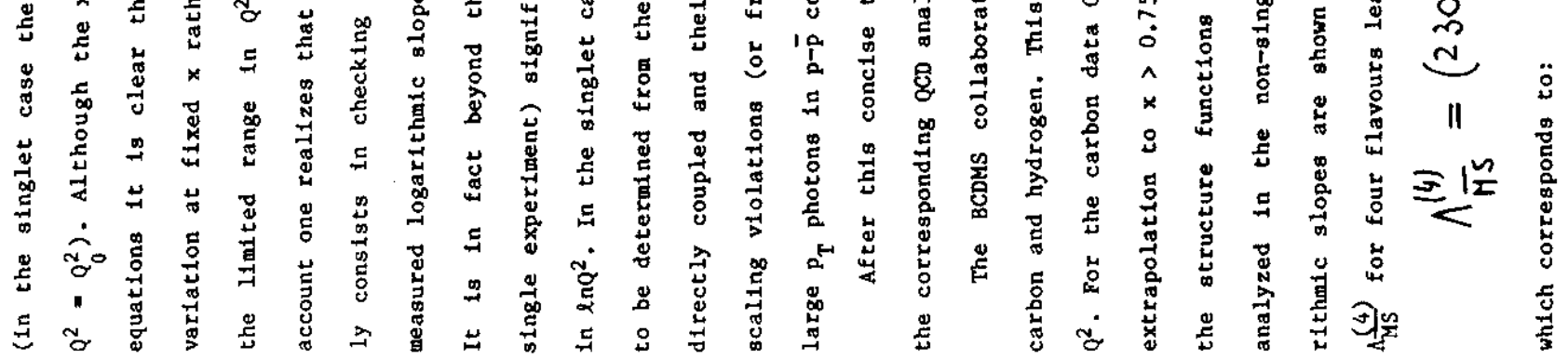




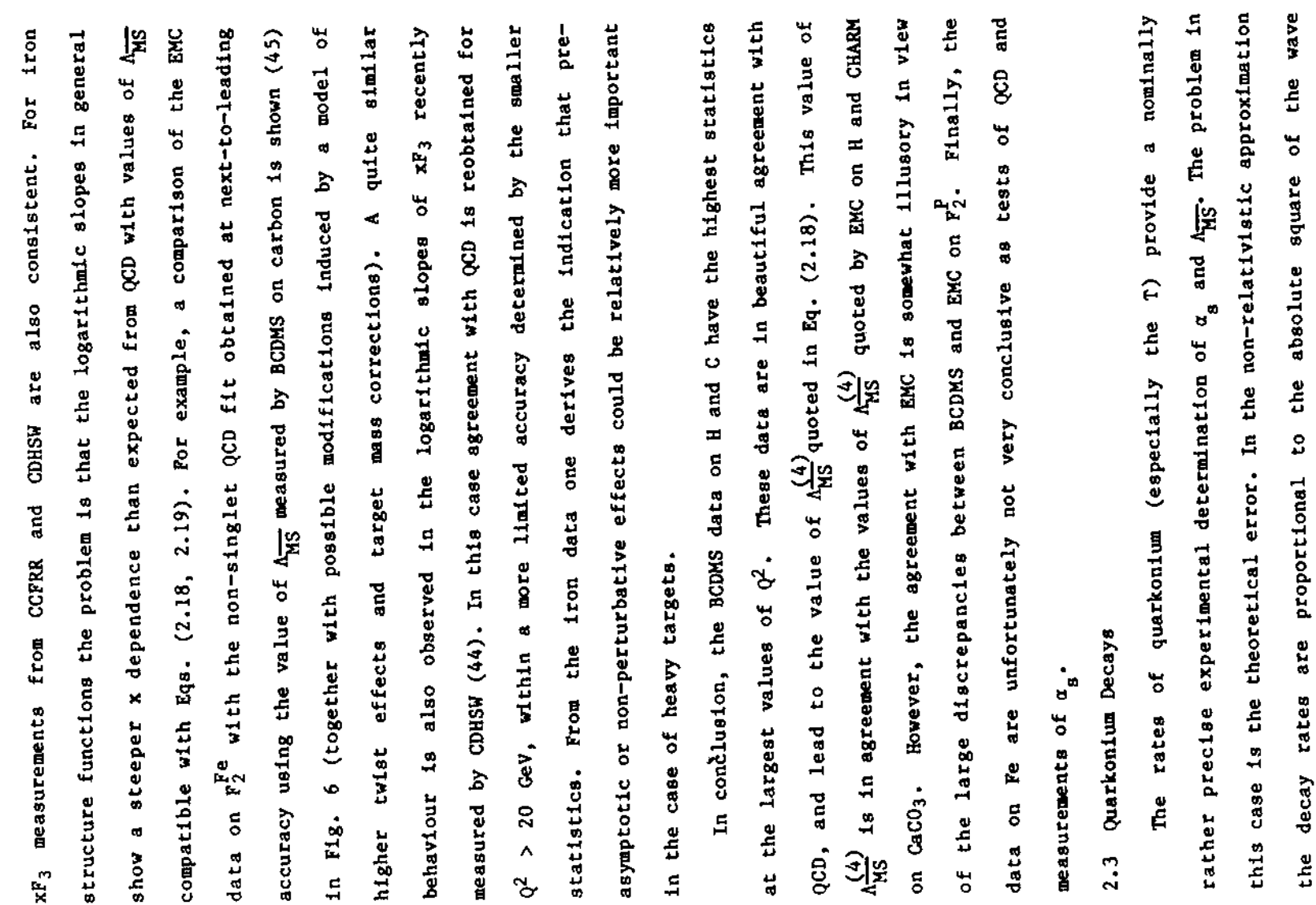

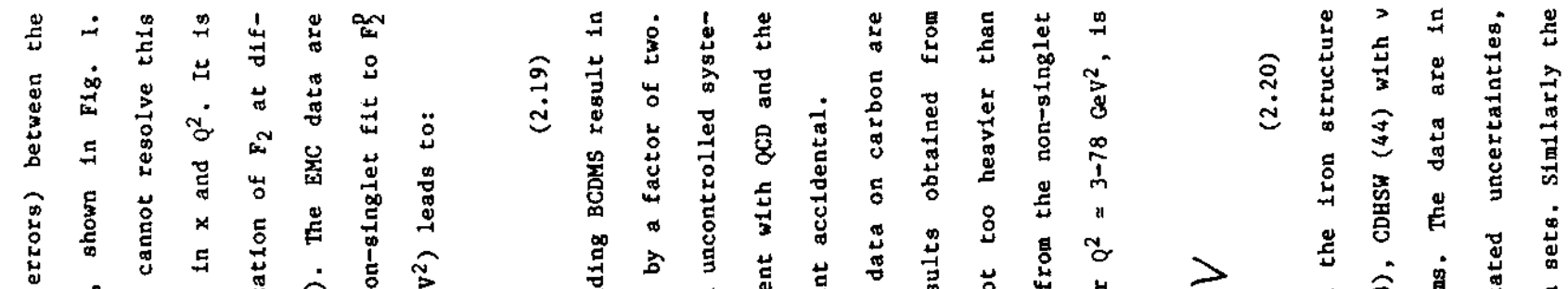

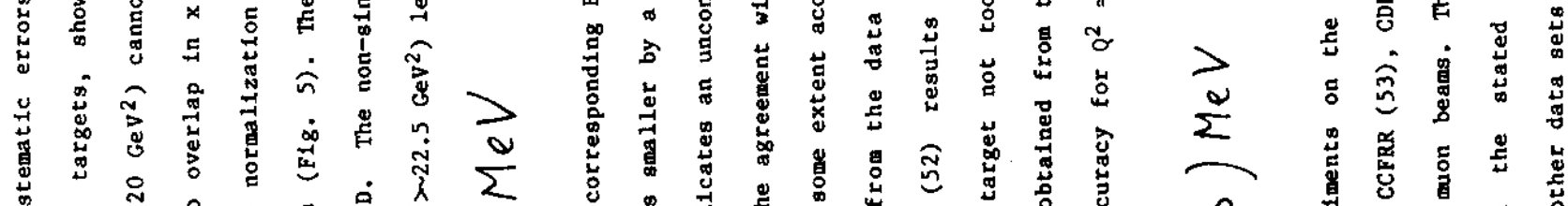

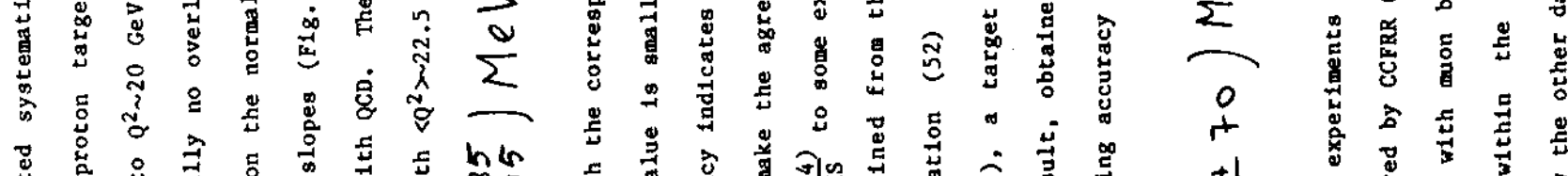

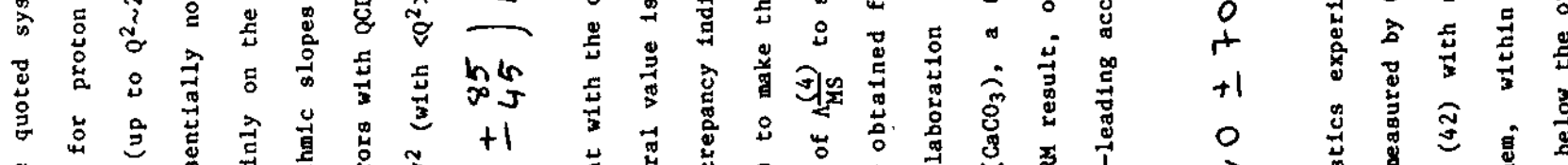

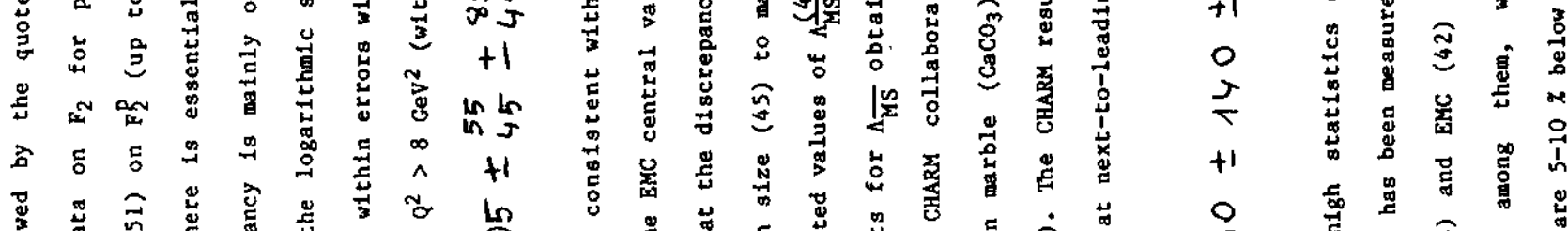

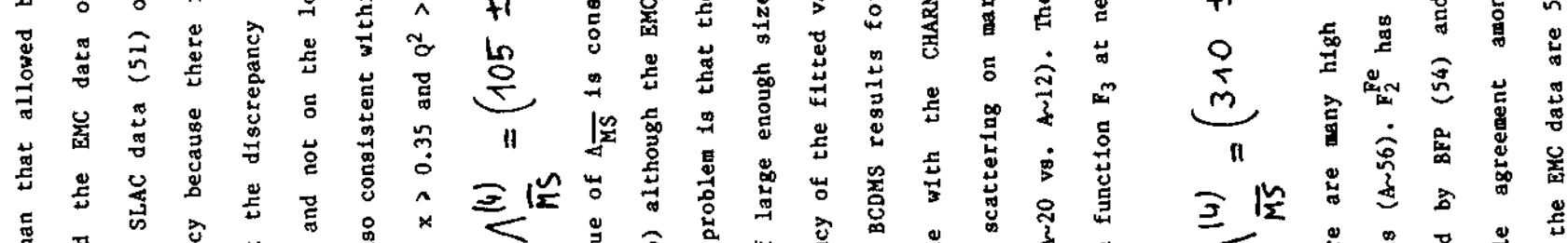

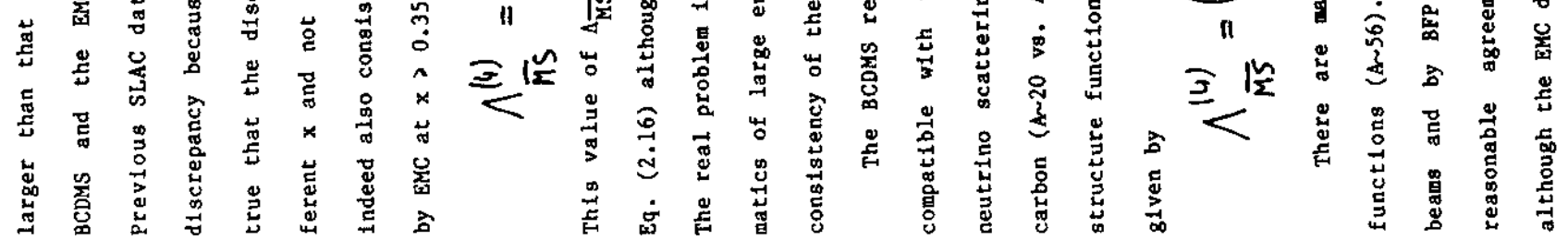




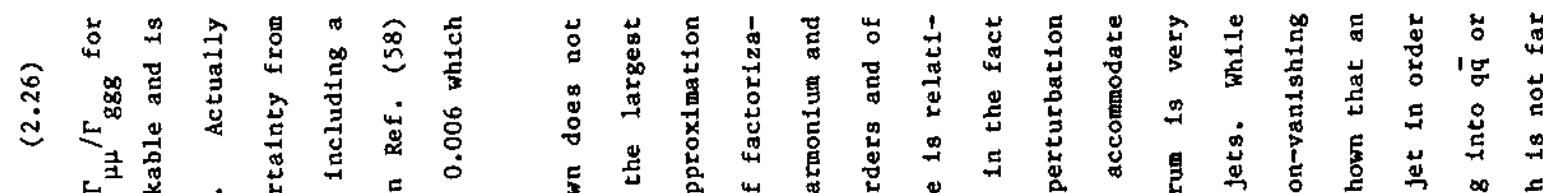

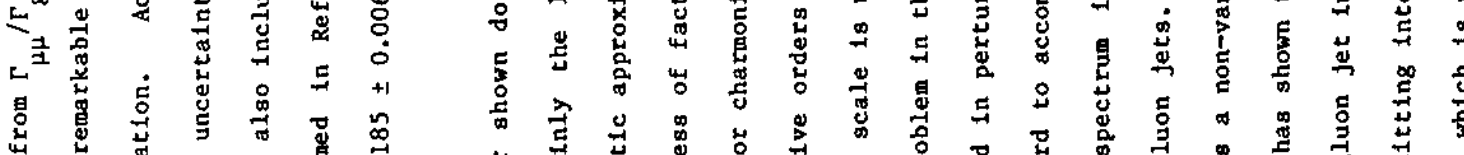

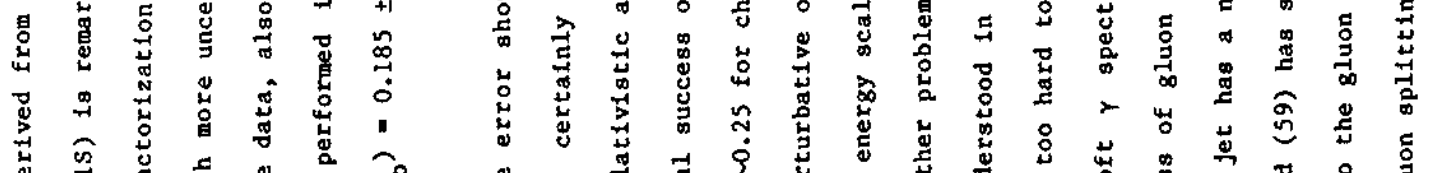

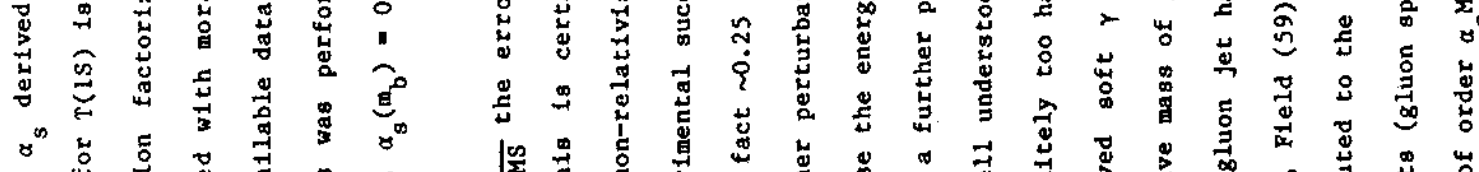

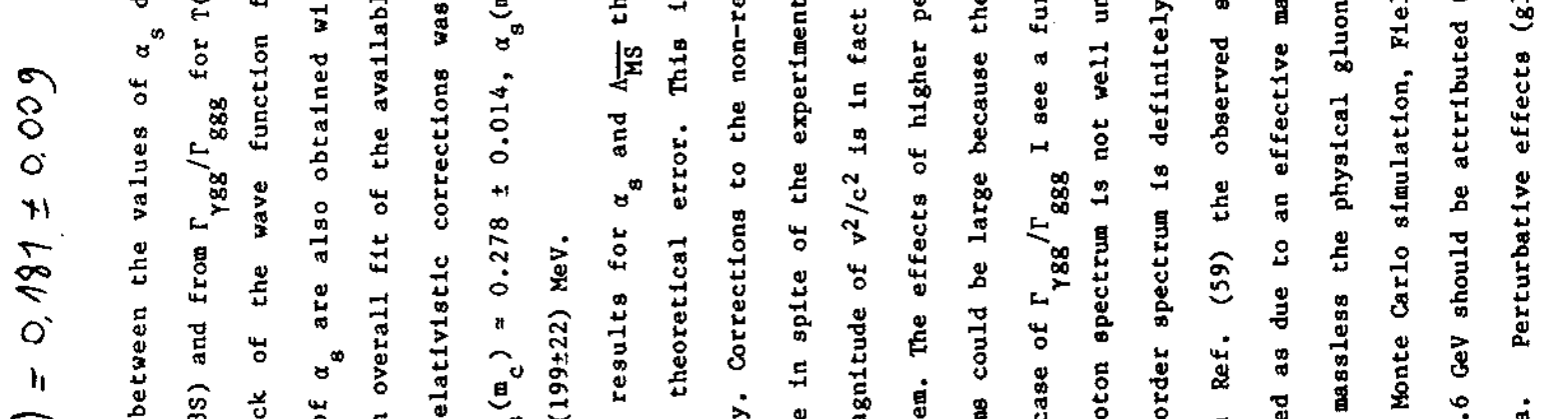

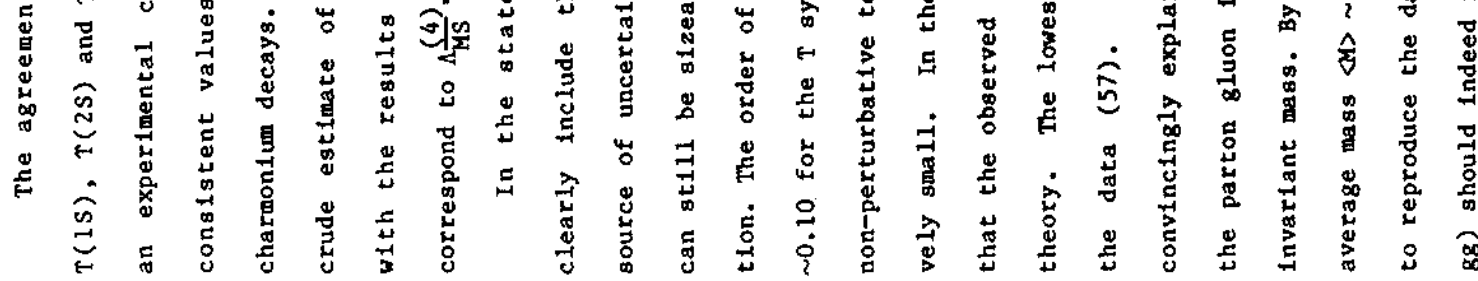

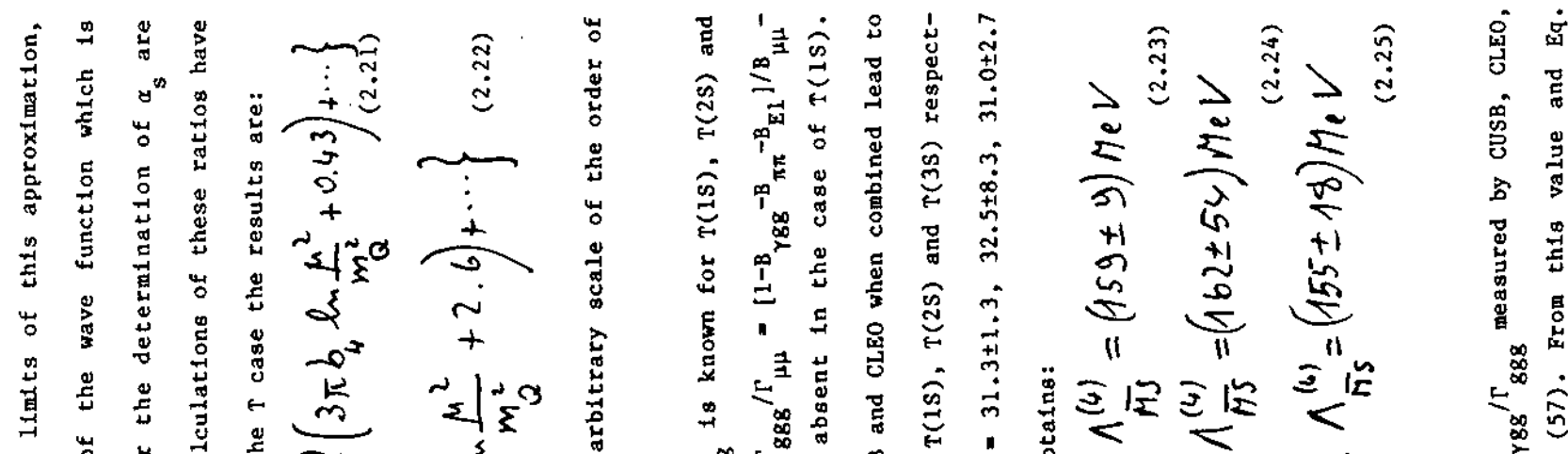

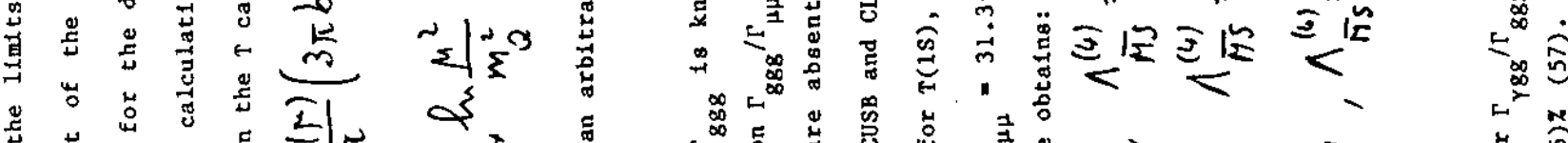

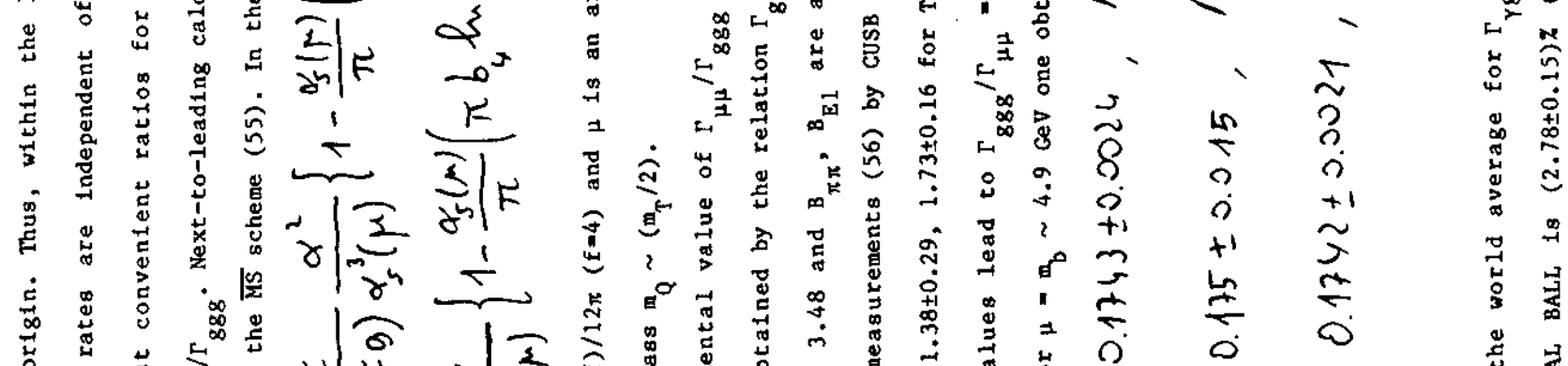

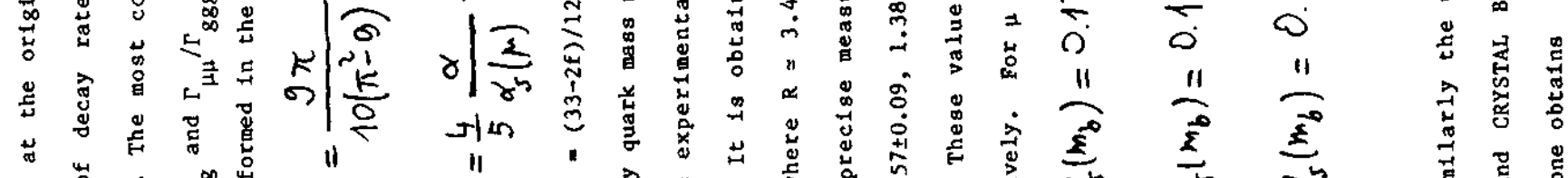

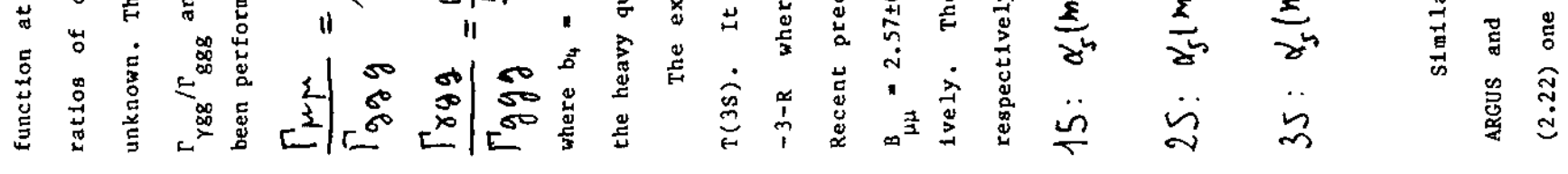



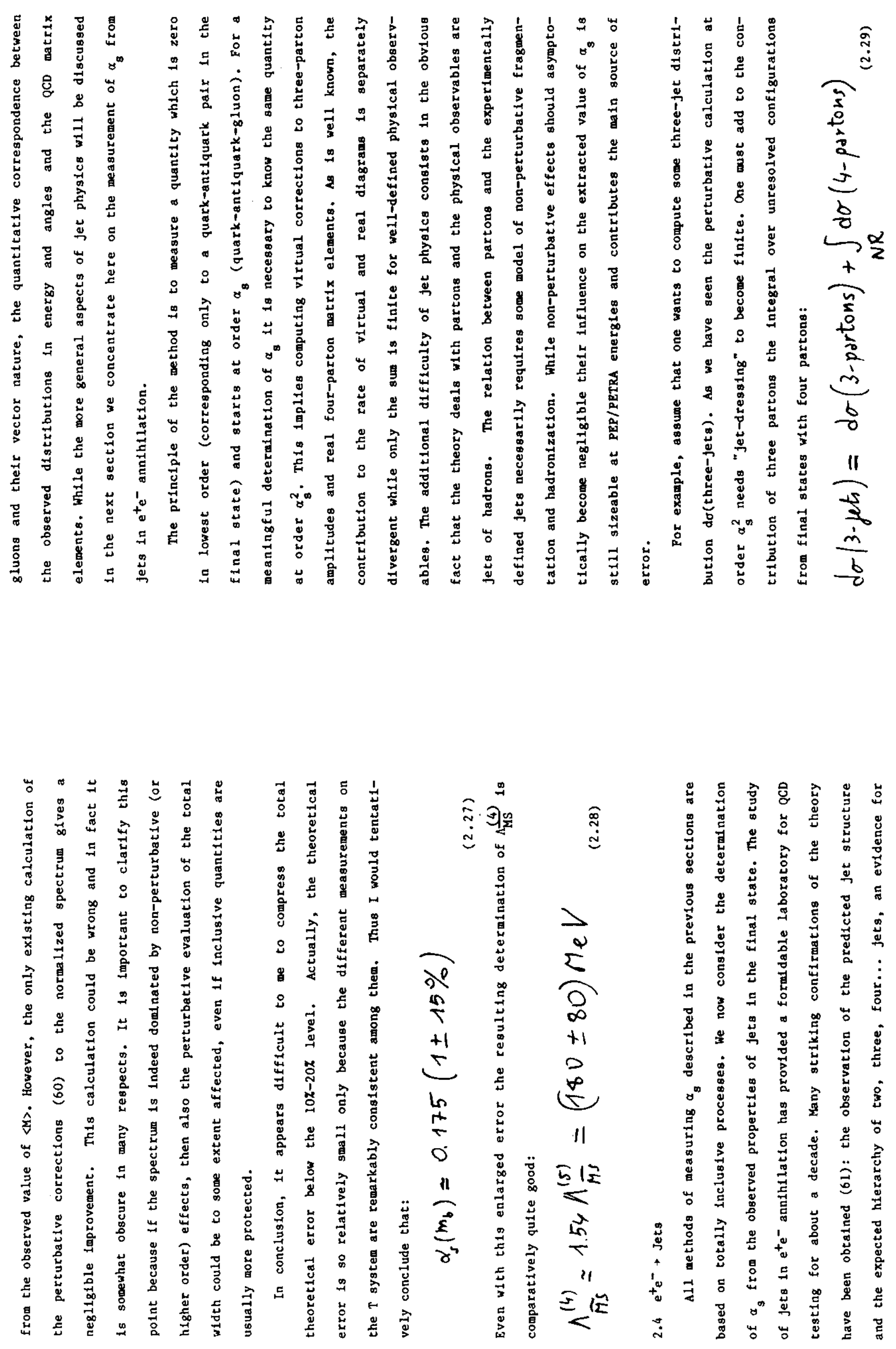


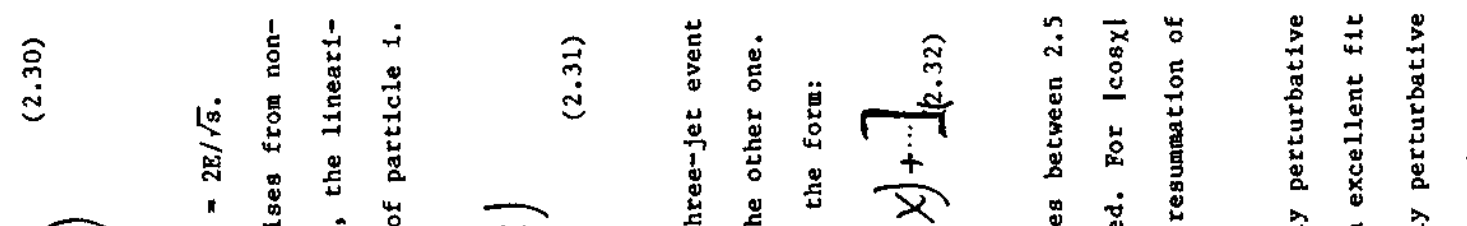

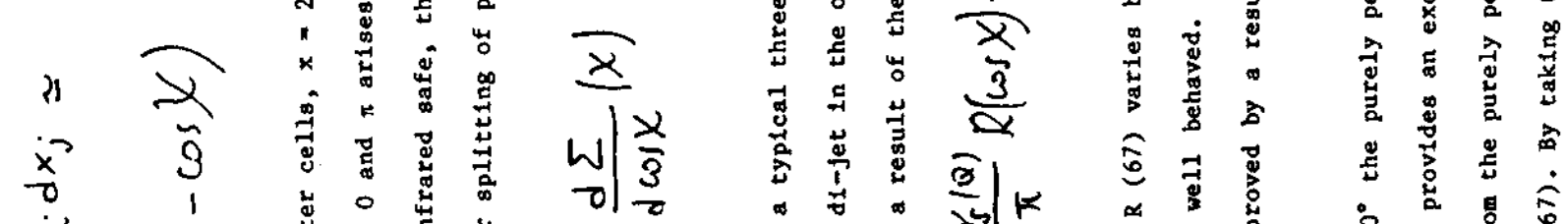

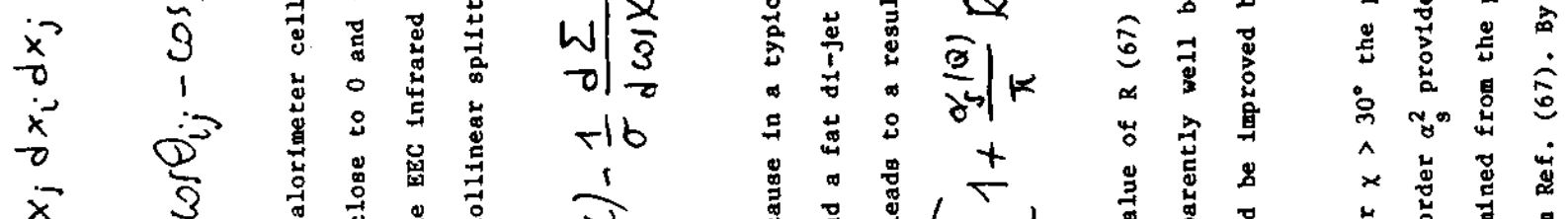

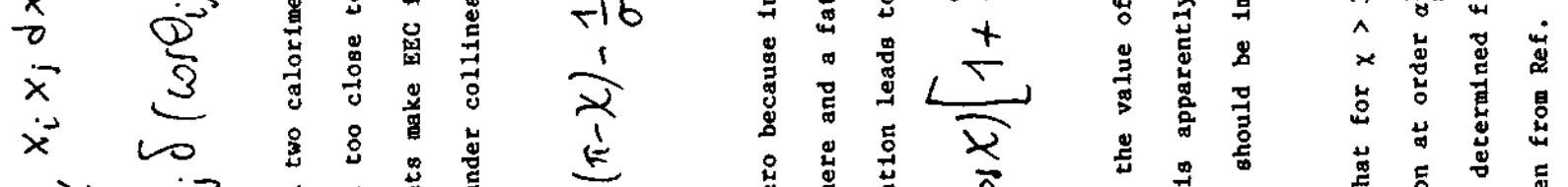
W.

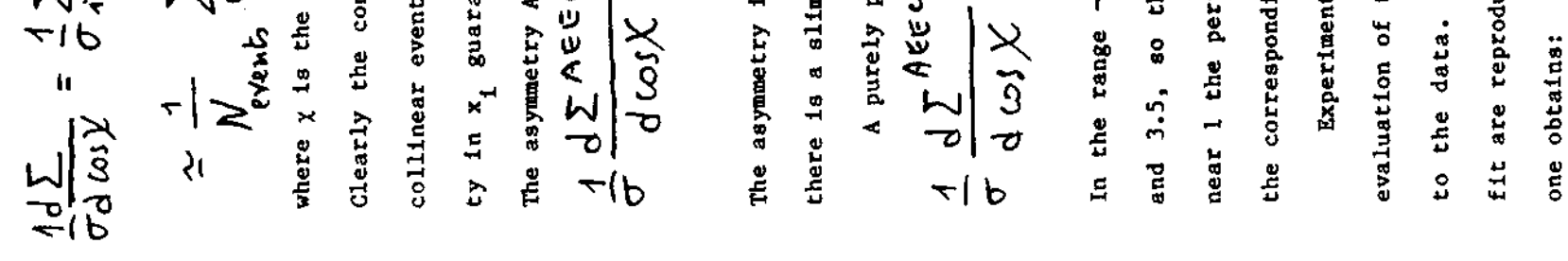
年)

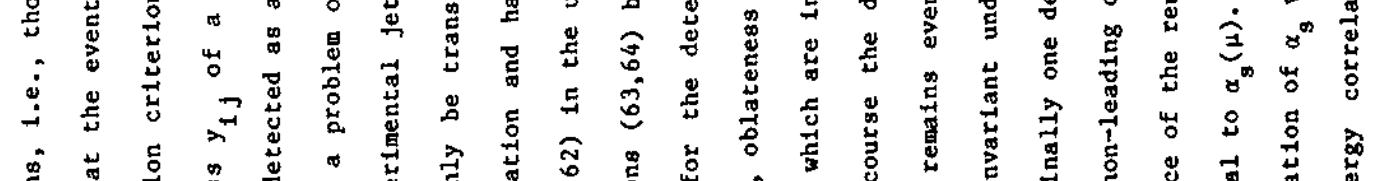
1) II $\therefore 4$

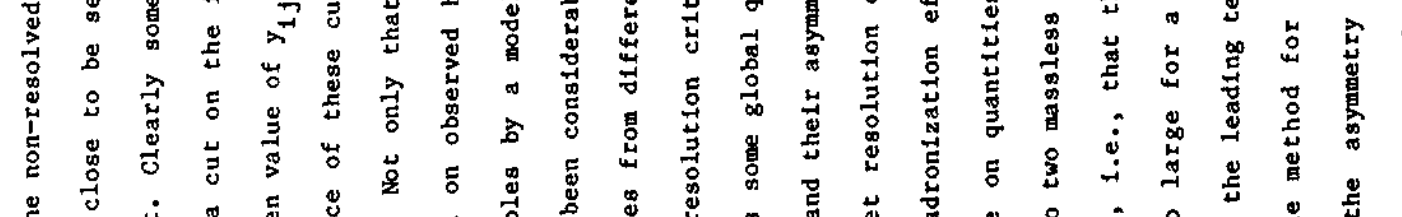
(1)

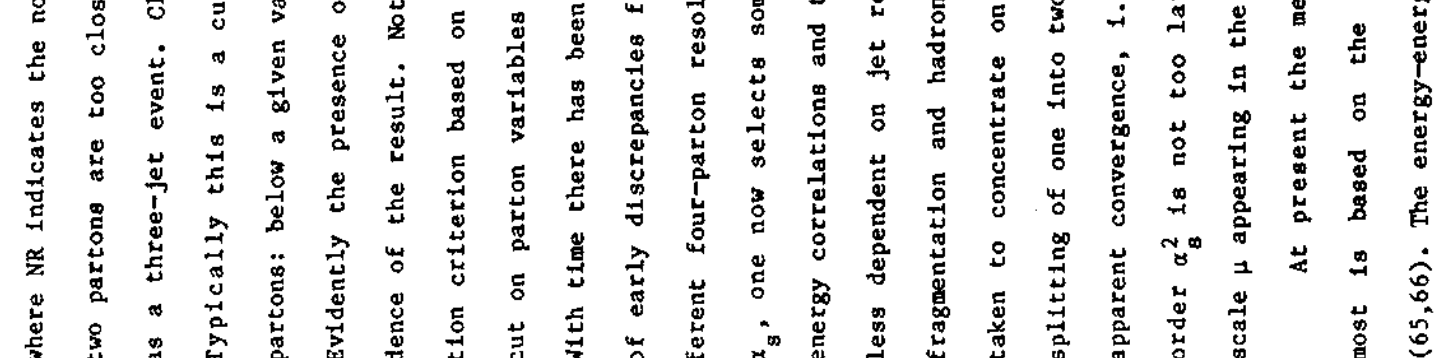



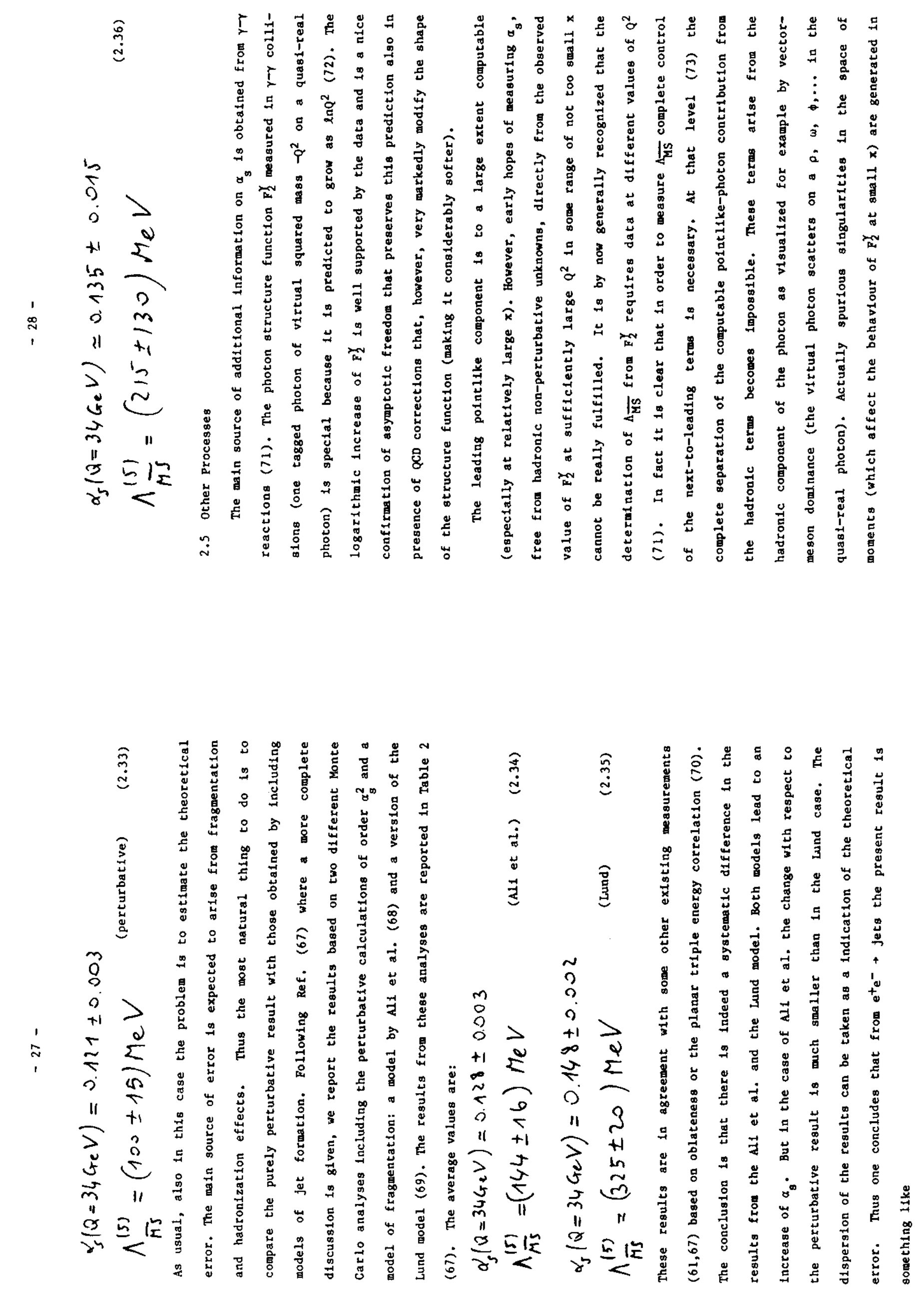


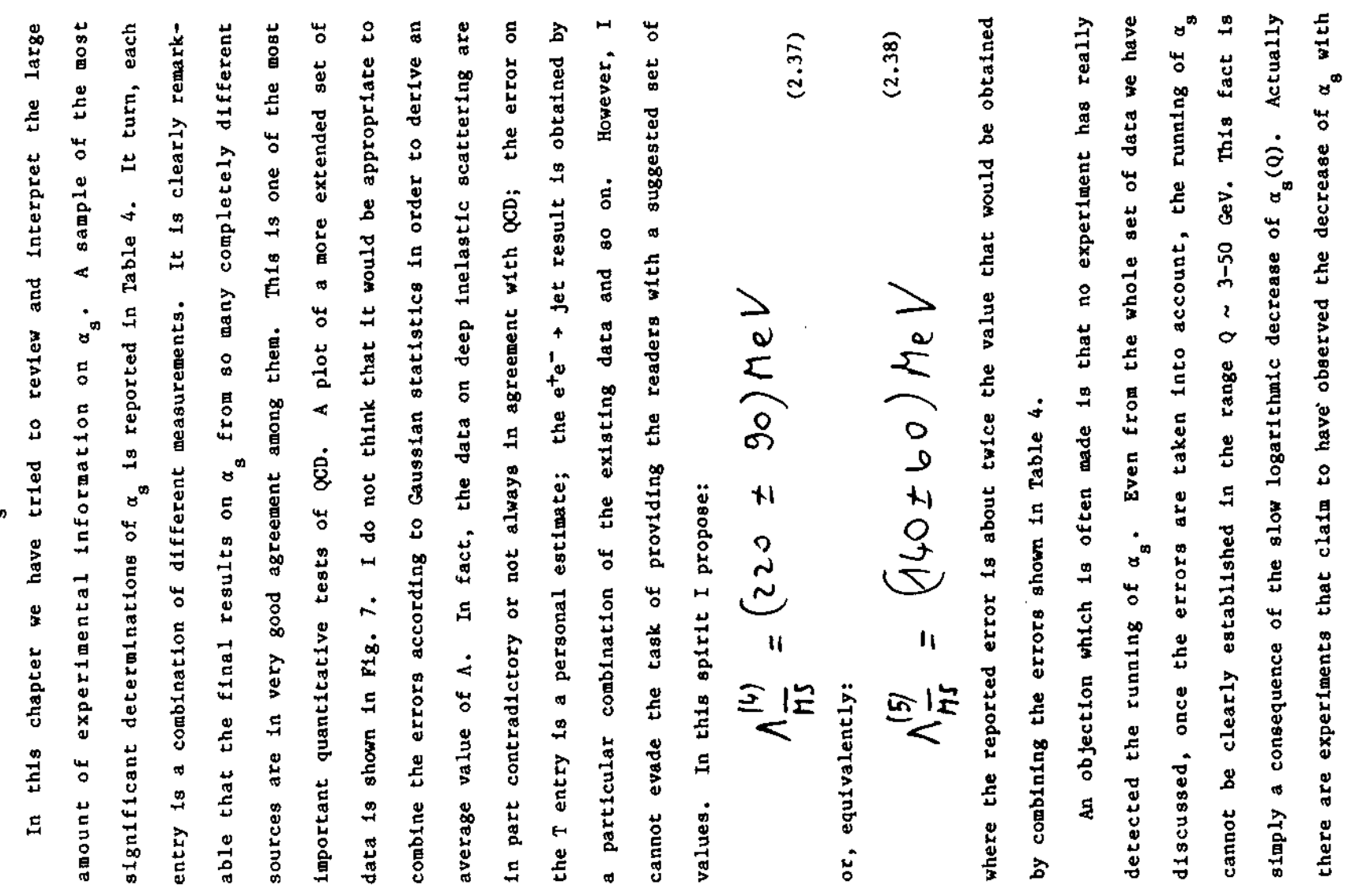

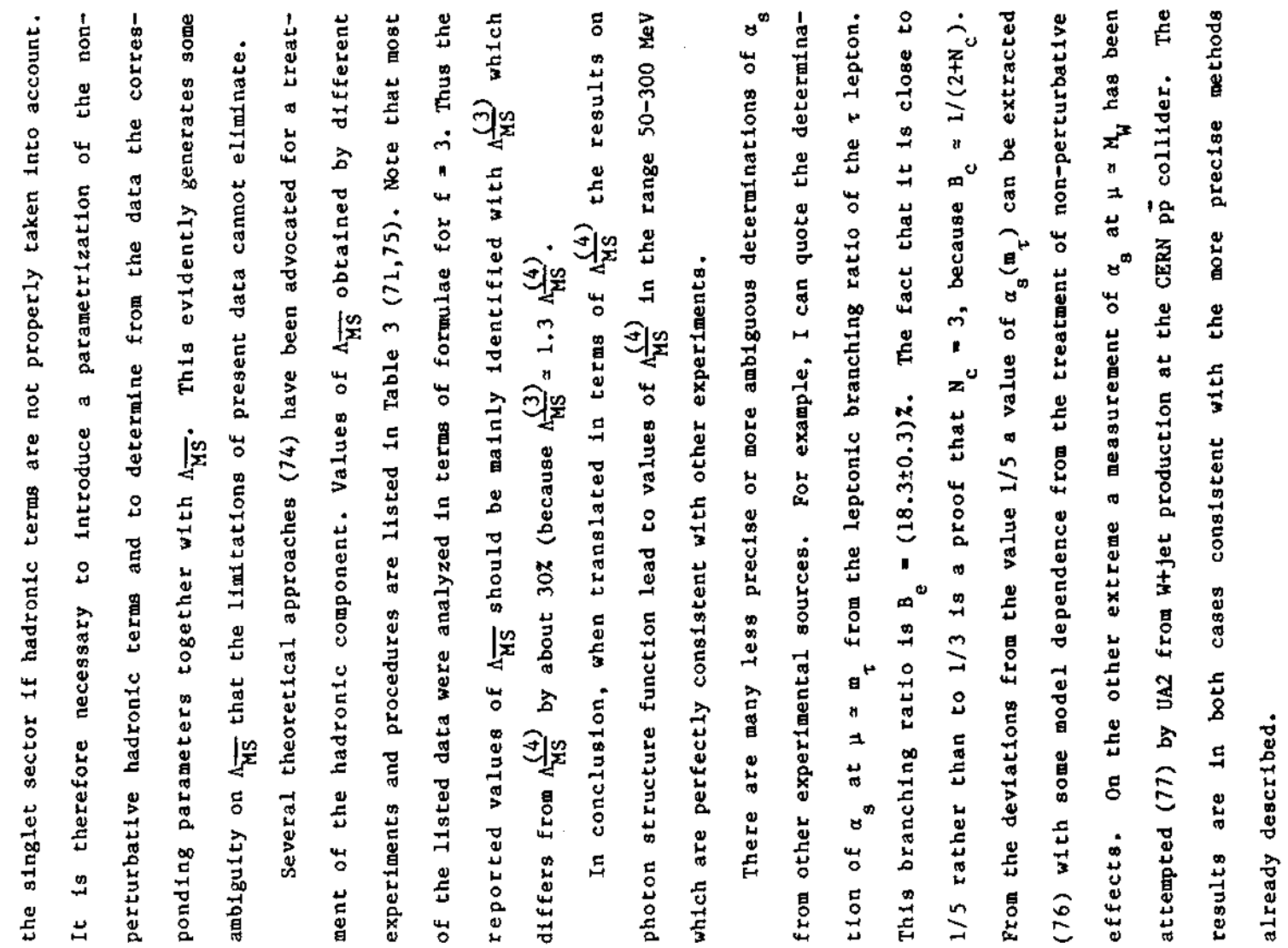




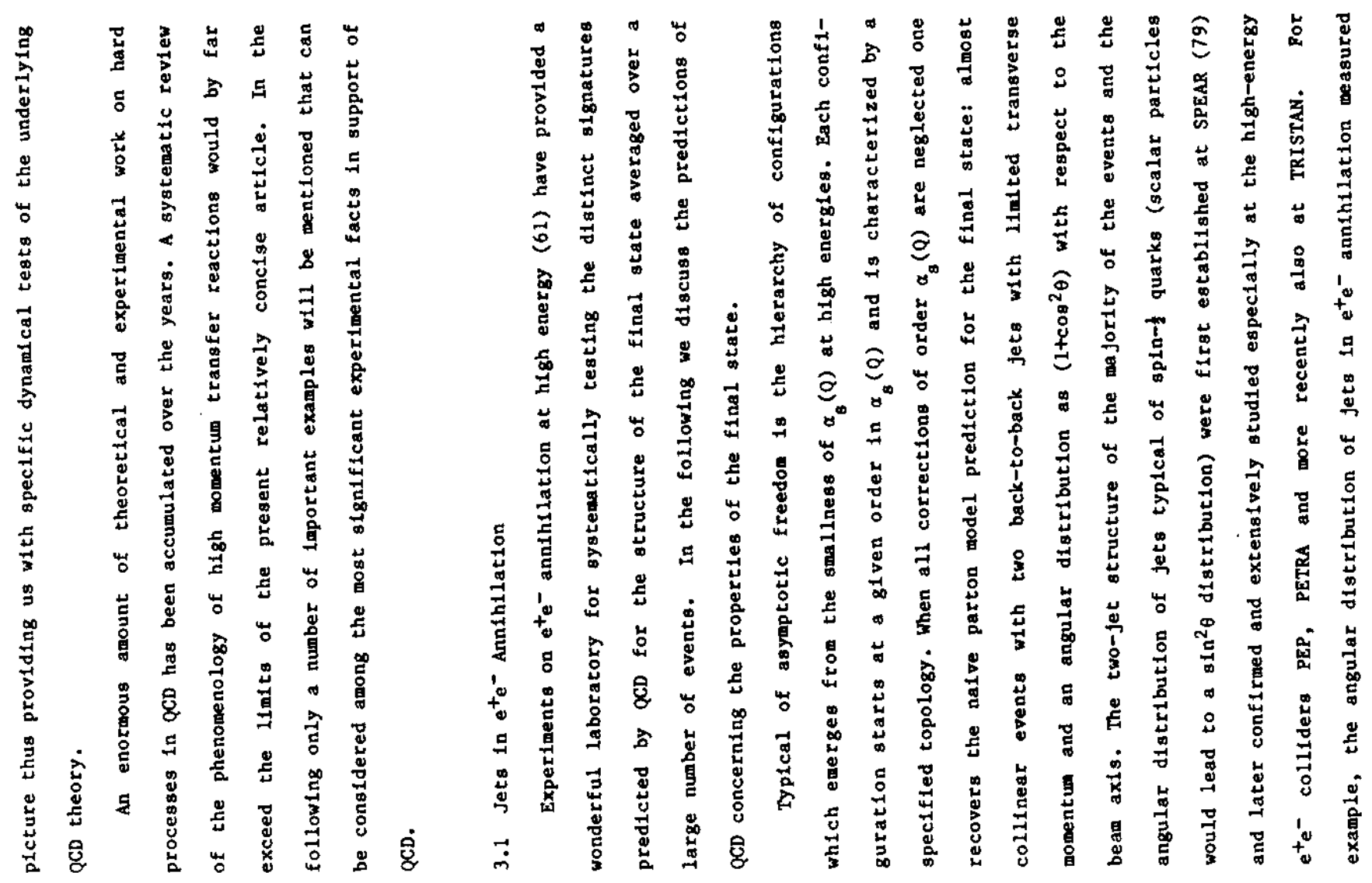

(3)

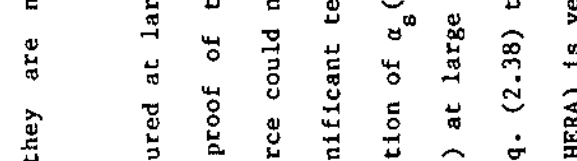

1

11

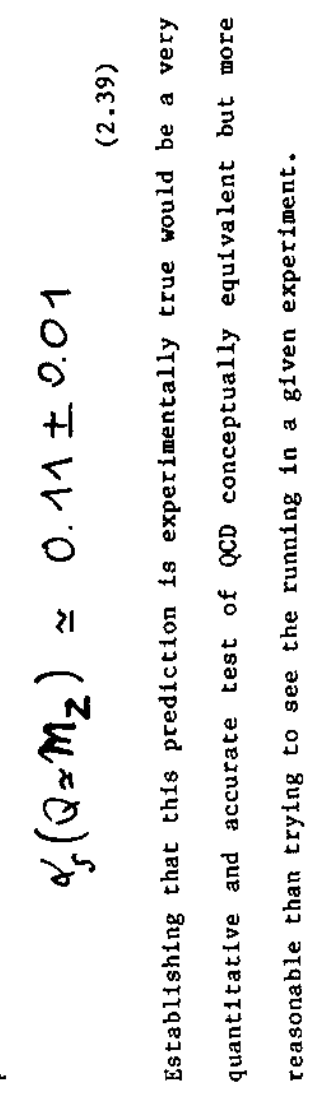

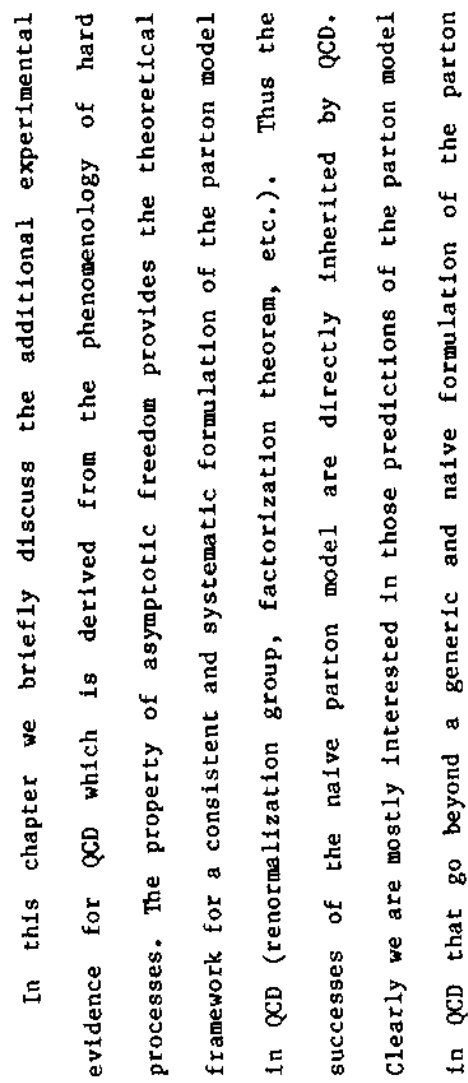




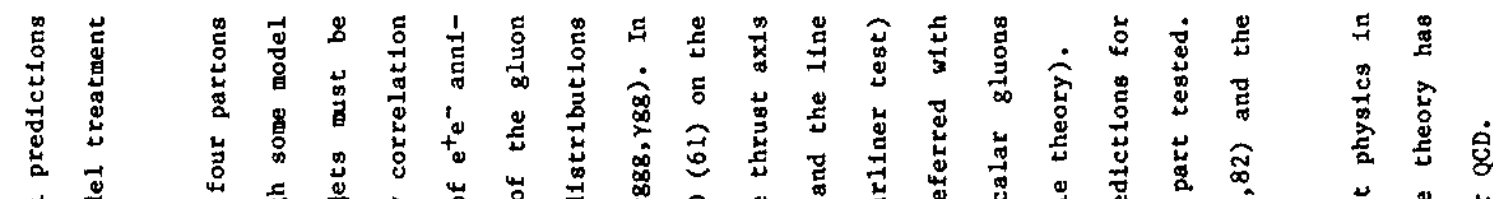

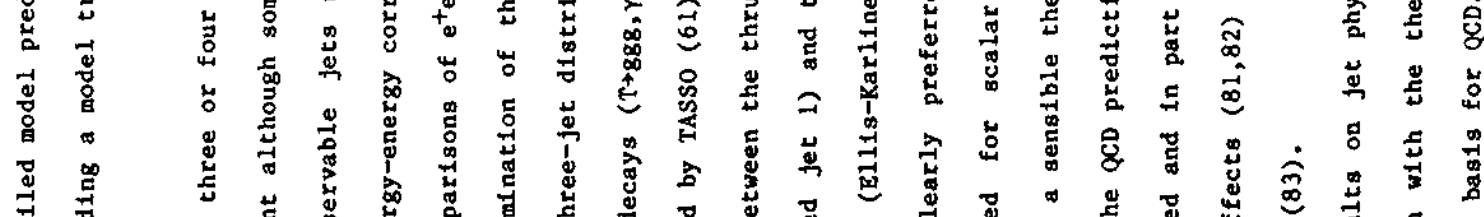

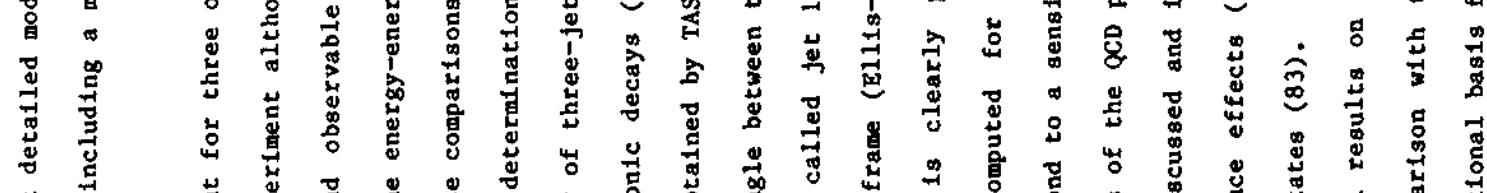

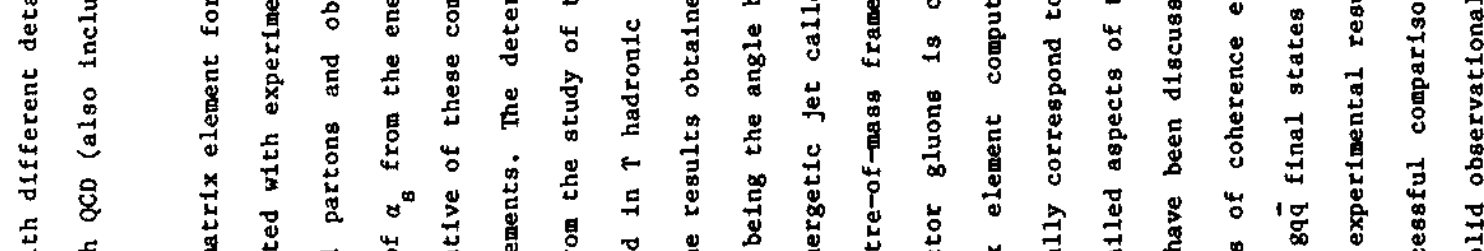

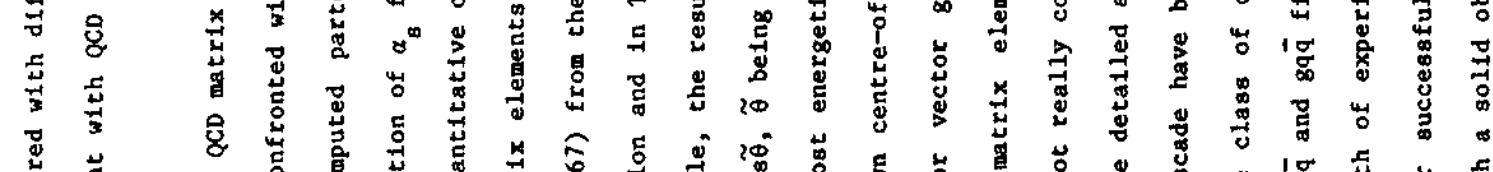

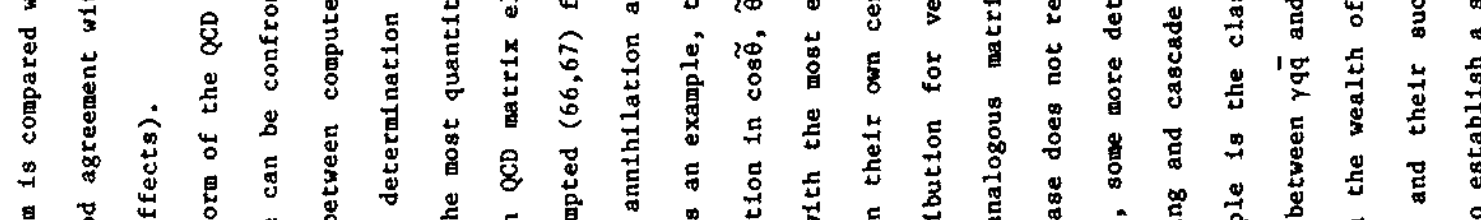

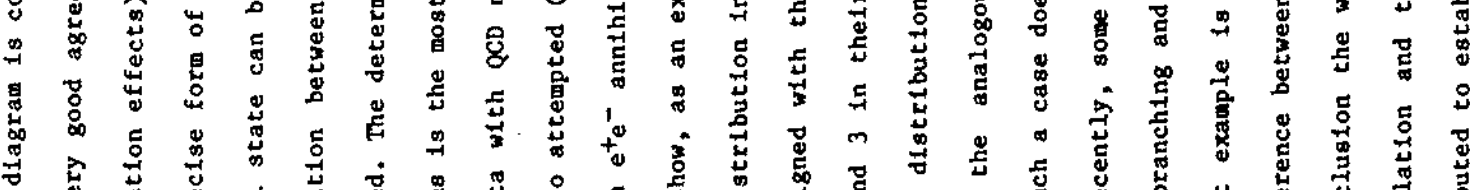

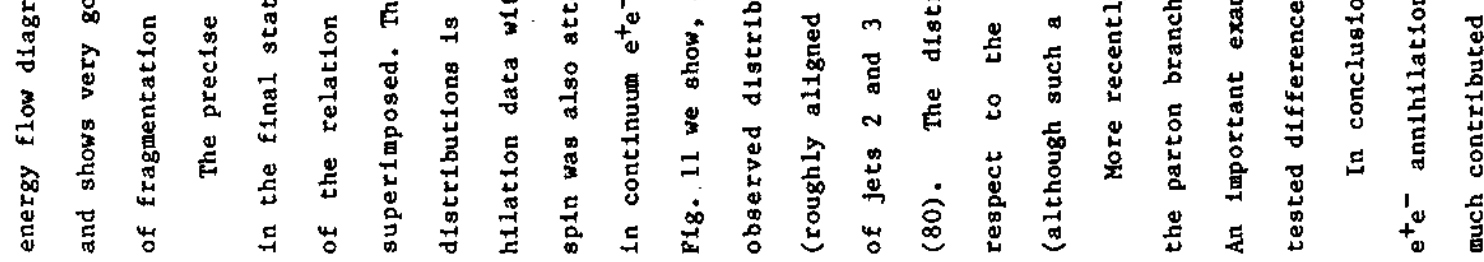

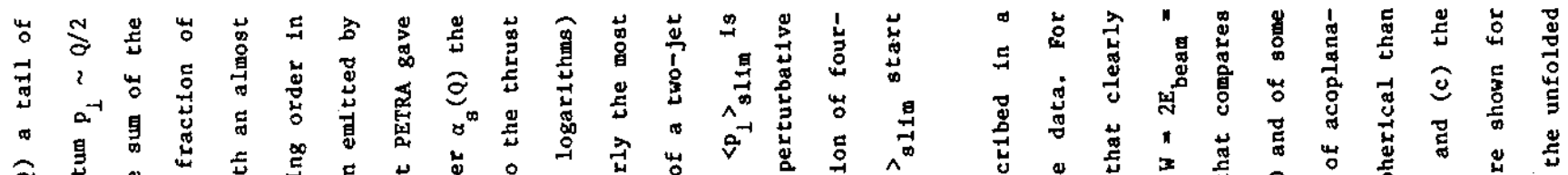

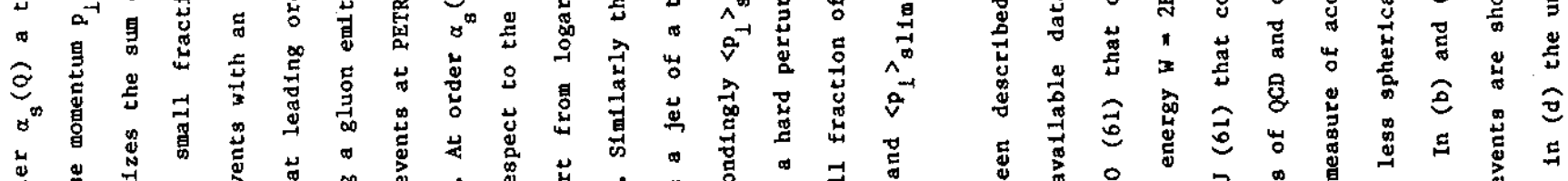

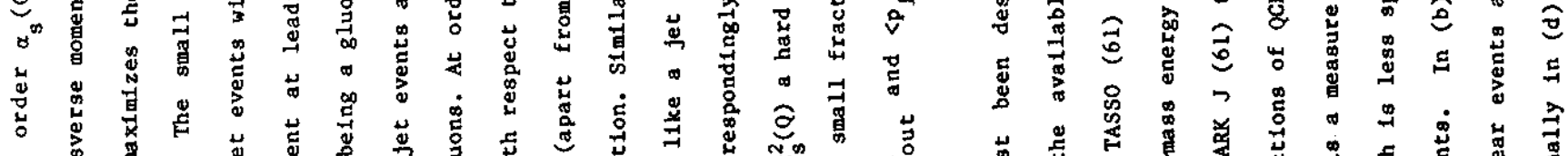

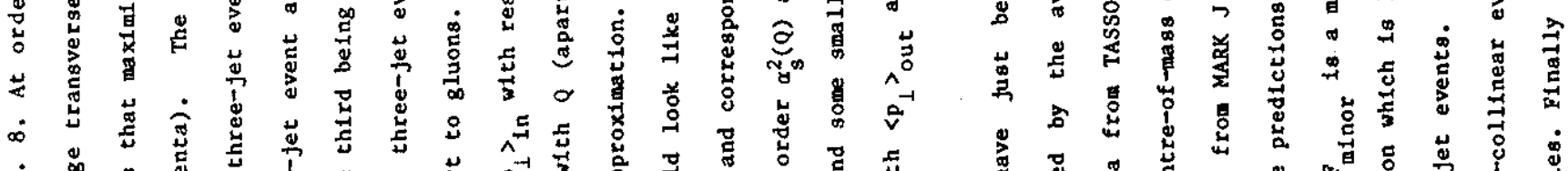

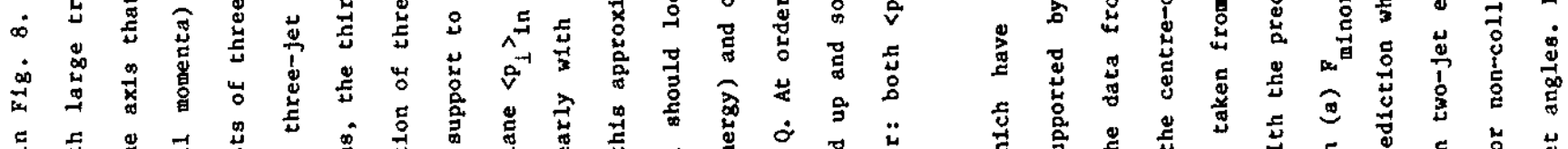

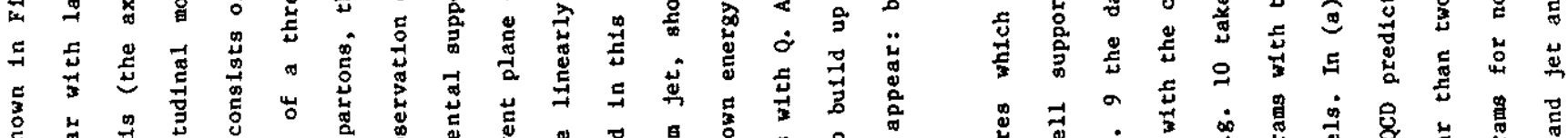

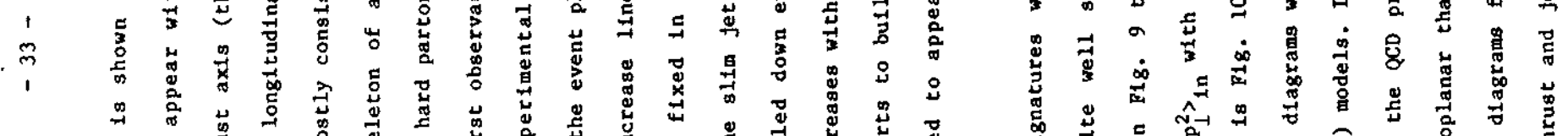

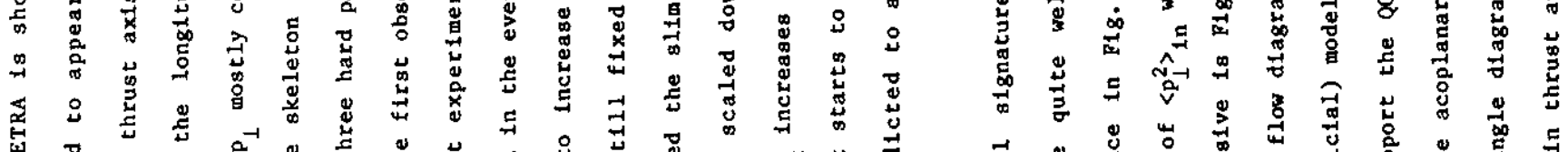

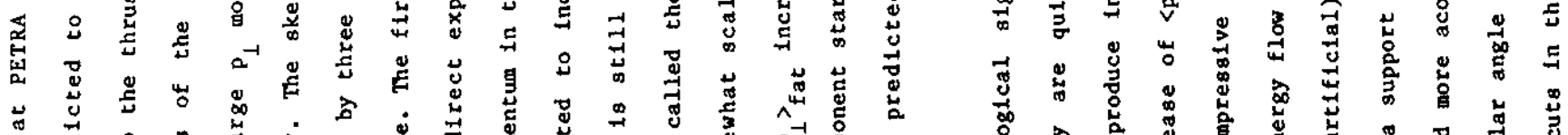

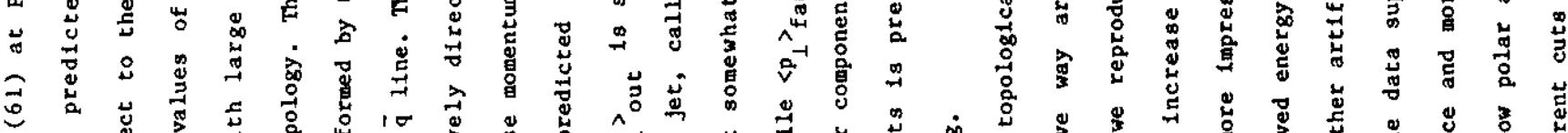

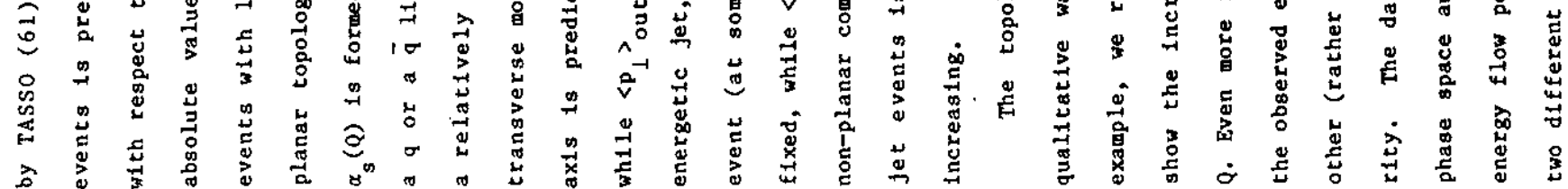



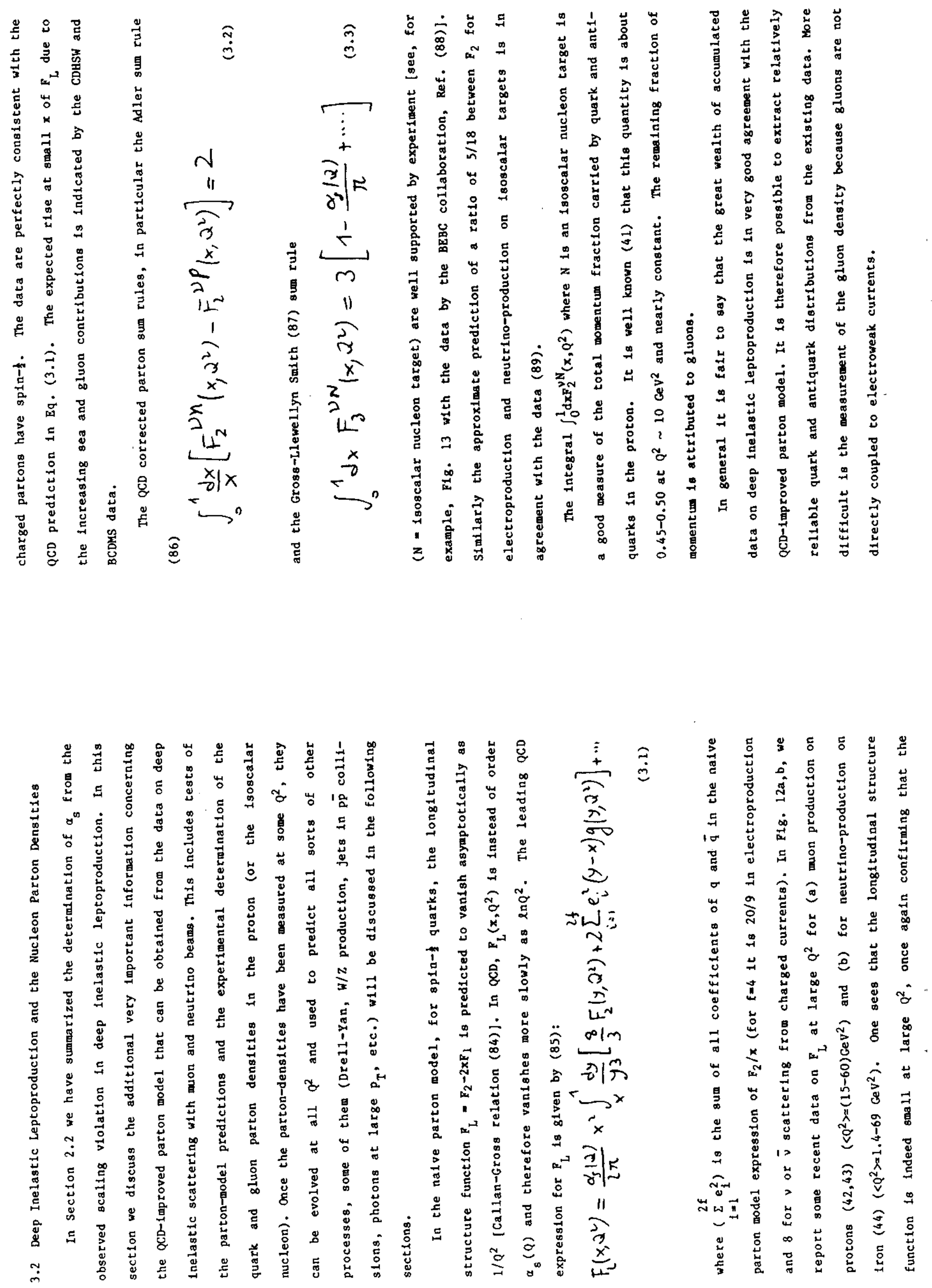


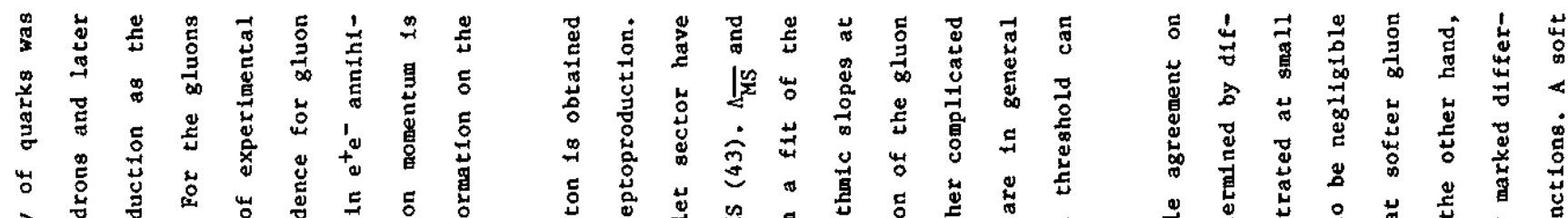

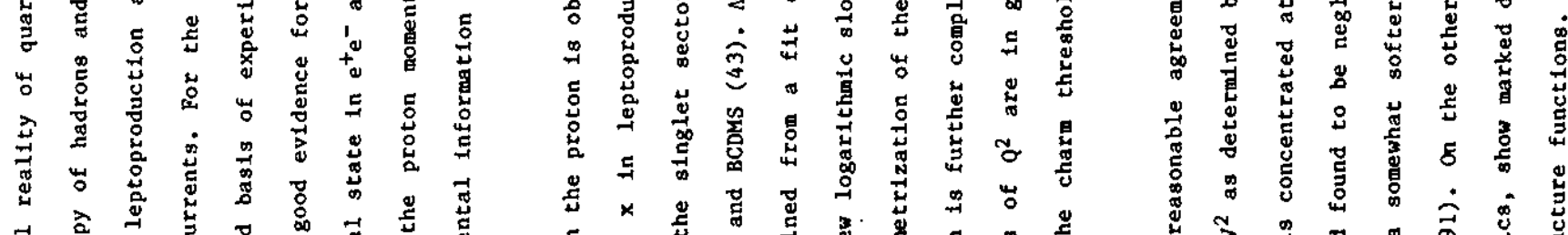

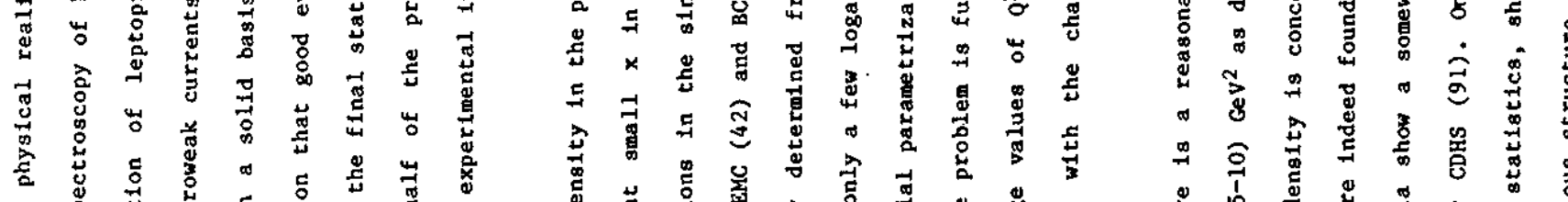

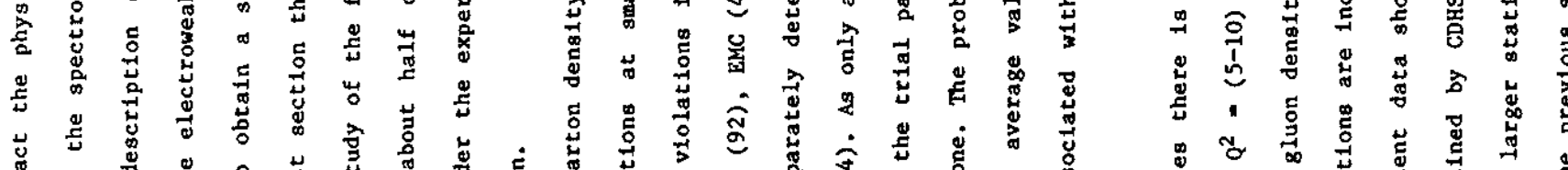

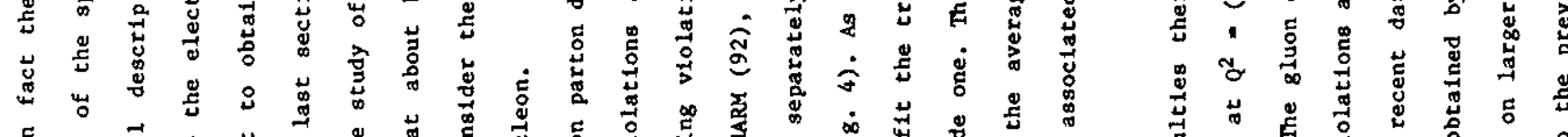

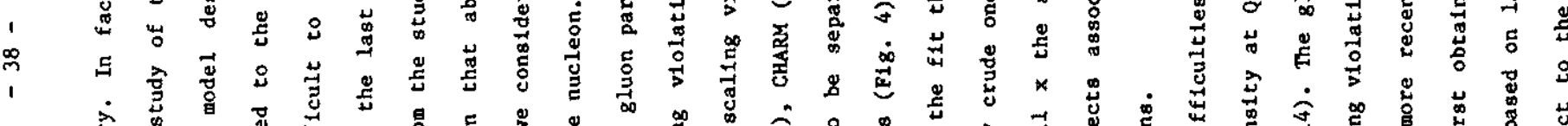

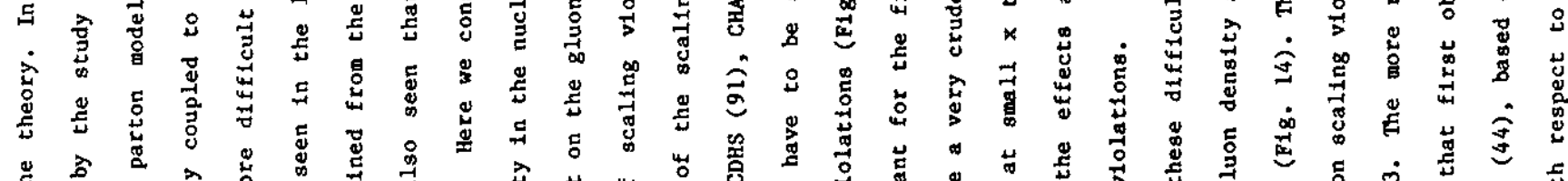

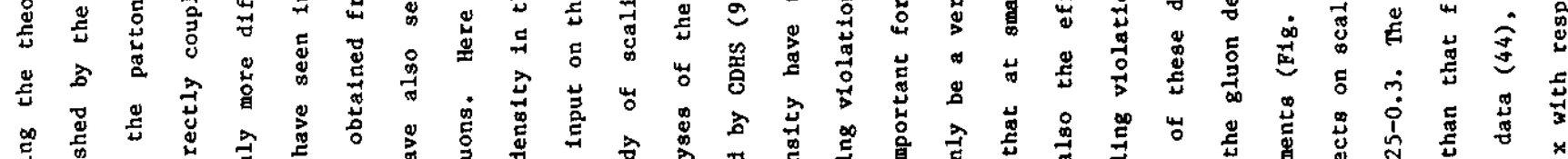

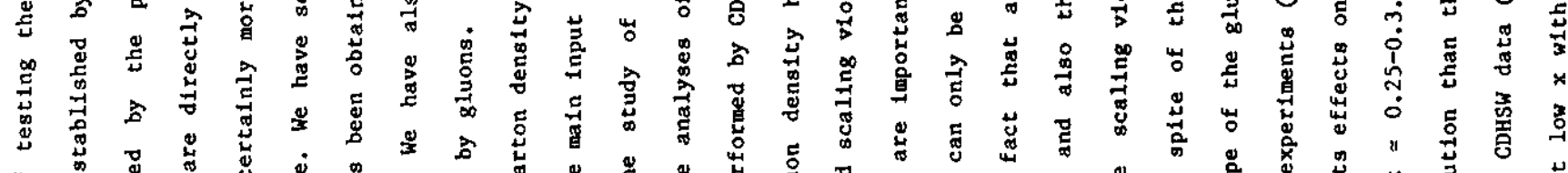

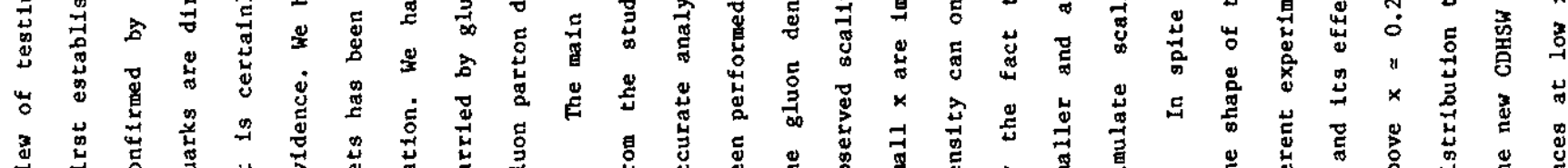

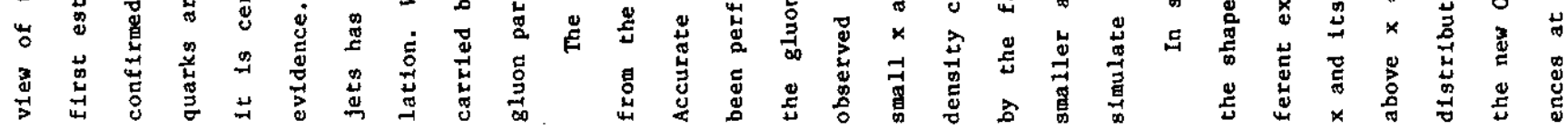

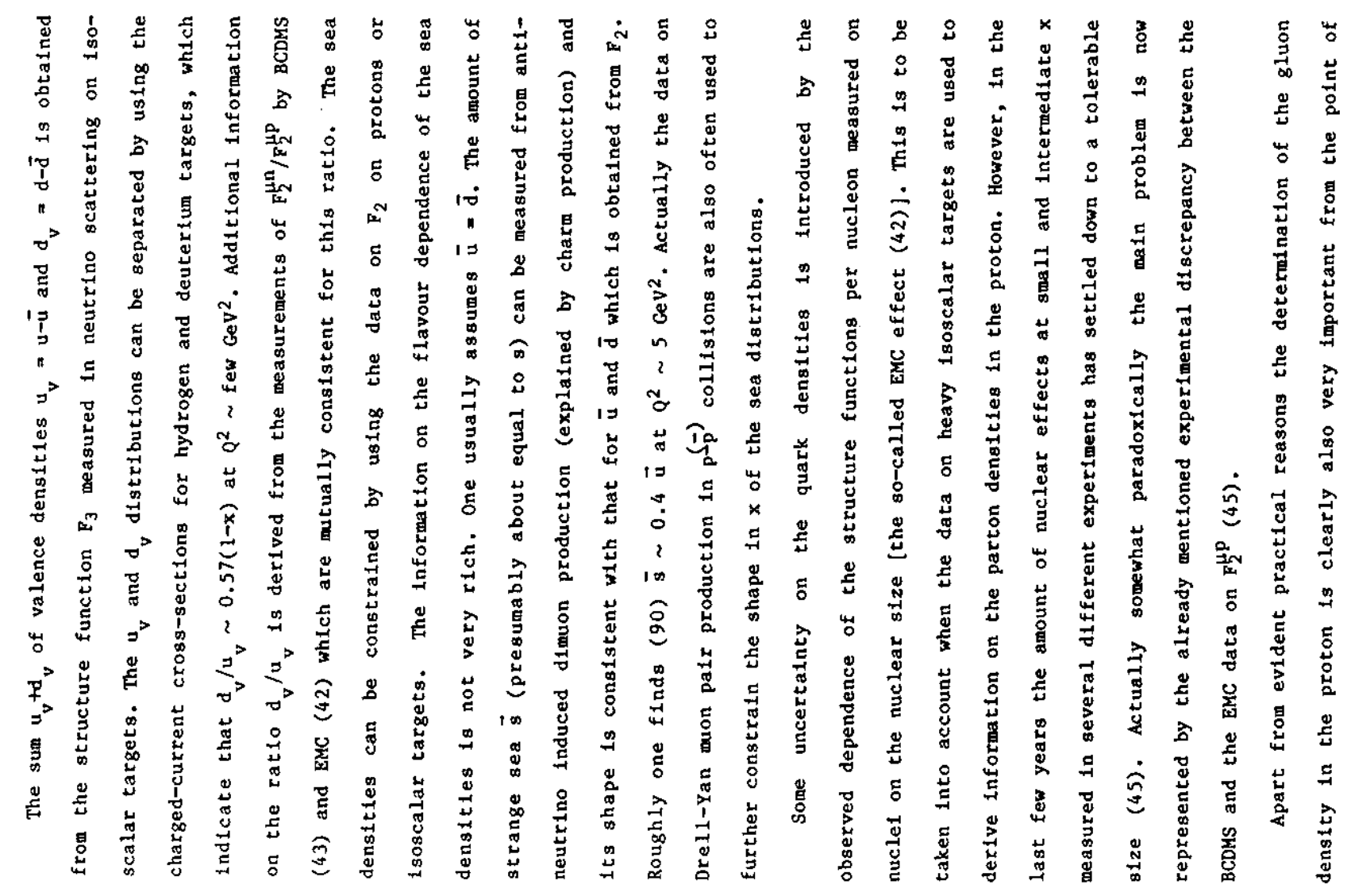




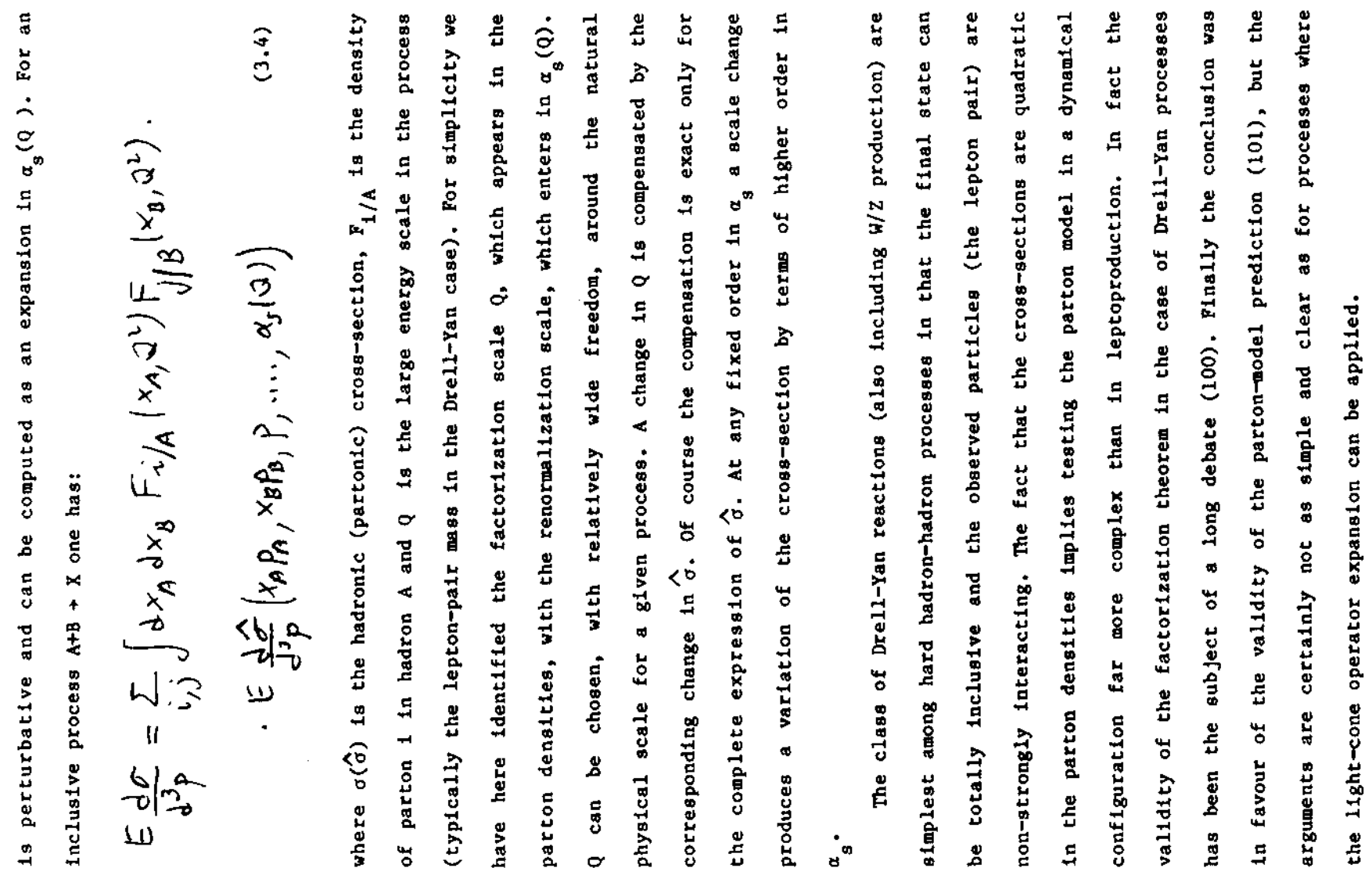

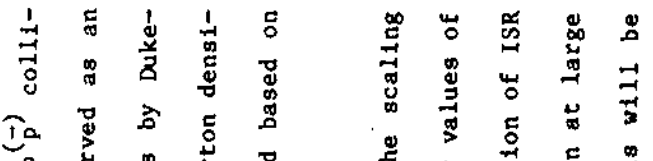

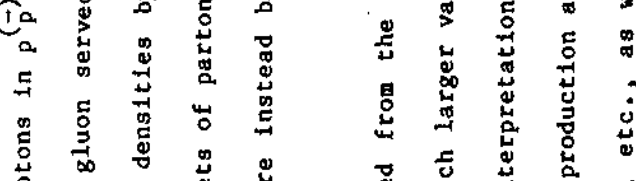

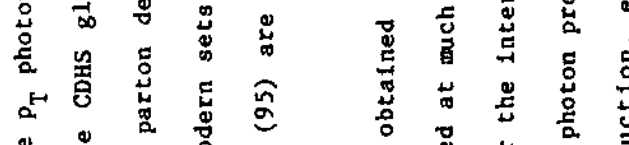

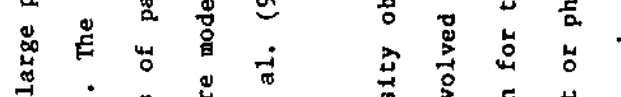

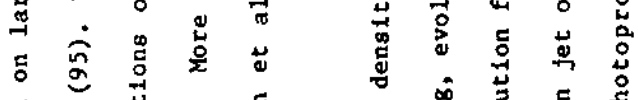

劳

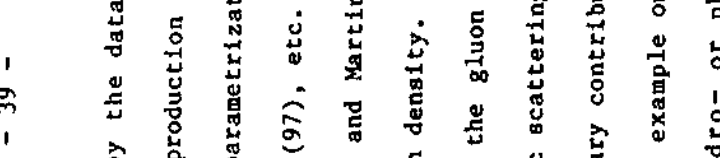

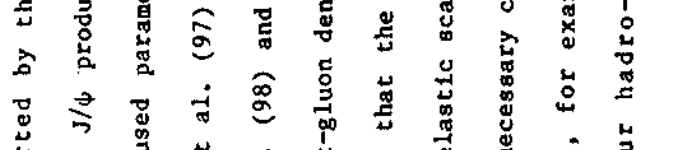

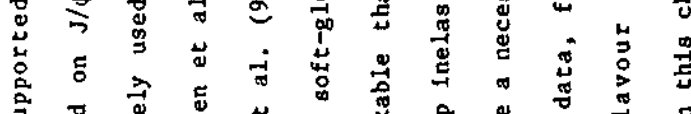

焉

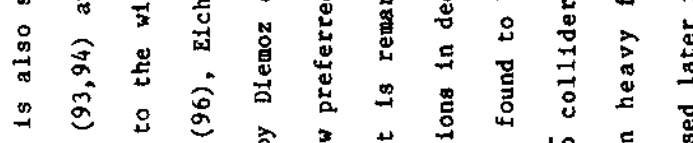

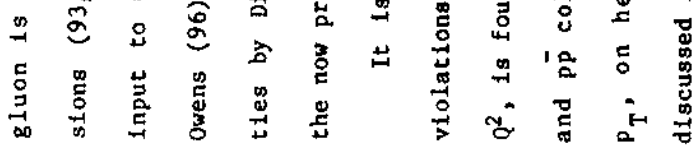

节

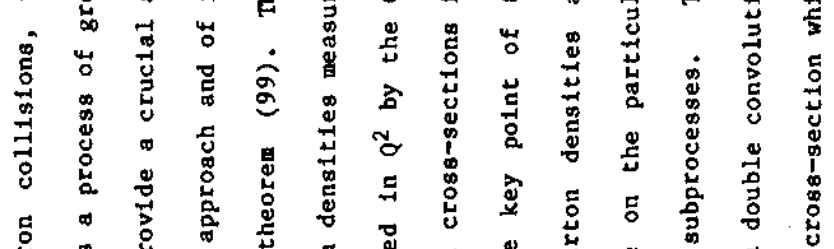

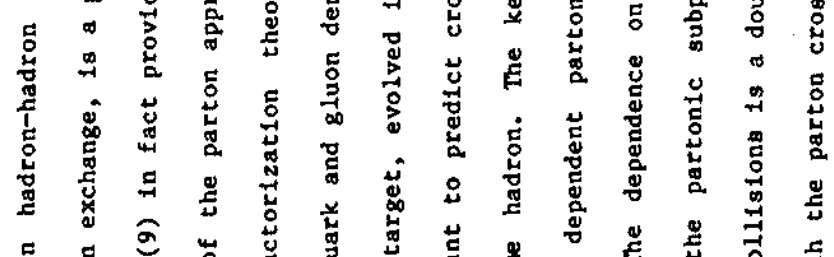

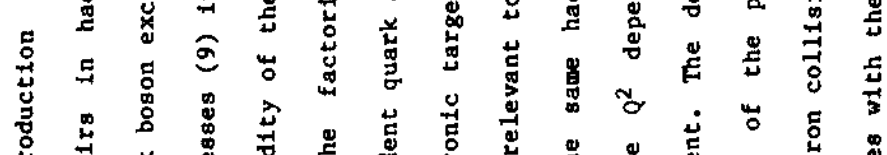

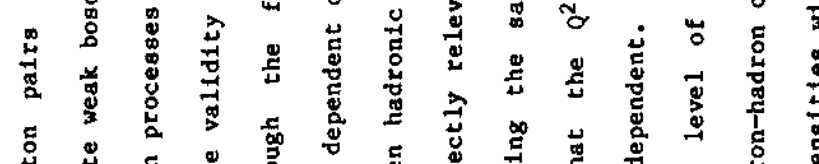

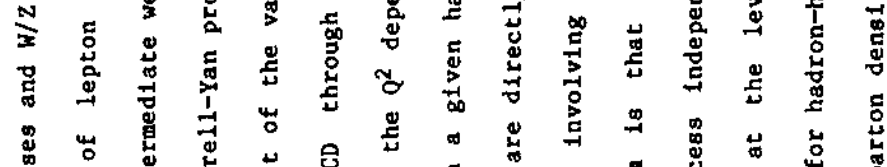

总

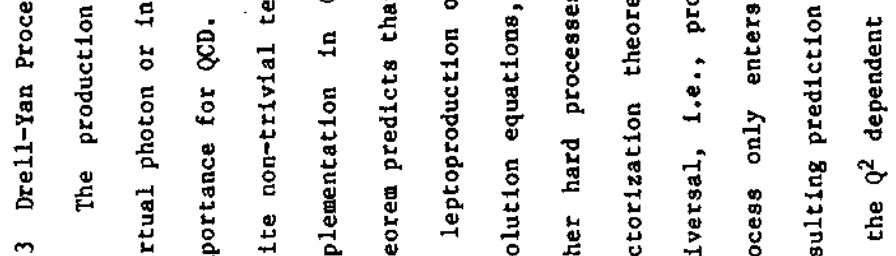



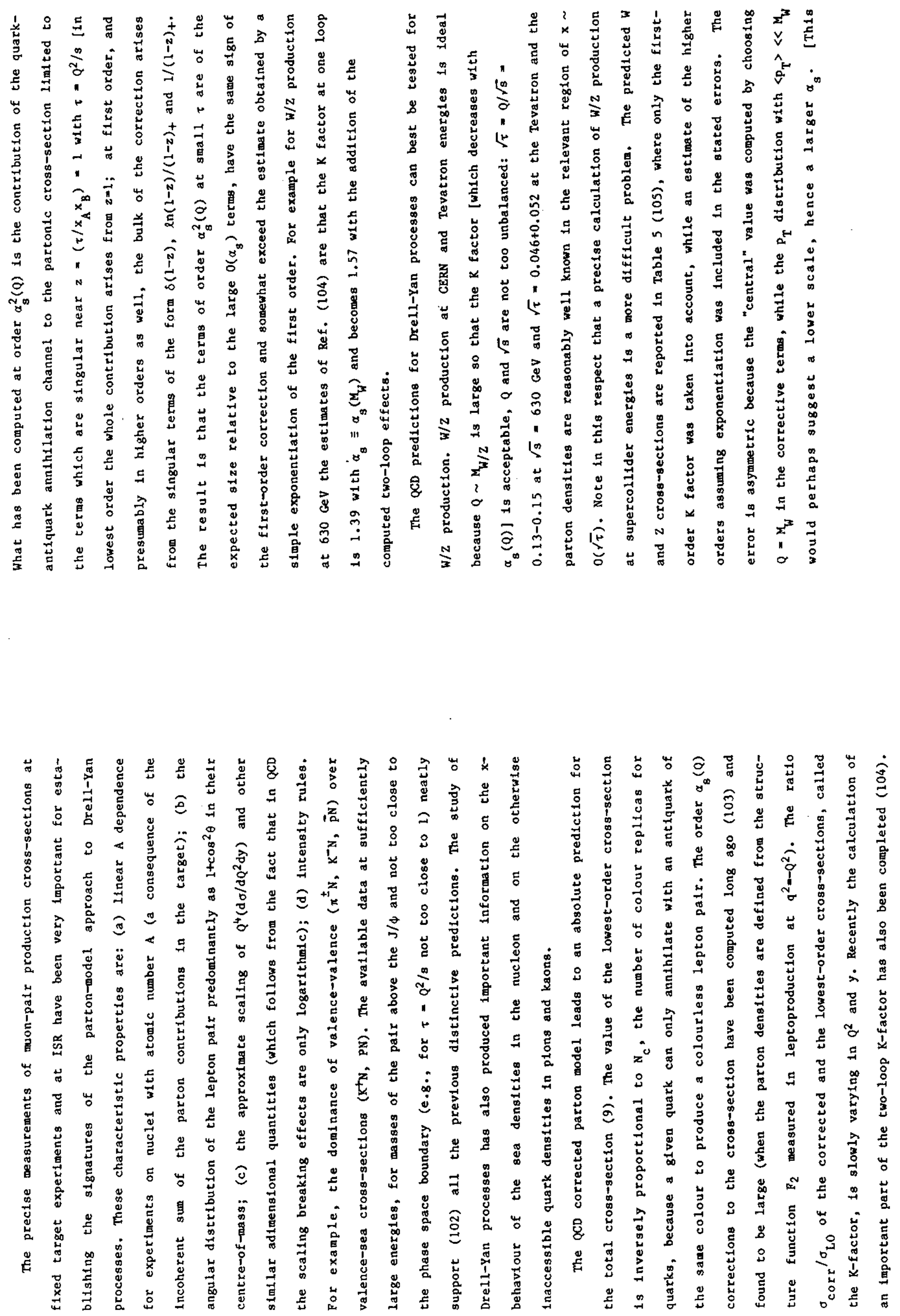


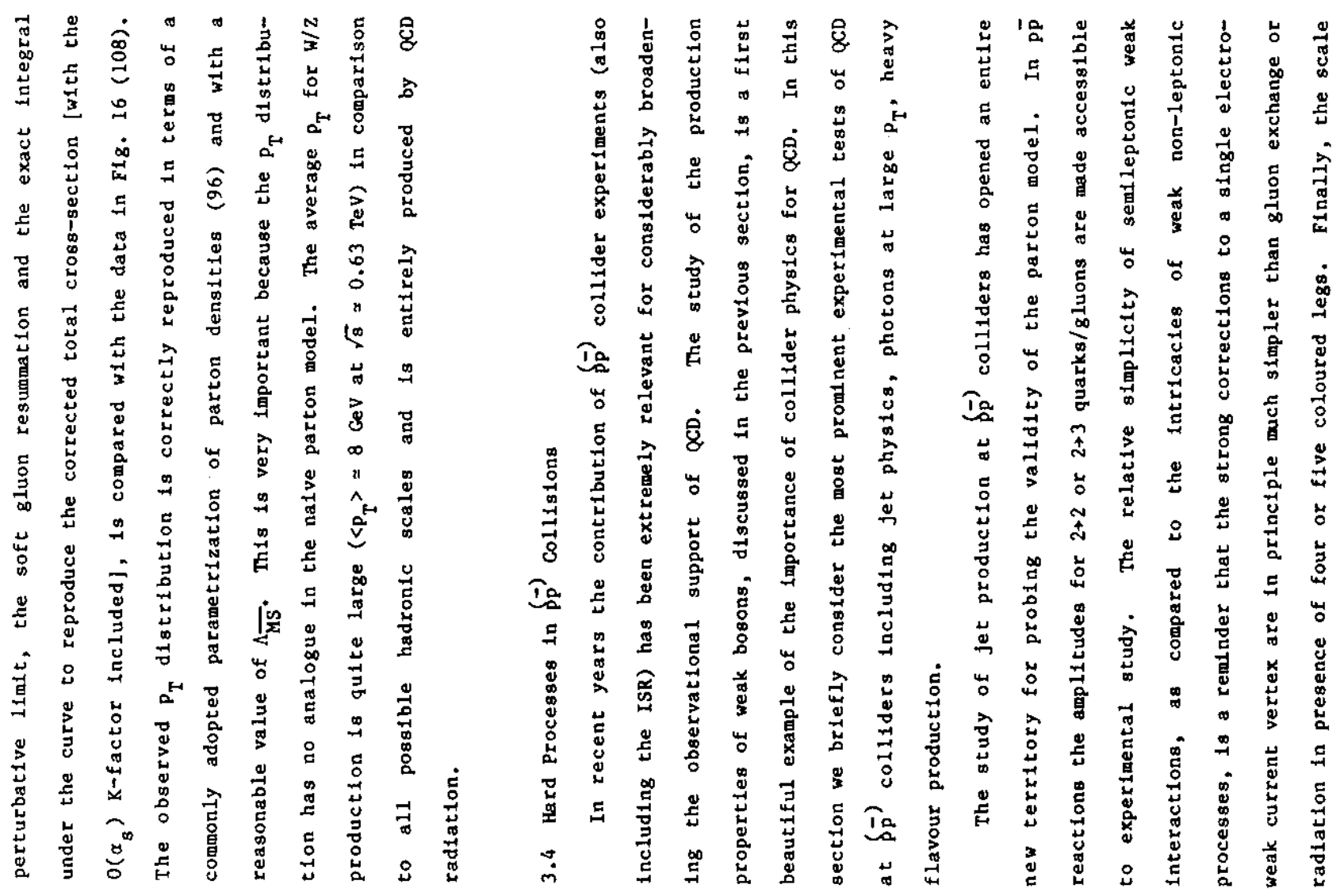

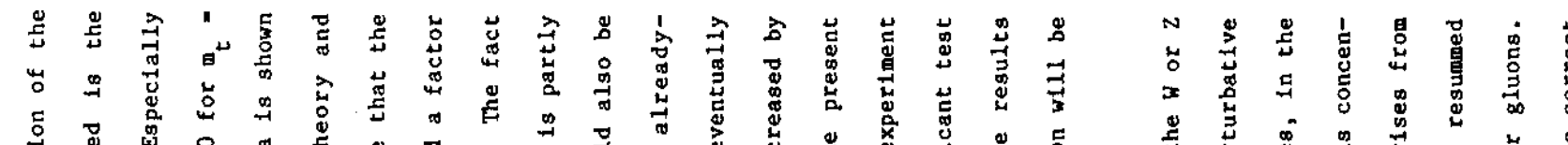

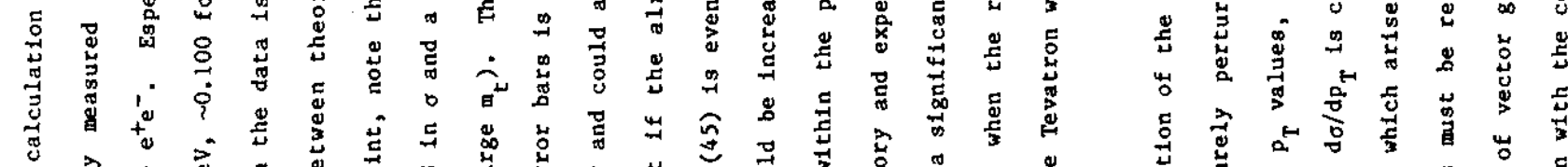

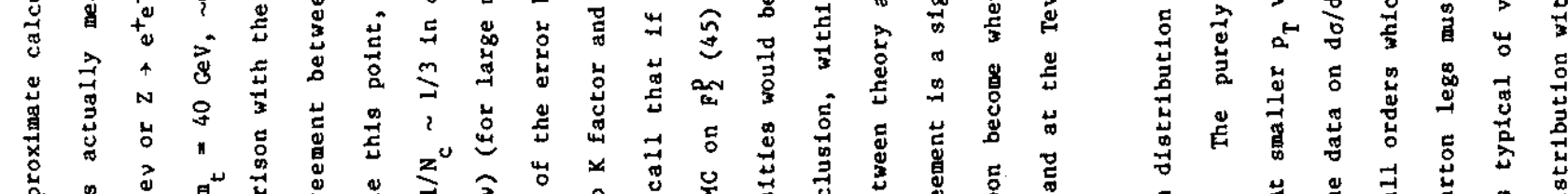

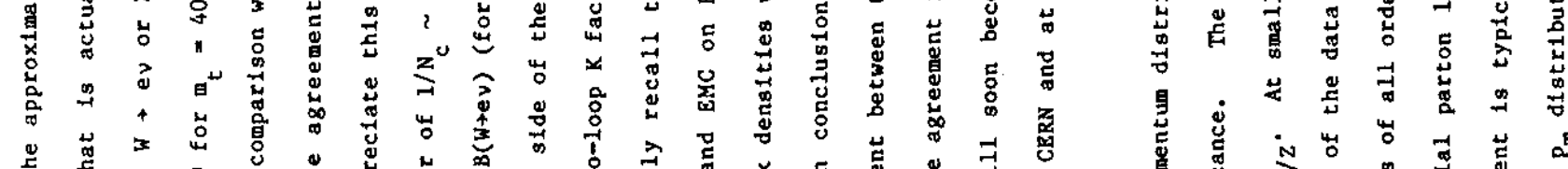

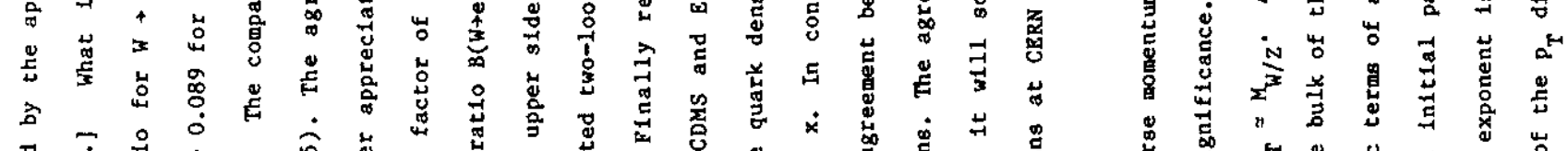

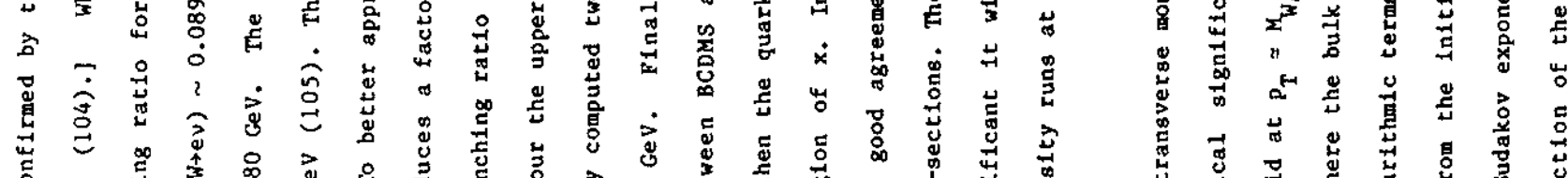

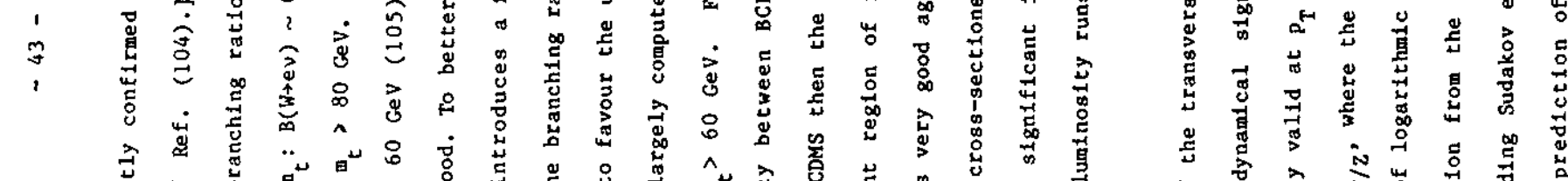

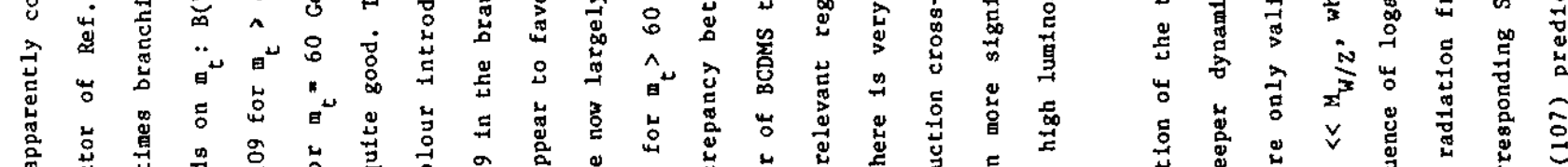

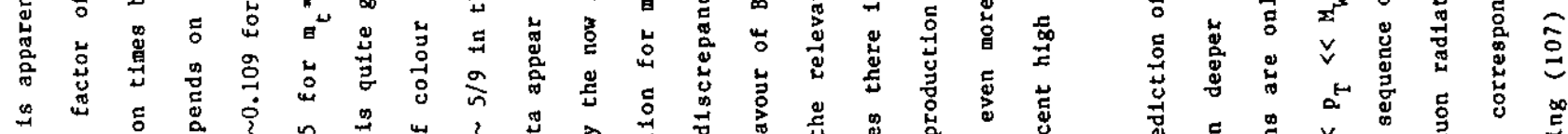

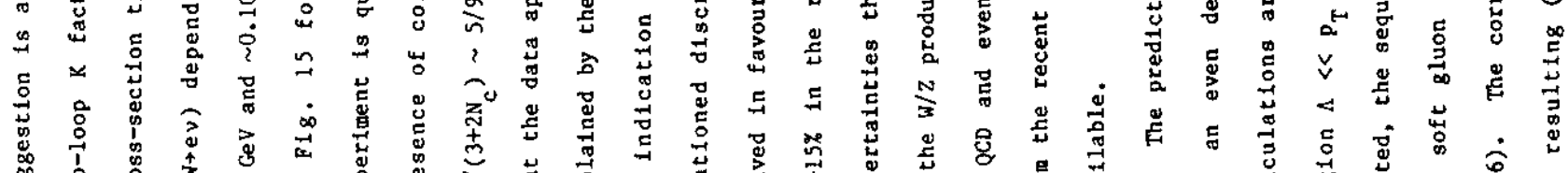

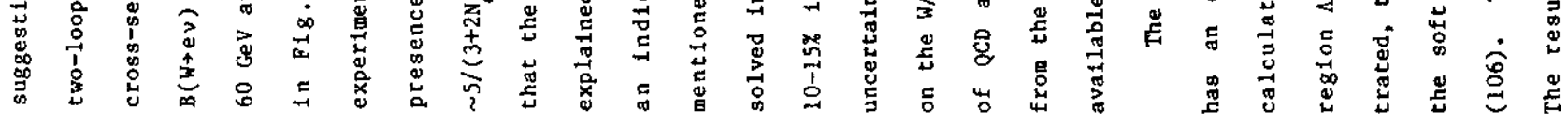




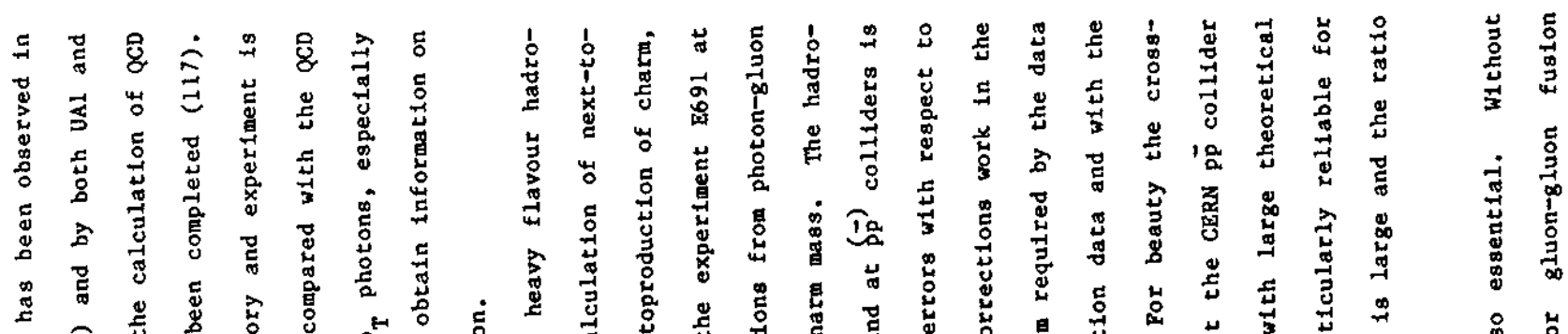

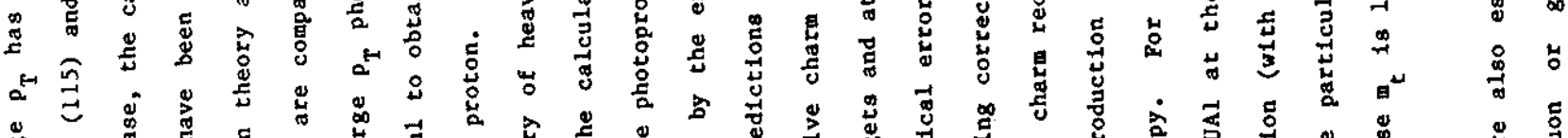

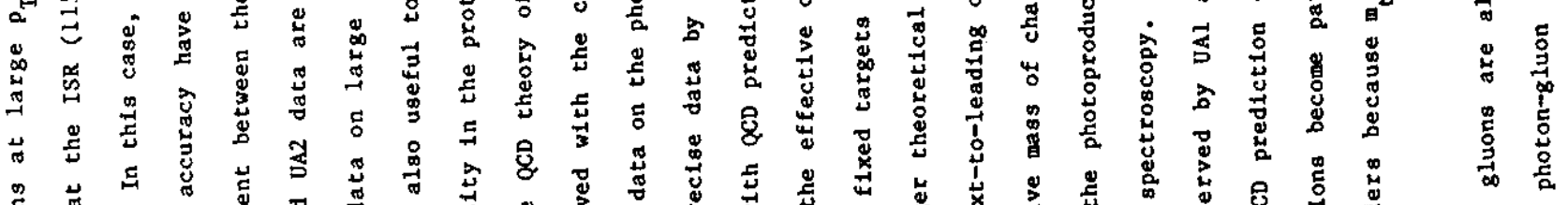

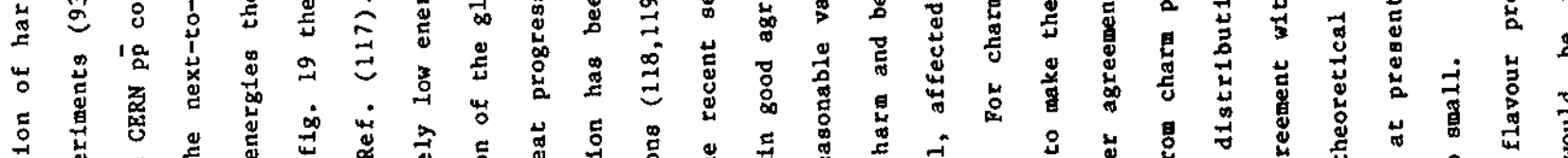

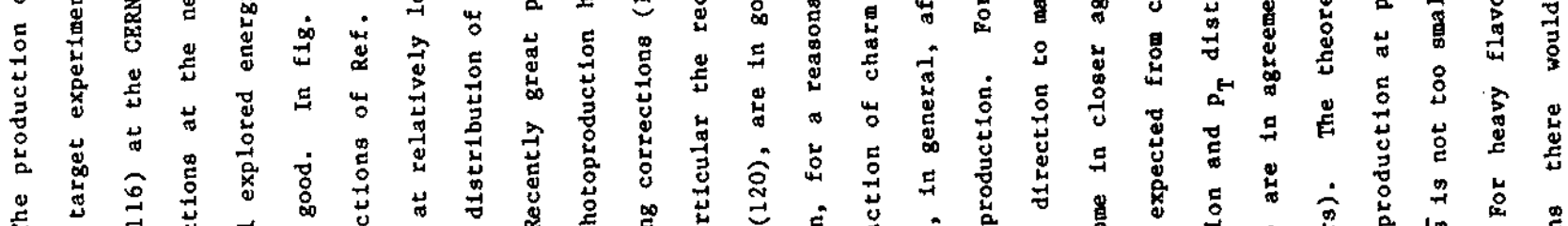

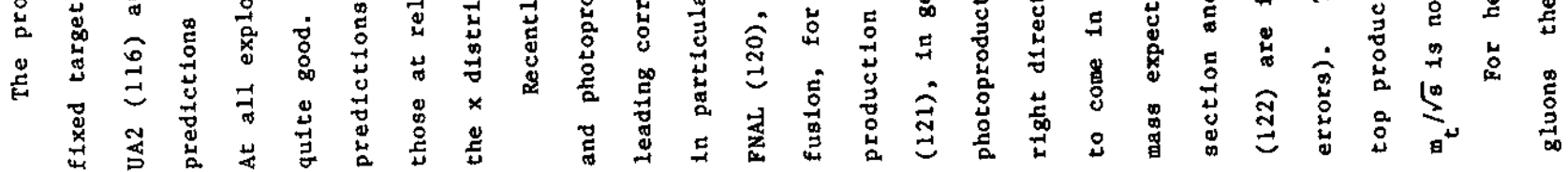

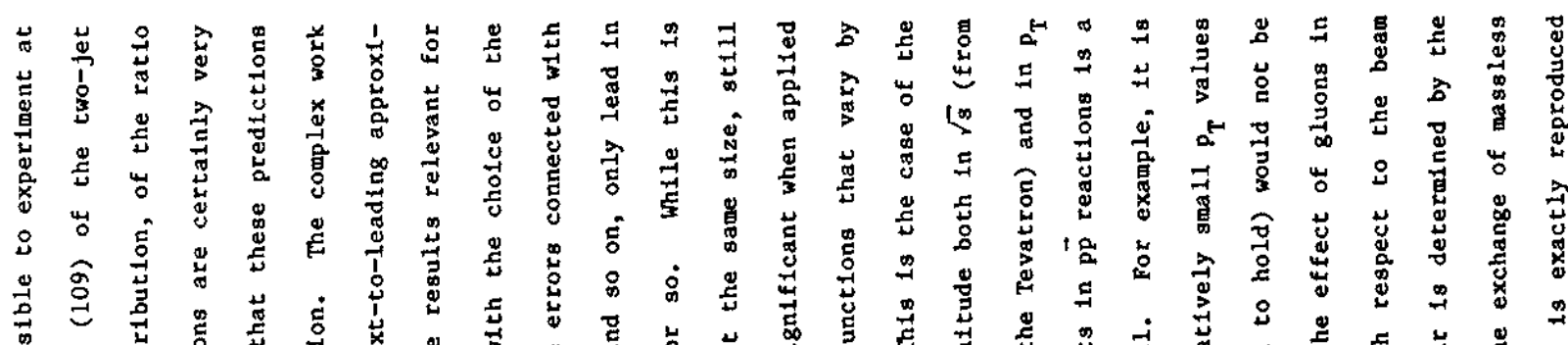

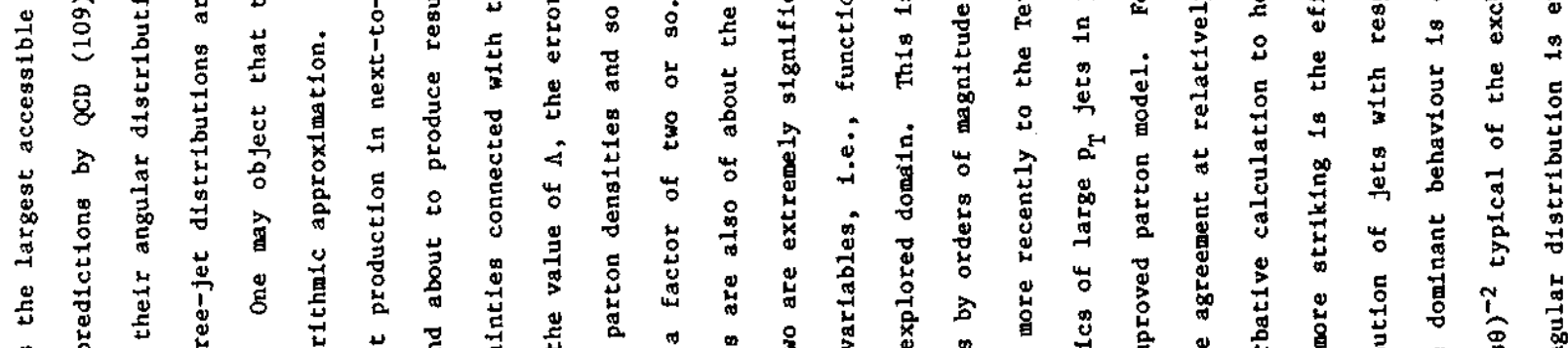

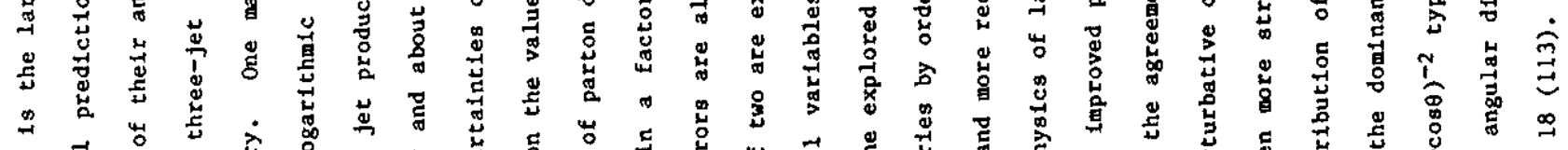

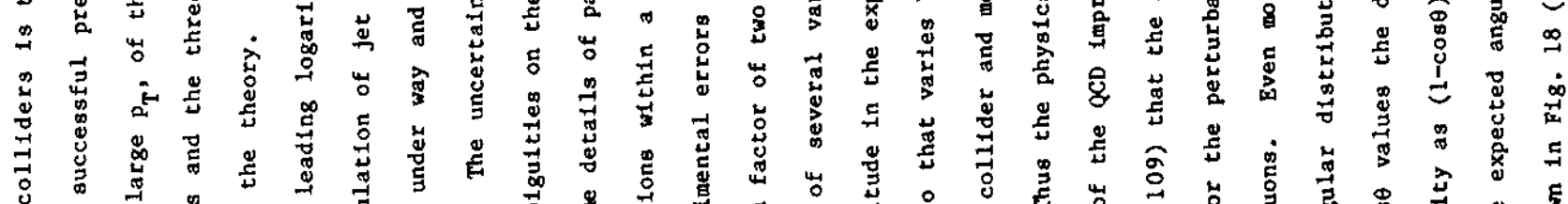

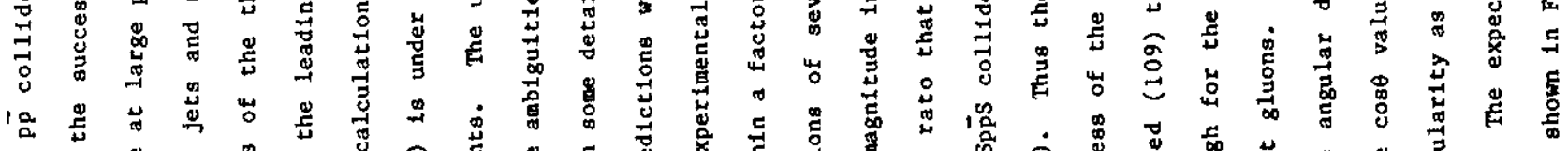

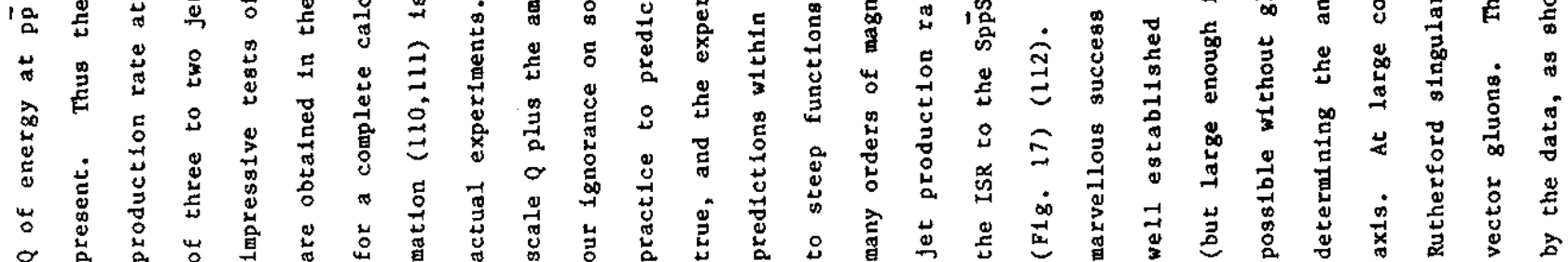



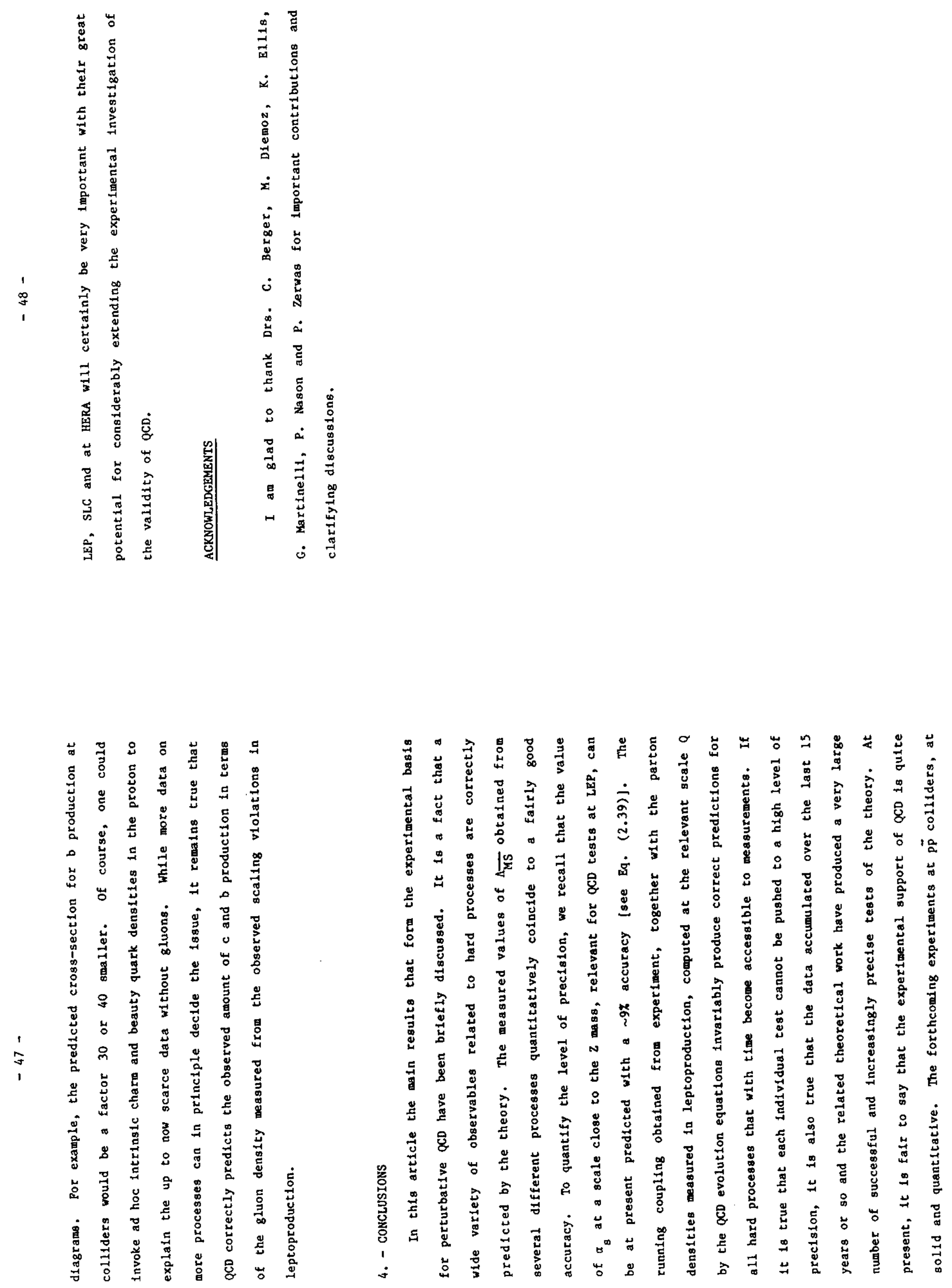


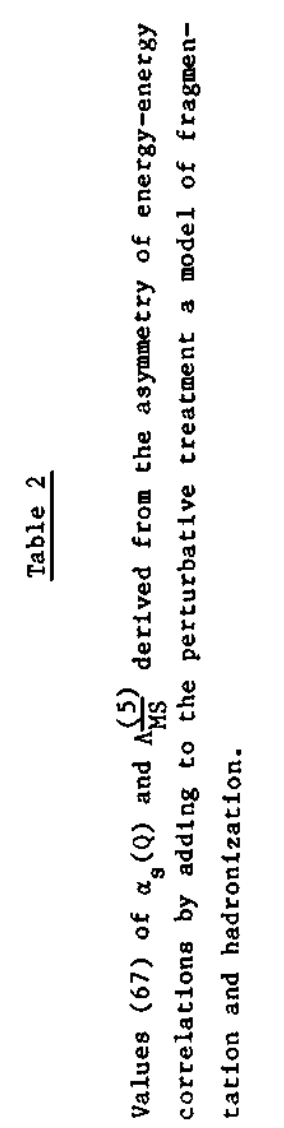

\begin{tabular}{|c|c|c|c|c|c|c|c|c|}
\hline 离 & 曾 & 总 & $\begin{array}{l}\text { 号 } \\
\text { a }\end{array}$ & 美 & $\begin{array}{l}\stackrel{8}{8} \\
\text { 岁 }\end{array}$ & 总 & $\begin{array}{l}\stackrel{\bigcirc}{9} \\
\text { 画 }\end{array}$ & 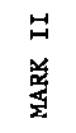 \\
\hline 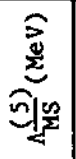 & $\begin{array}{c}\stackrel{ \pm}{N} \\
+1 \\
\infty \\
\stackrel{8}{9}\end{array}$ & \begin{tabular}{l}
8 \\
+1 \\
+1 \\
$\&$ \\
\hdashline
\end{tabular} & $\begin{array}{l}8 \\
+1 \\
+1 \\
\infty \\
\stackrel{-}{-1}\end{array}$ & 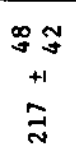 & 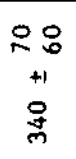 & $\begin{array}{l}\stackrel{8}{+} \\
+1 \\
\stackrel{0}{0}\end{array}$ & $\begin{array}{c}80 \\
8 \\
+1 \\
8 \\
9 \\
0\end{array}$ & 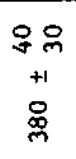 \\
\hline$\widehat{Q}_{\theta^{\infty}}$ & 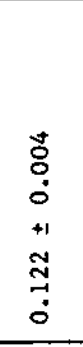 & 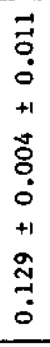 & $\begin{array}{l}\overrightarrow{0} \\
\dot{0} \\
\dot{+} \\
+1 \\
\stackrel{2}{?} \\
\stackrel{0}{0}\end{array}$ & $\begin{array}{l}\tilde{o} \\
0 \\
\dot{+} \\
+1 \\
\tilde{m} \\
0 \\
0 \\
0\end{array}$ & 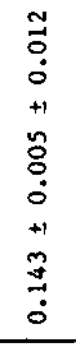 & 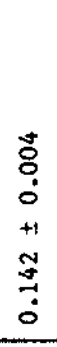 & 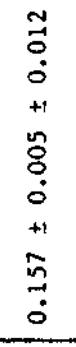 & \begin{tabular}{l}
$\infty$ \\
0 \\
0 \\
0 \\
+1 \\
0 \\
0 \\
0 \\
0 \\
+1 \\
0 \\
0 \\
\hdashline \\
0 \\
0
\end{tabular} \\
\hline $\begin{array}{l}\overrightarrow{\mathrm{v}} \\
\mathrm{d}\end{array}$ & 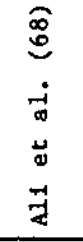 & $=$ & s & $\begin{array}{l}\hat{\theta} \\
\hat{\theta} \\
\tilde{3} \\
\overrightarrow{3}\end{array}$ & $=$ & $=$ & : & 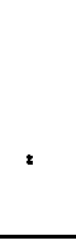 \\
\hline $\begin{array}{l}\widehat{P} \\
\vec{y} \\
0\end{array}$ & $\approx$ & 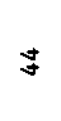 & $n$ & 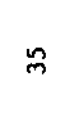 & $\exists$ & $\stackrel{n}{m}$ & $\stackrel{n}{m}$ & ని \\
\hline
\end{tabular}

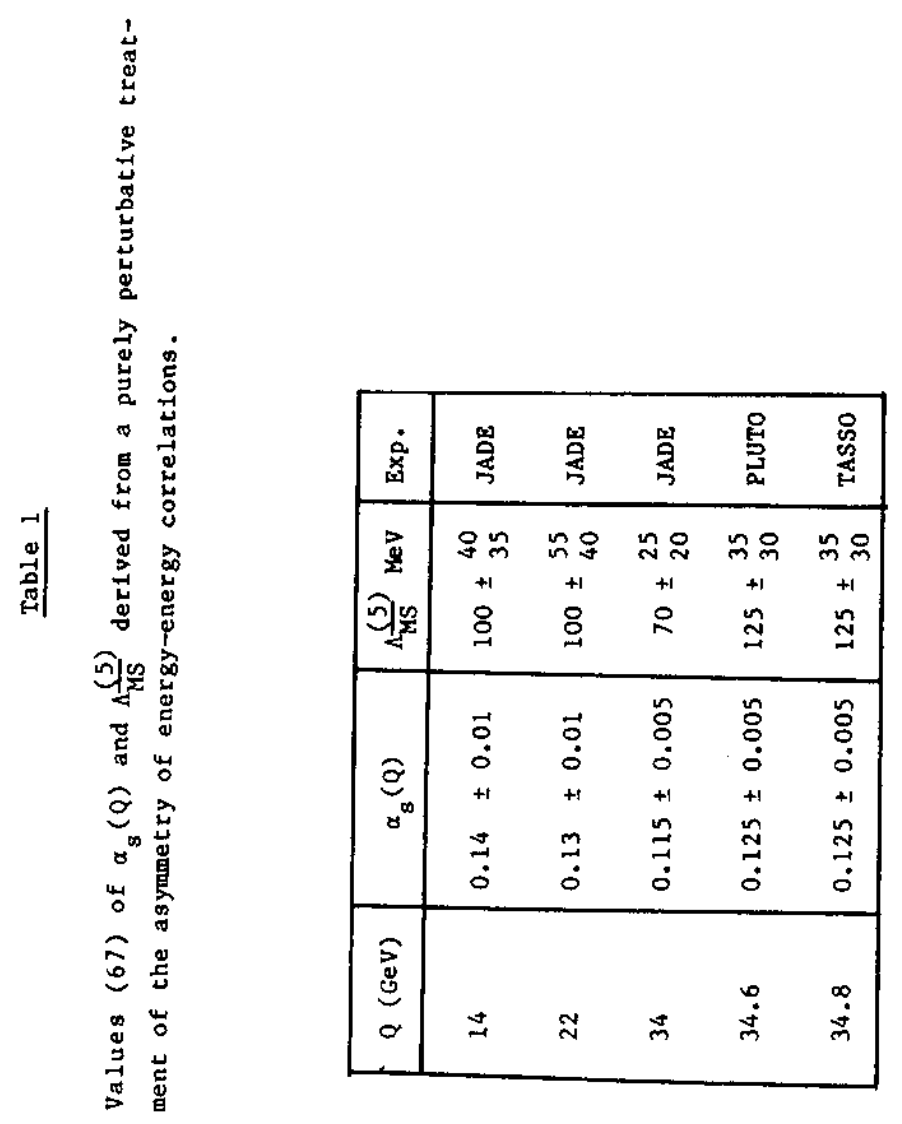




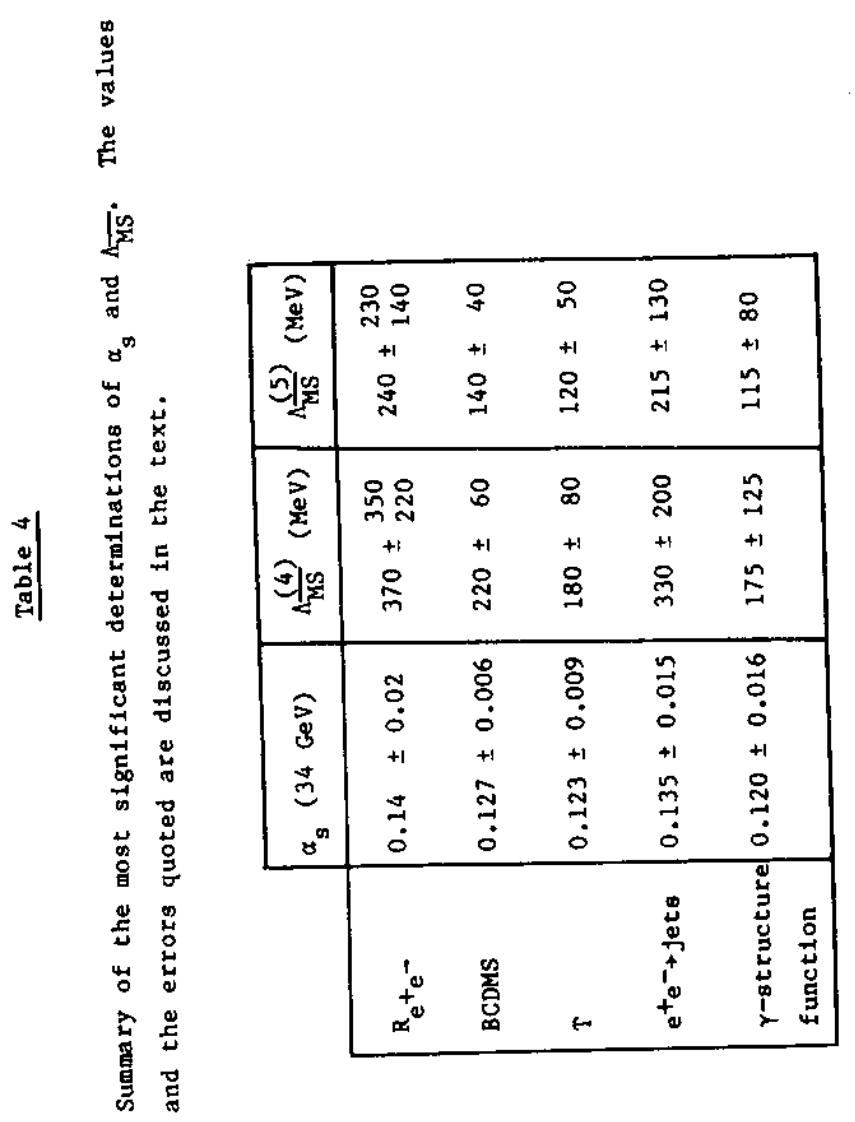

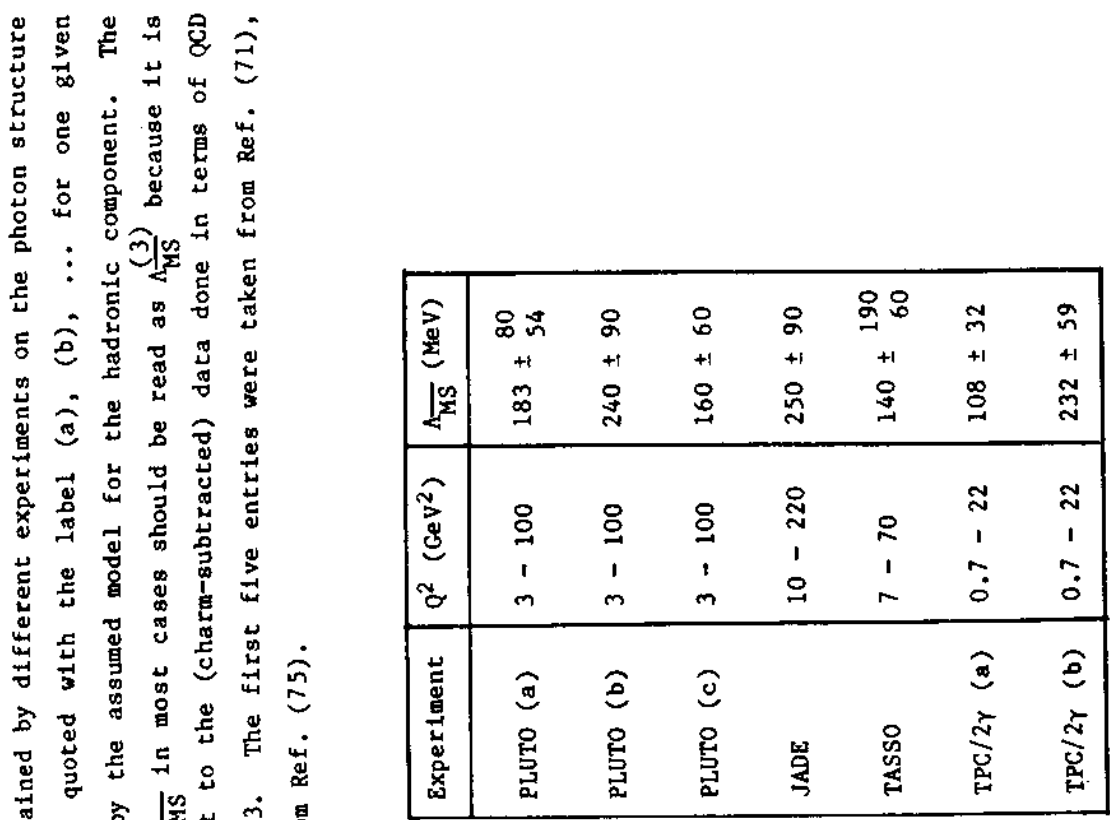

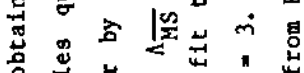

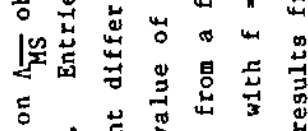

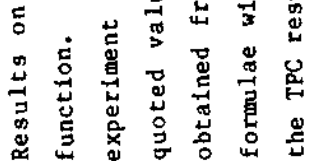



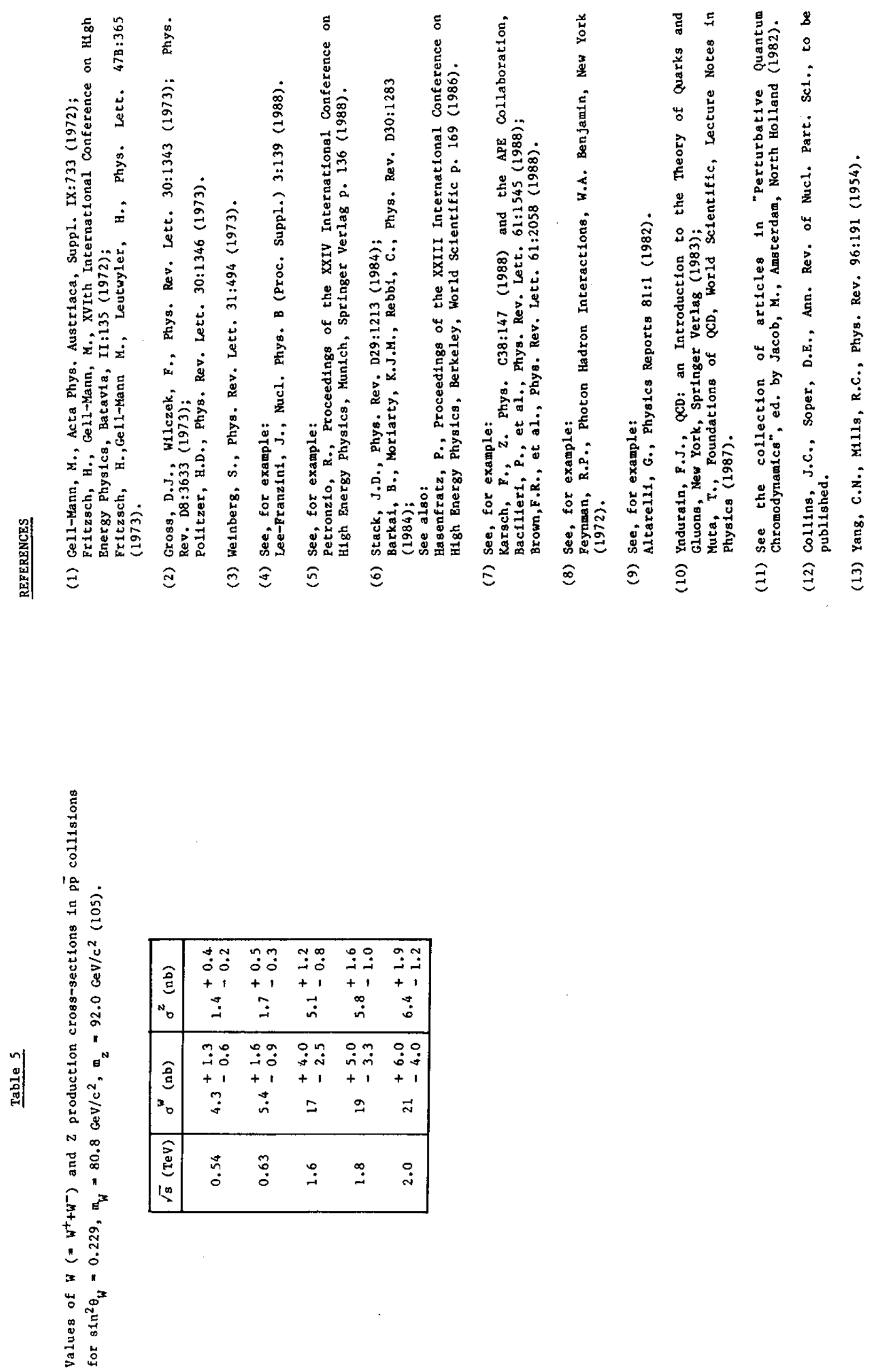


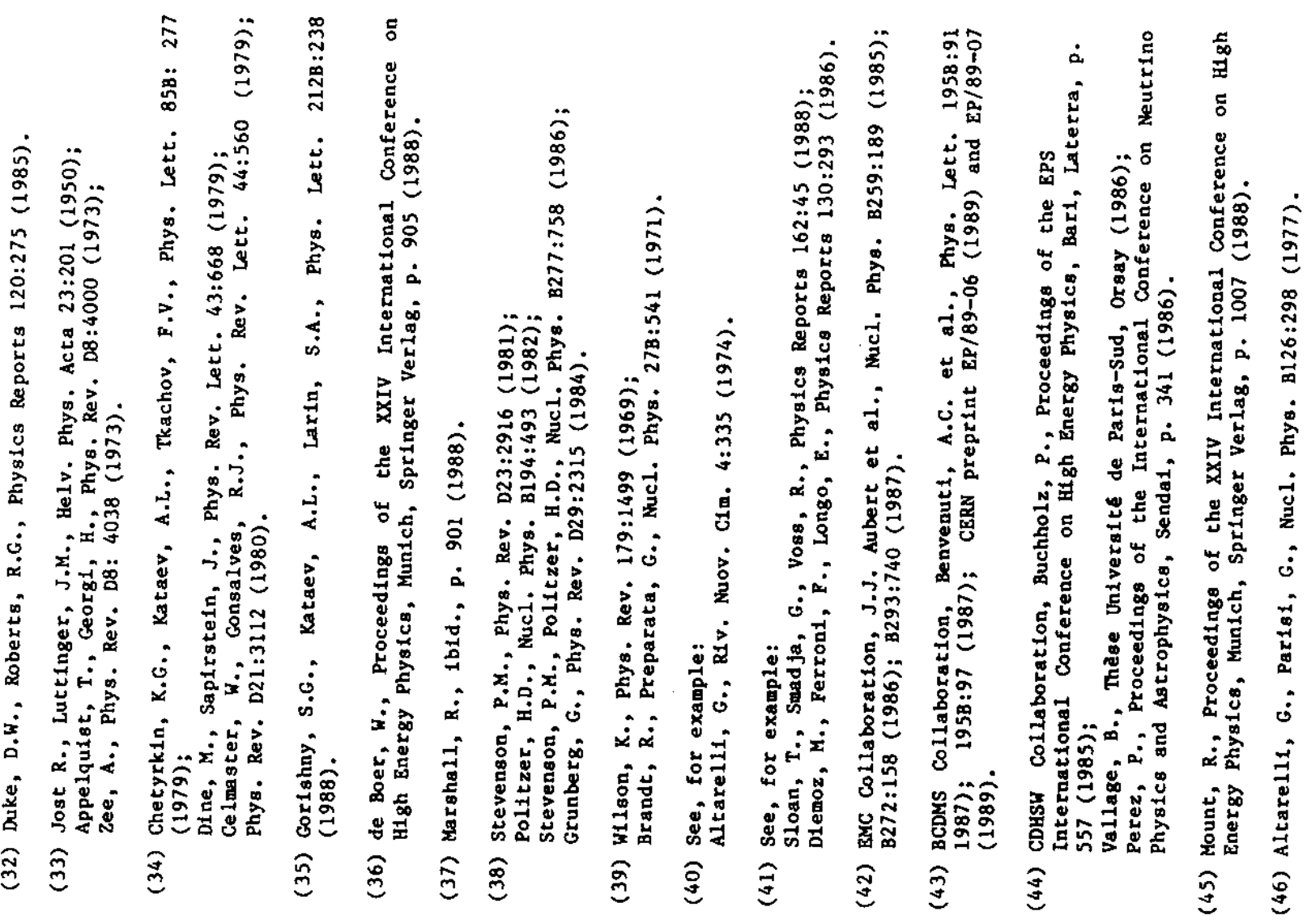

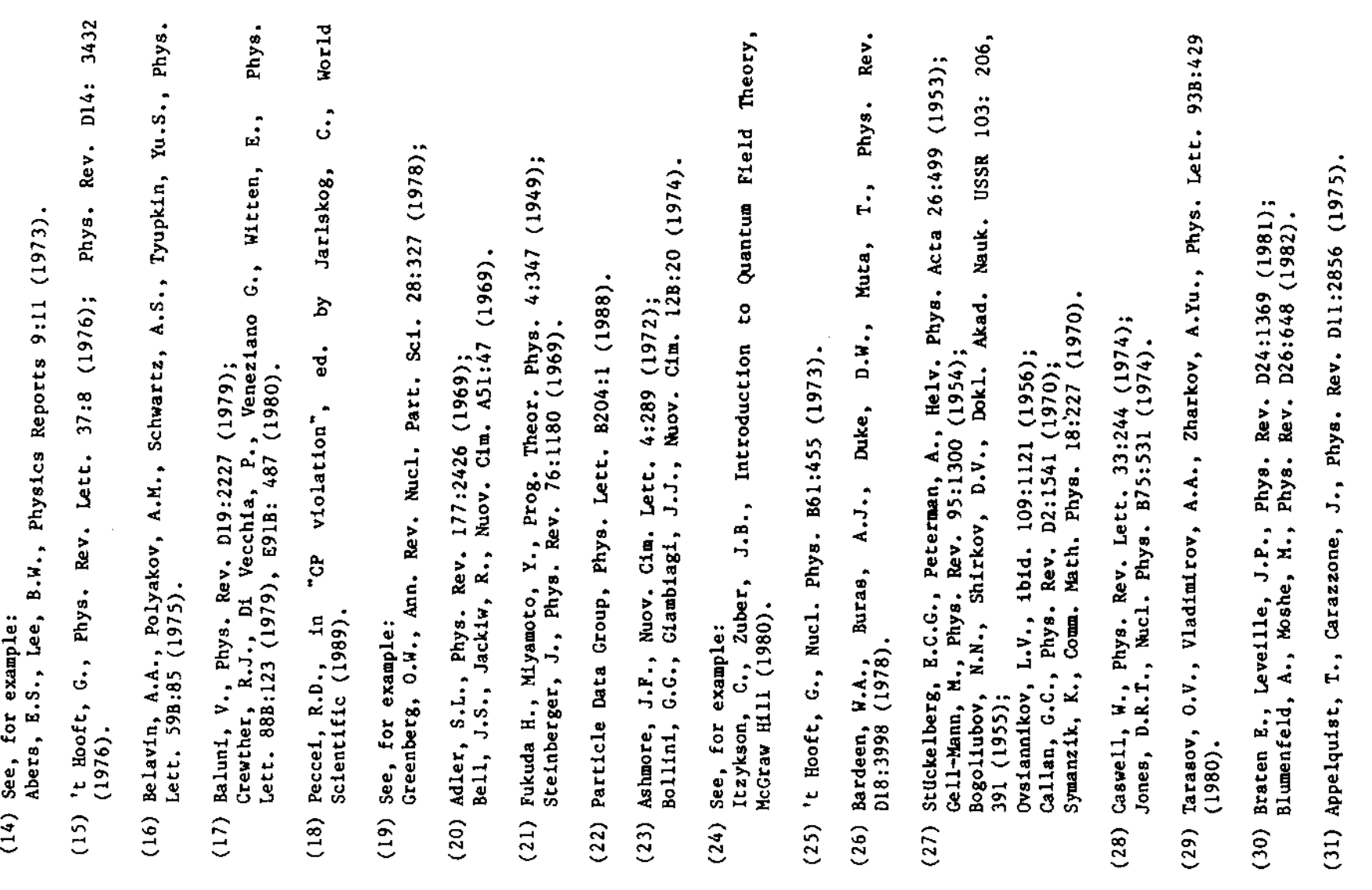




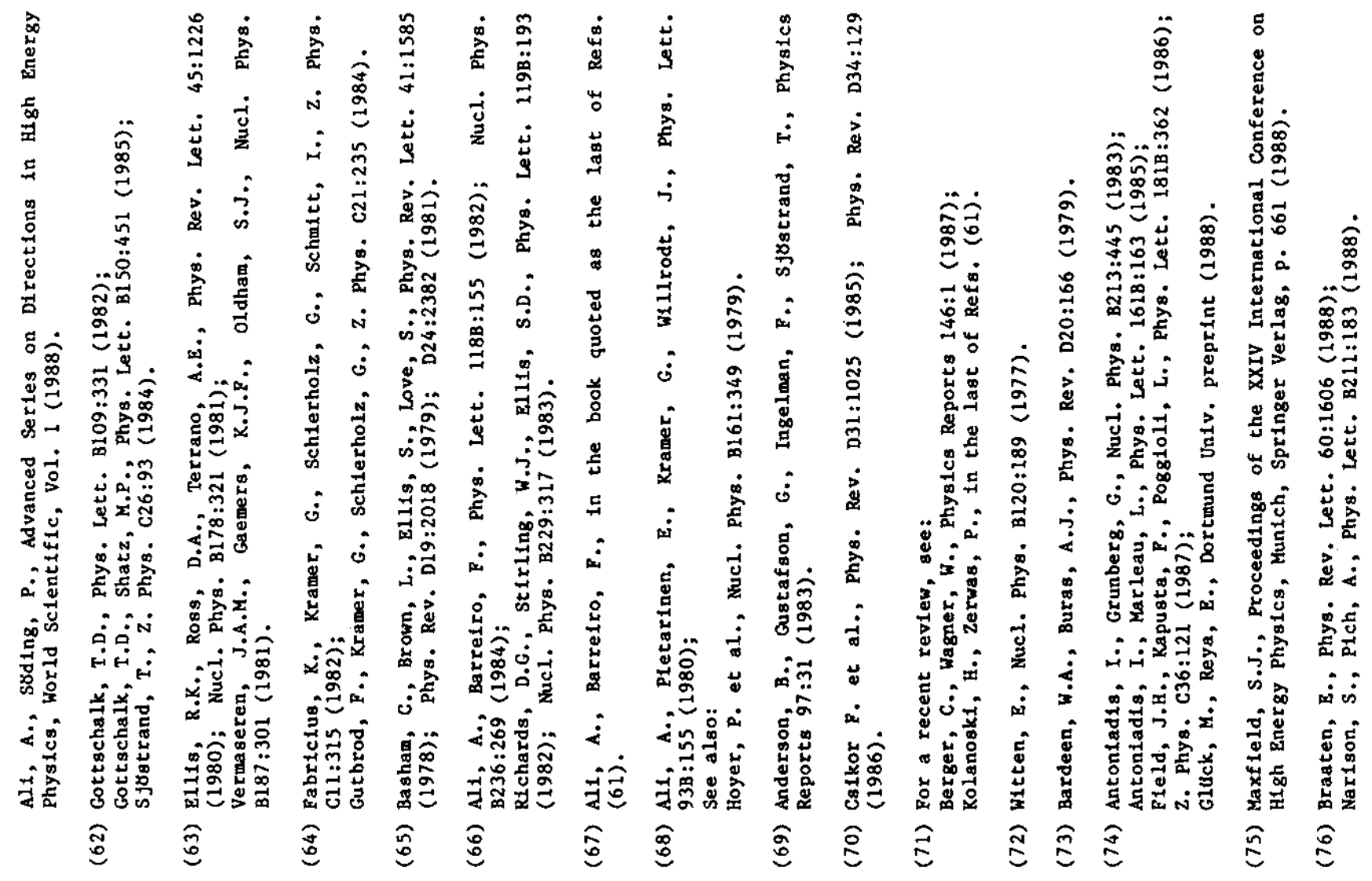

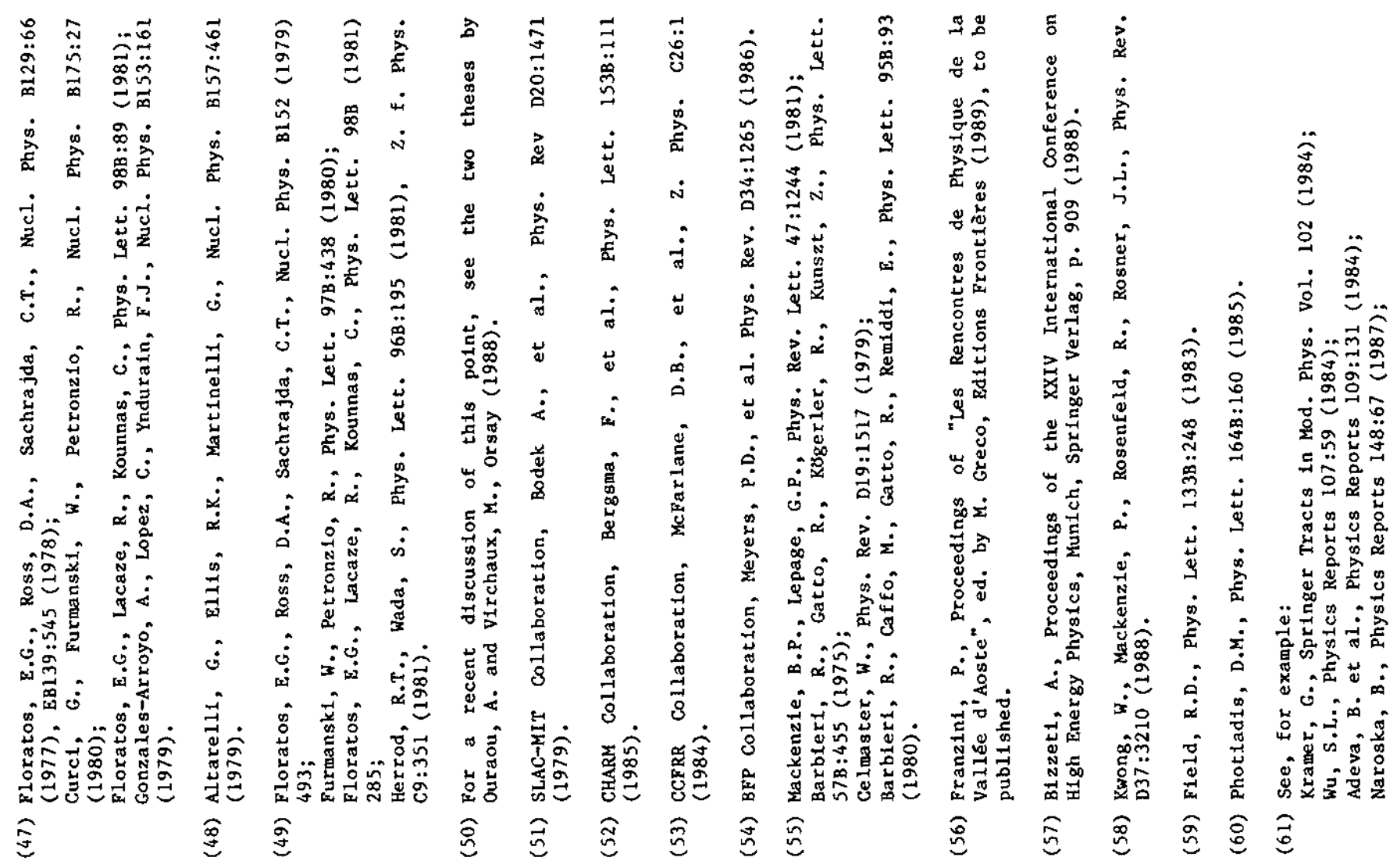


$\begin{array}{ccccccc} & & \\ 0\end{array}$

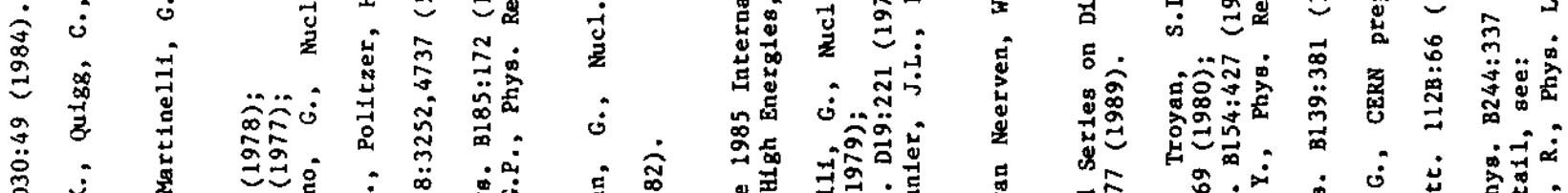

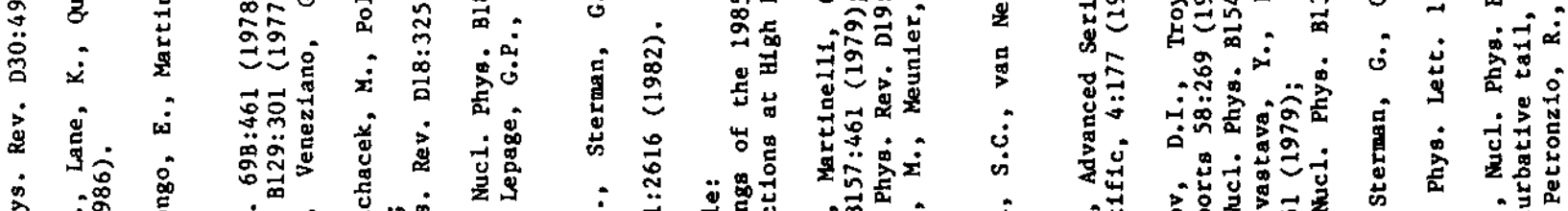

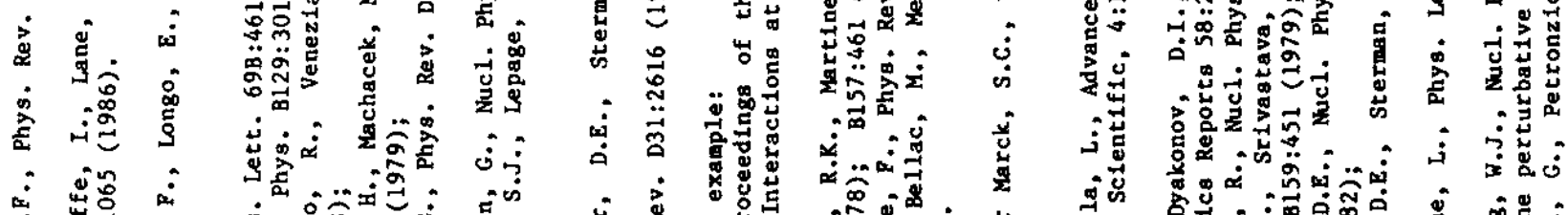

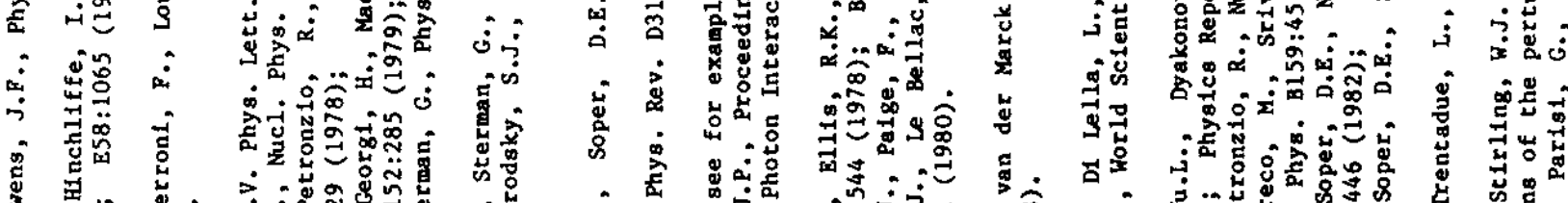

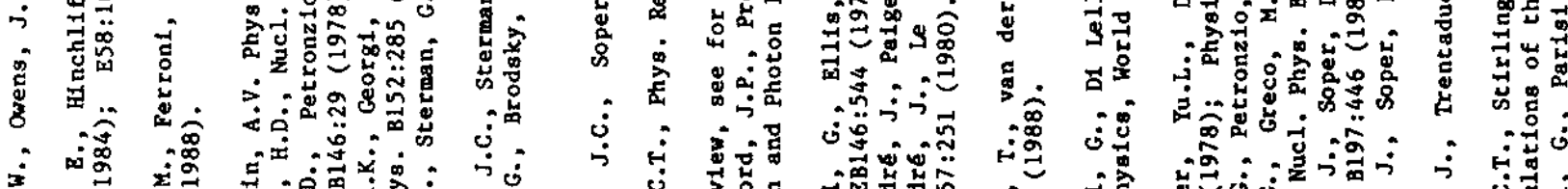

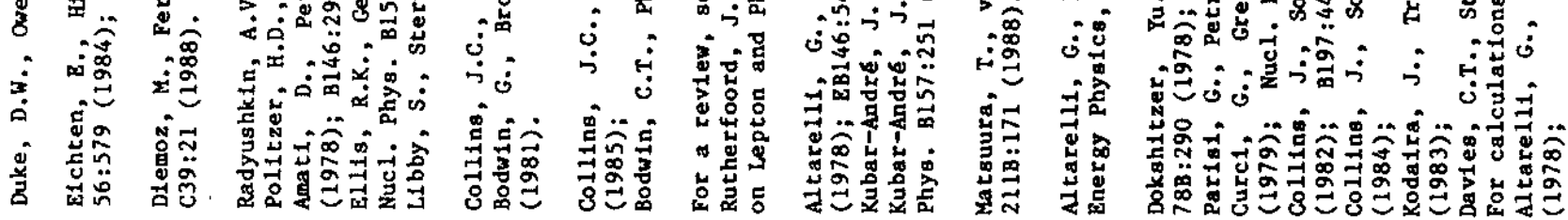
ฐ

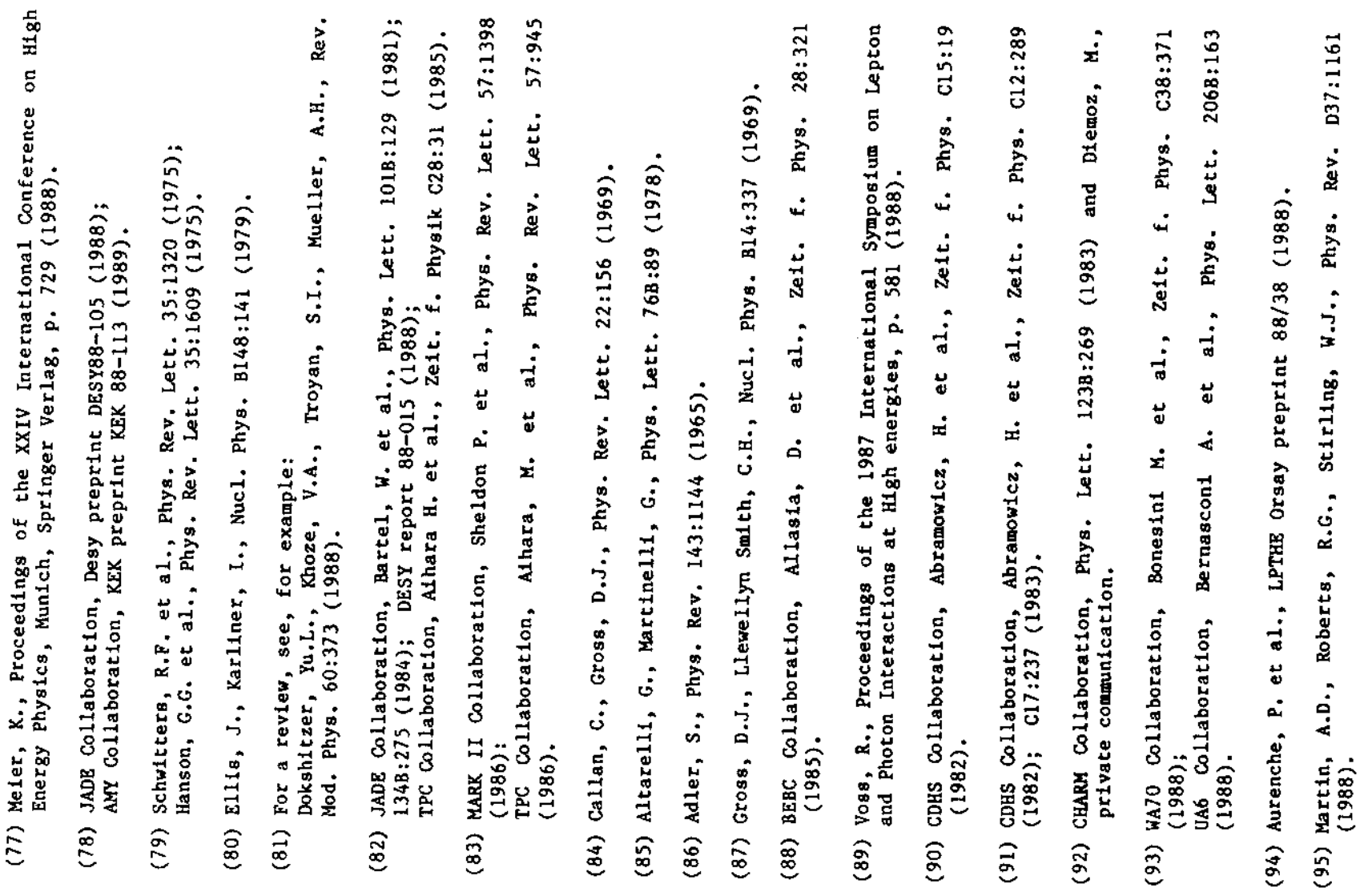



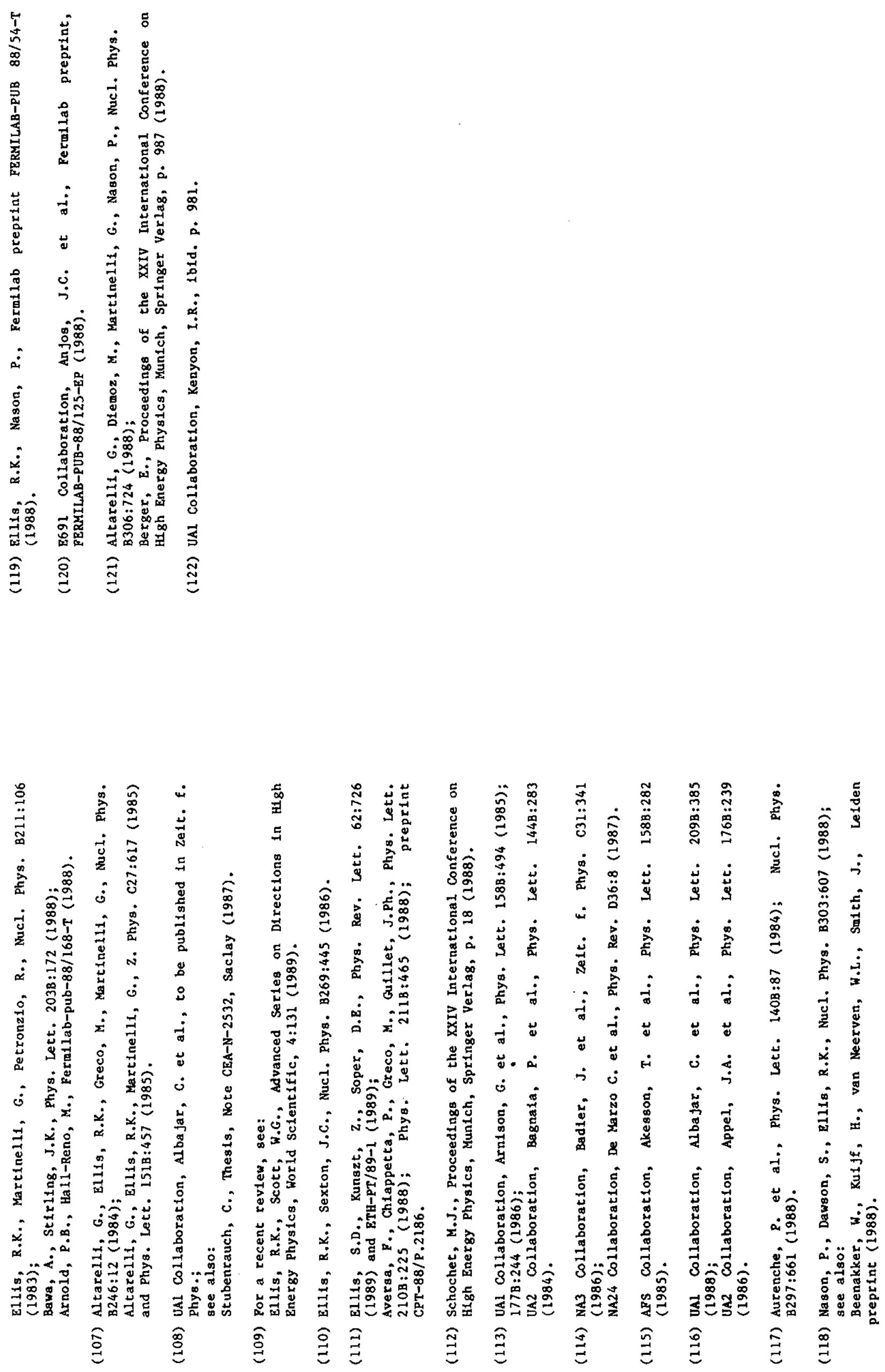

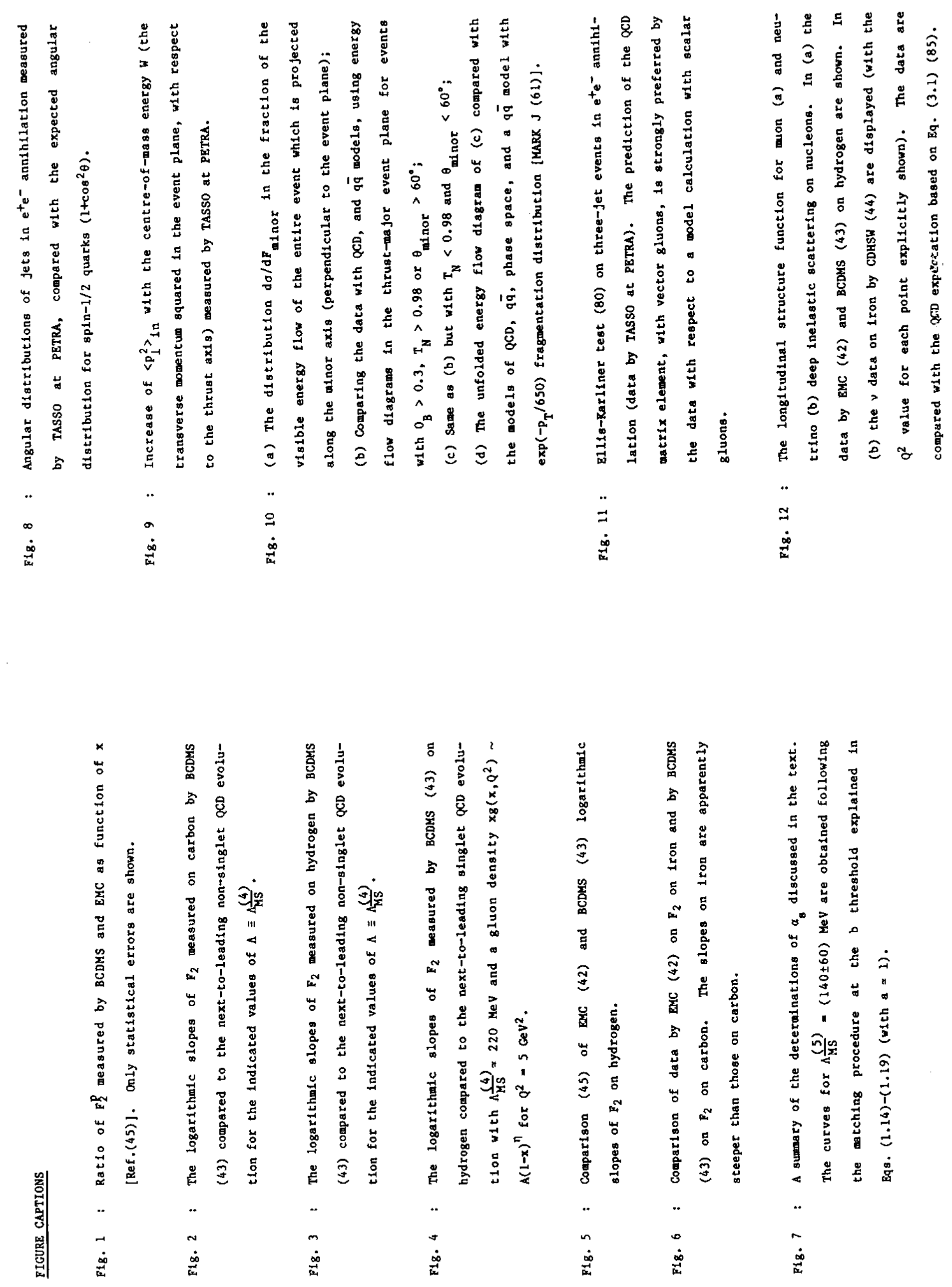

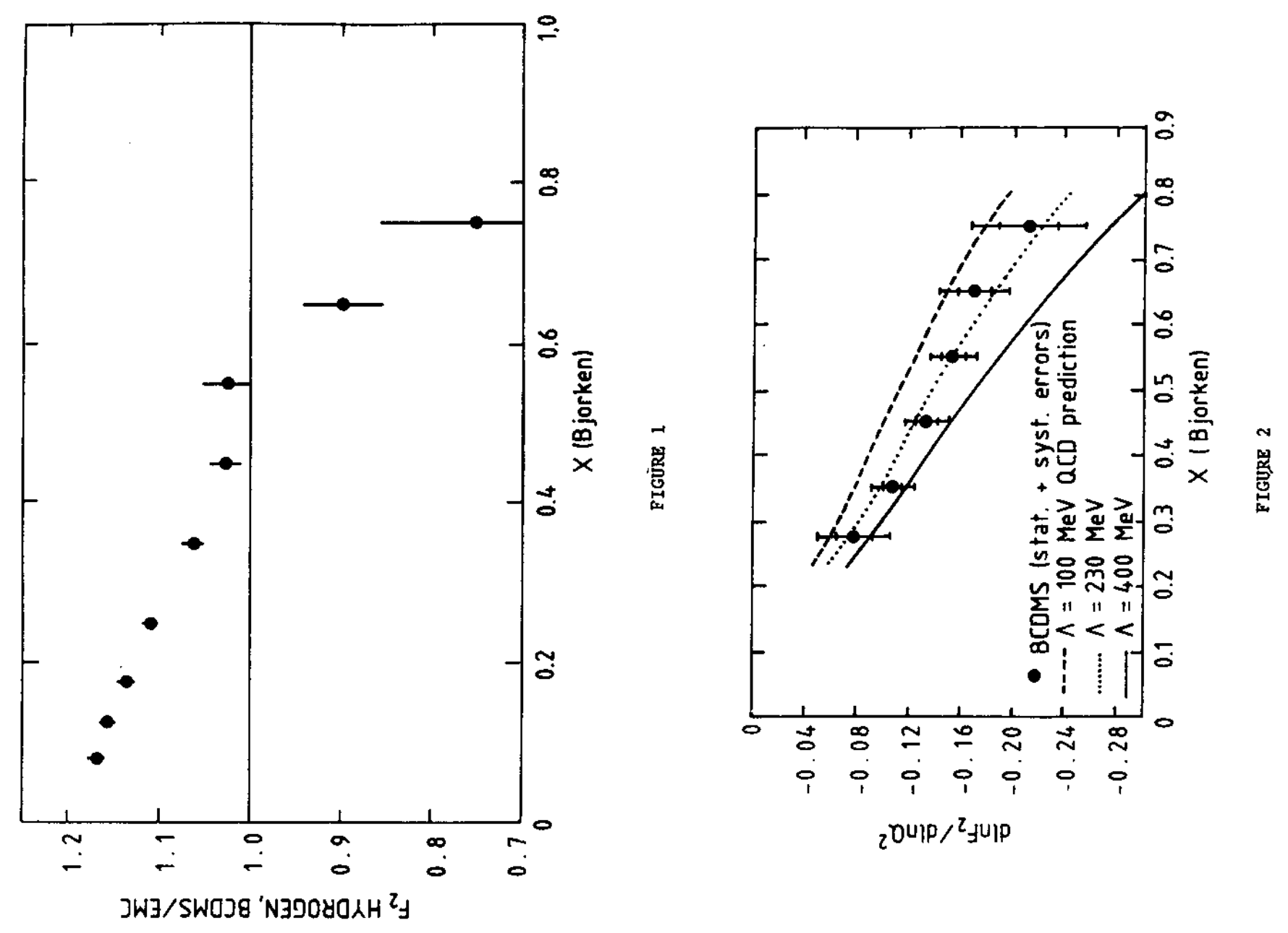

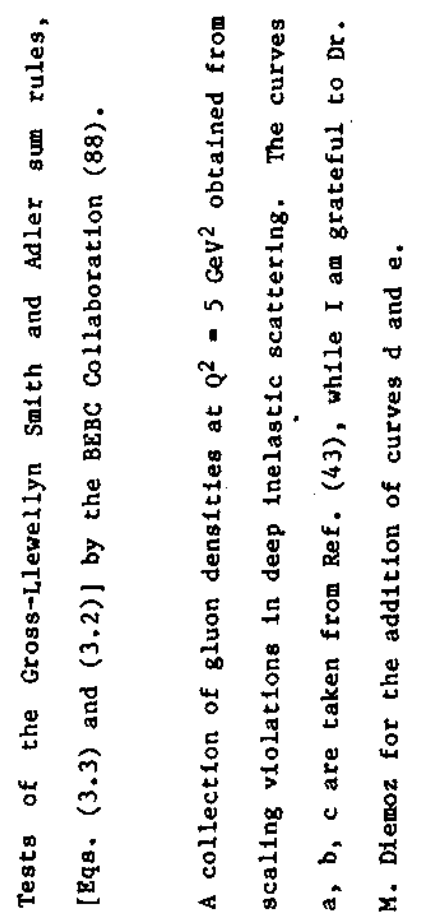

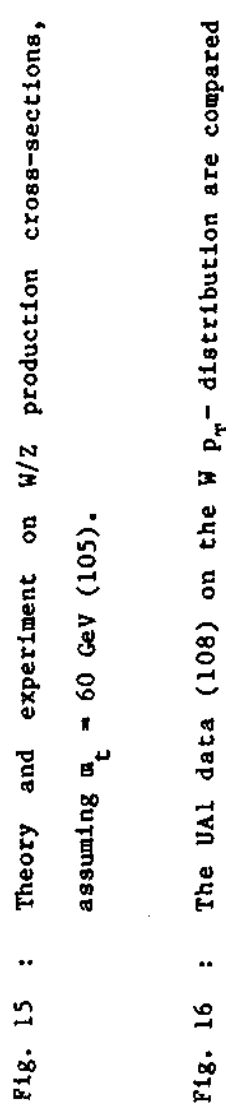

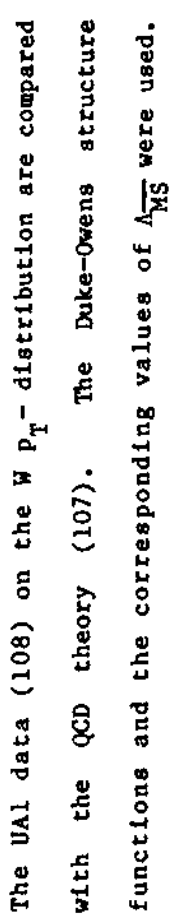
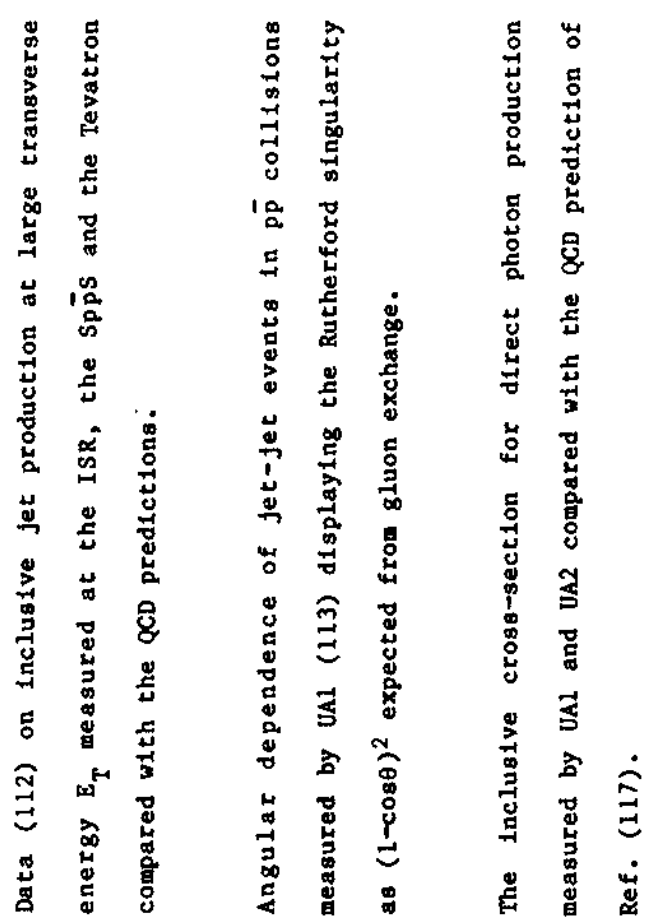

$\ddot{m} \quad \stackrel{ \pm}{m}$

$=$

$\stackrel{\sim}{\infty}$

$\stackrel{9}{2}$ 

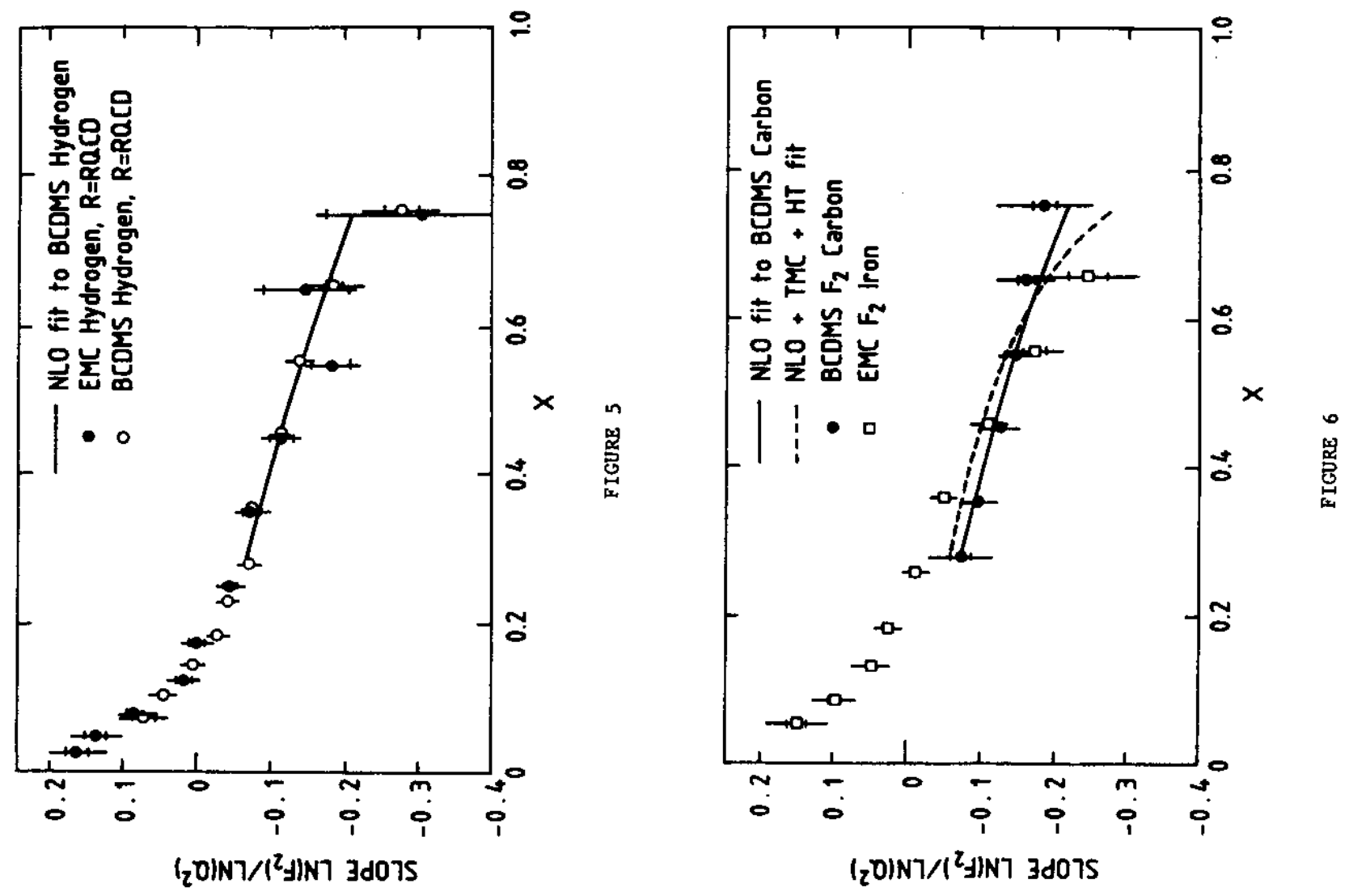

氮

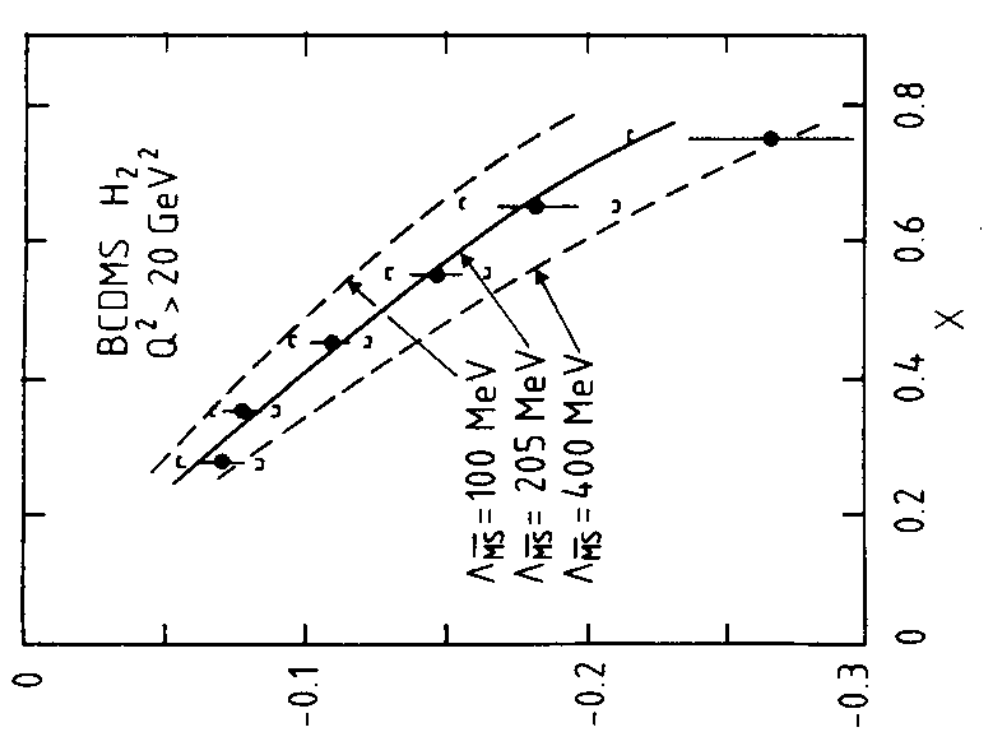

$r^{\mathrm{OU}}$

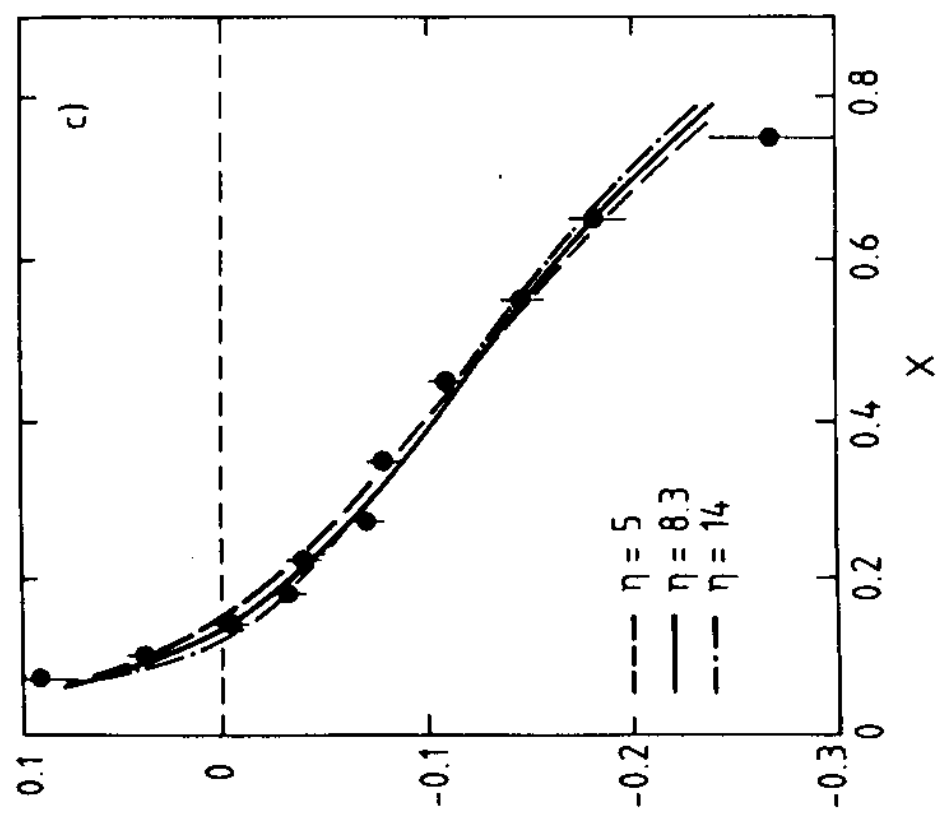

$2^{0}$ 6olp $/^{2}$ 与 601P 

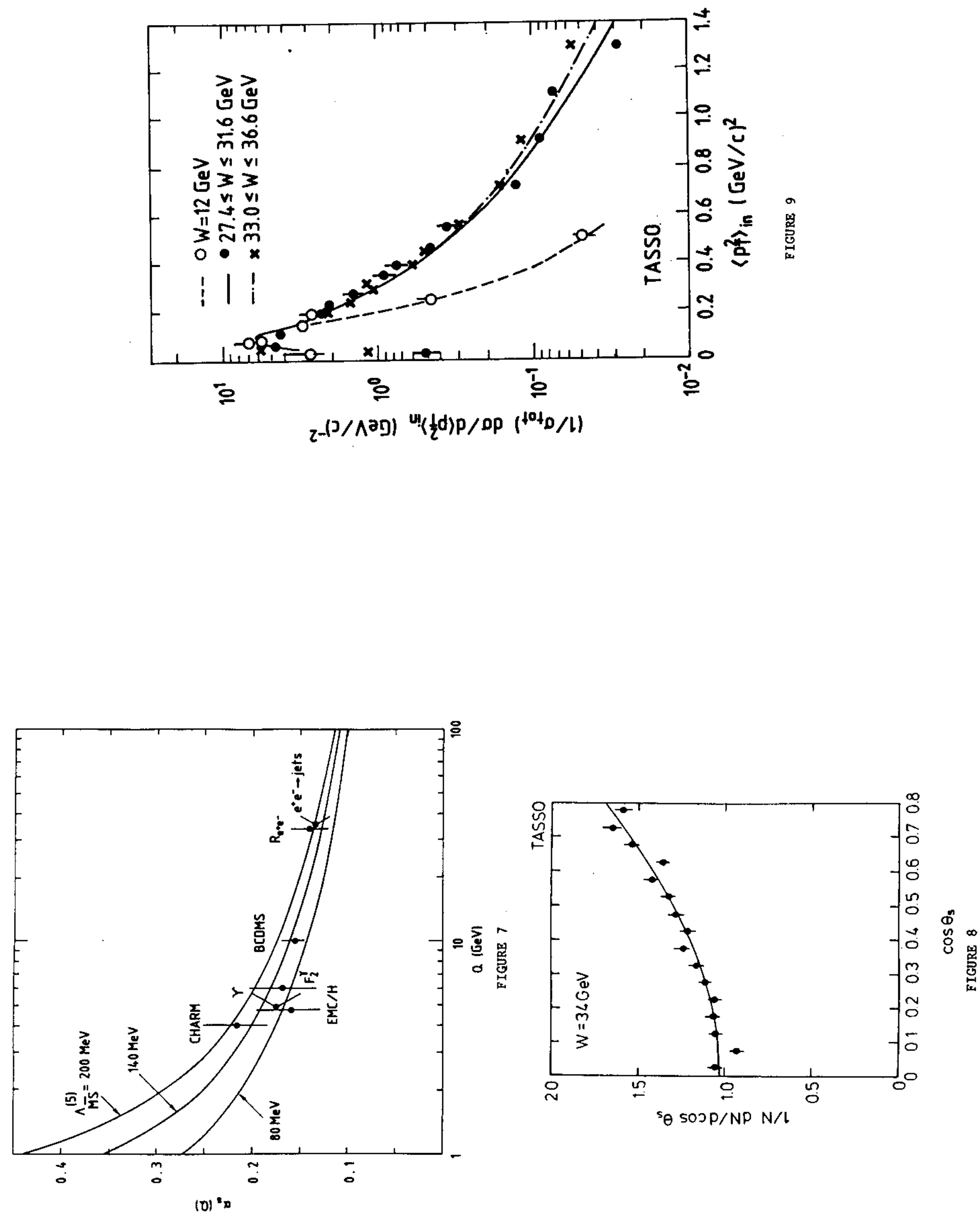

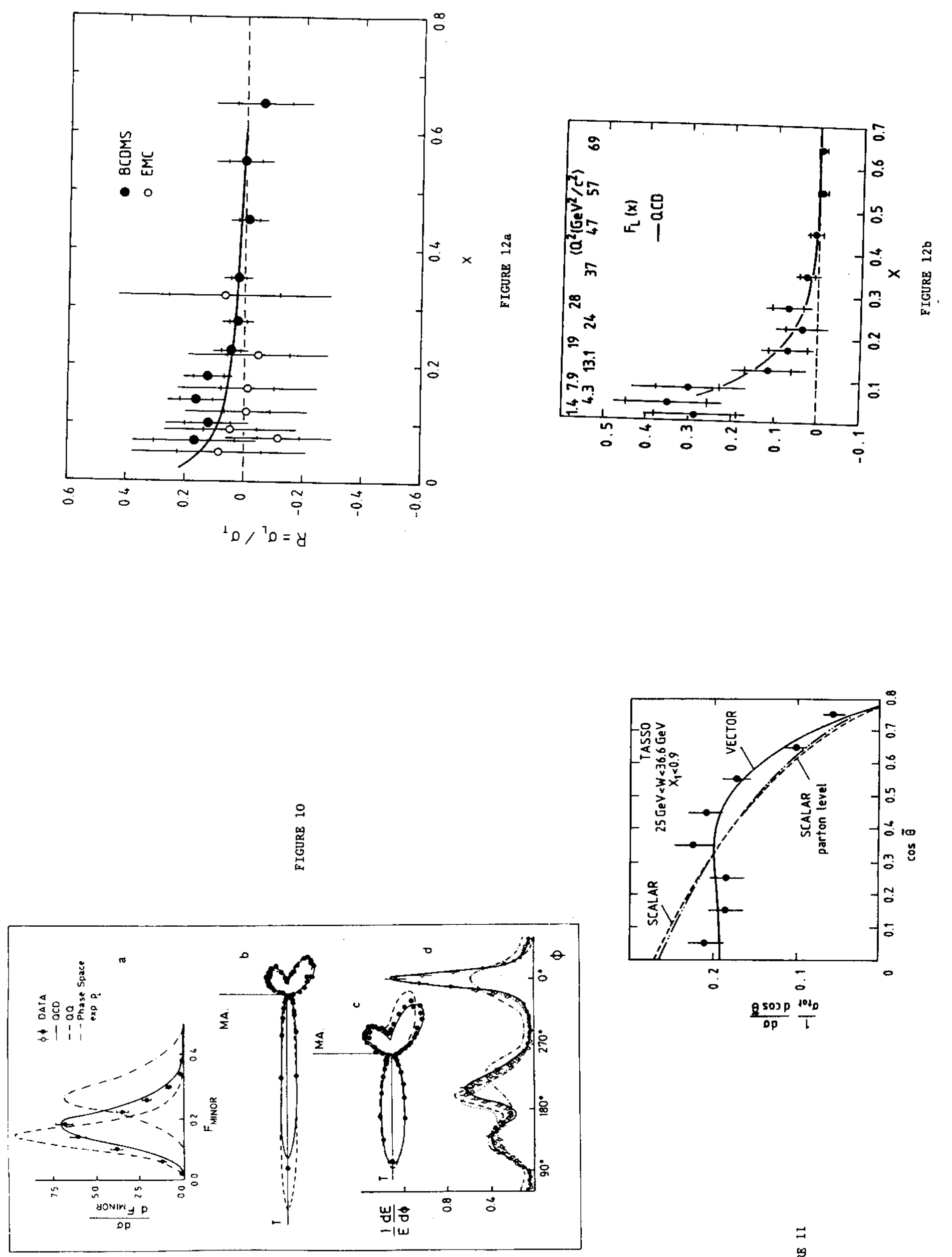


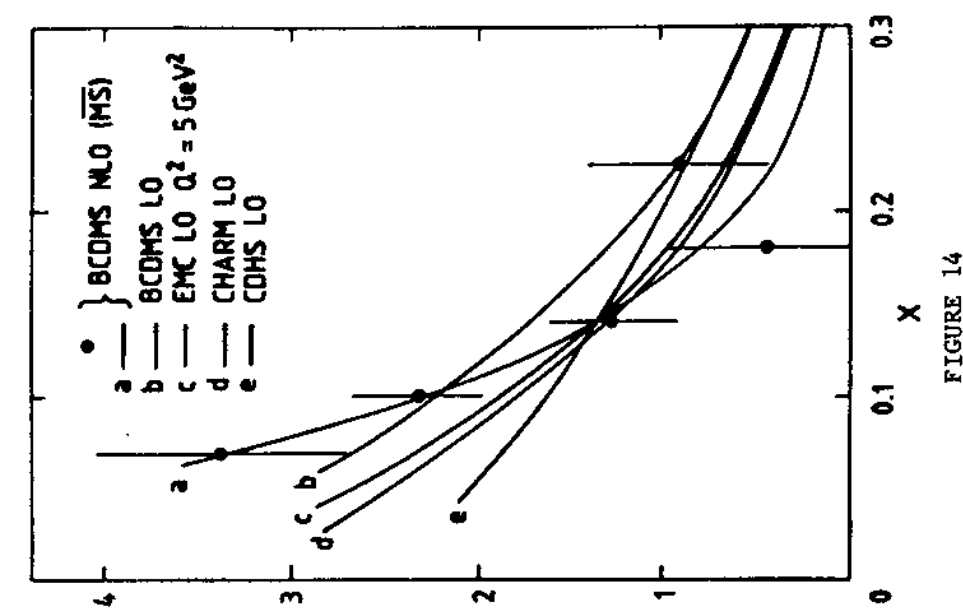

(x) פ
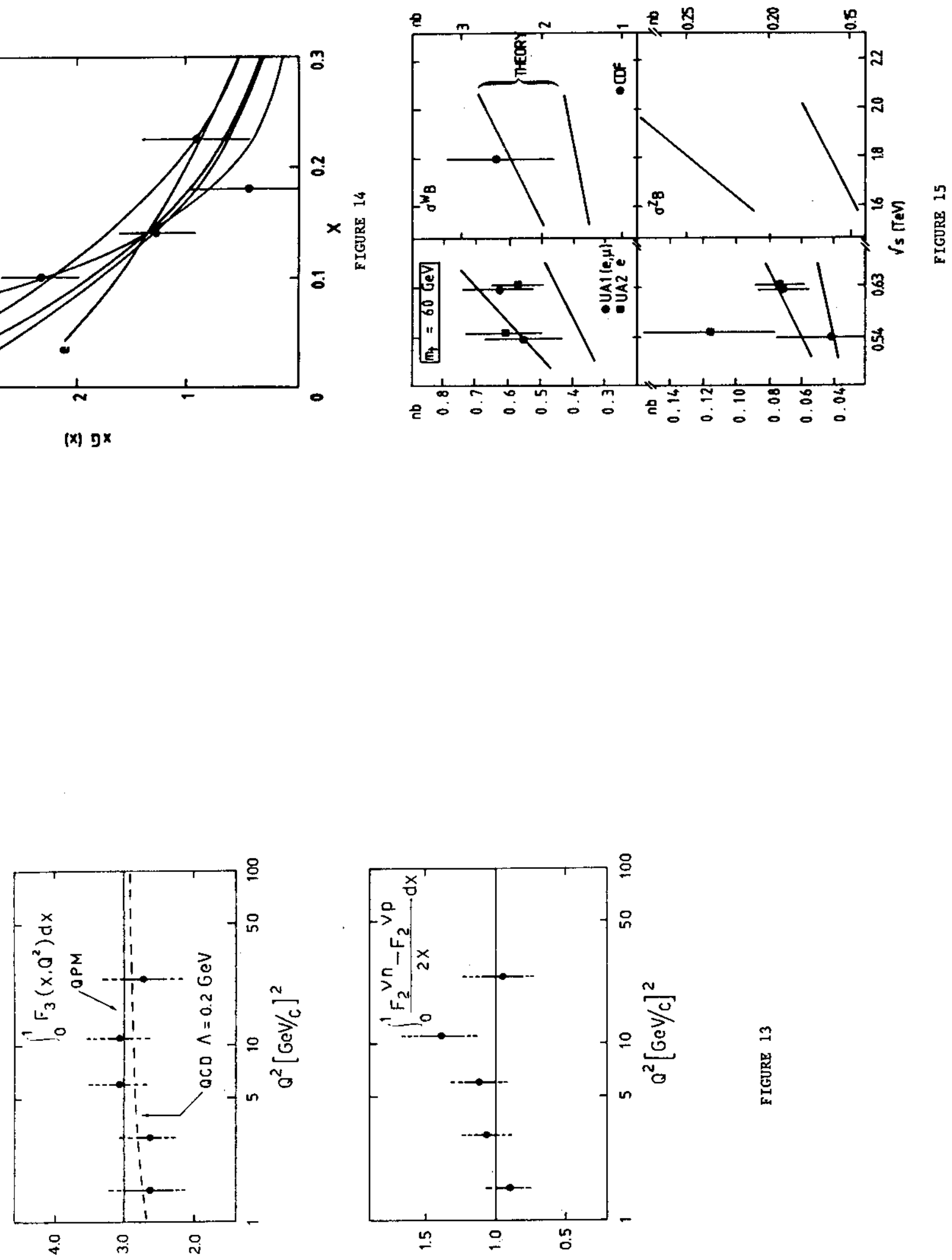

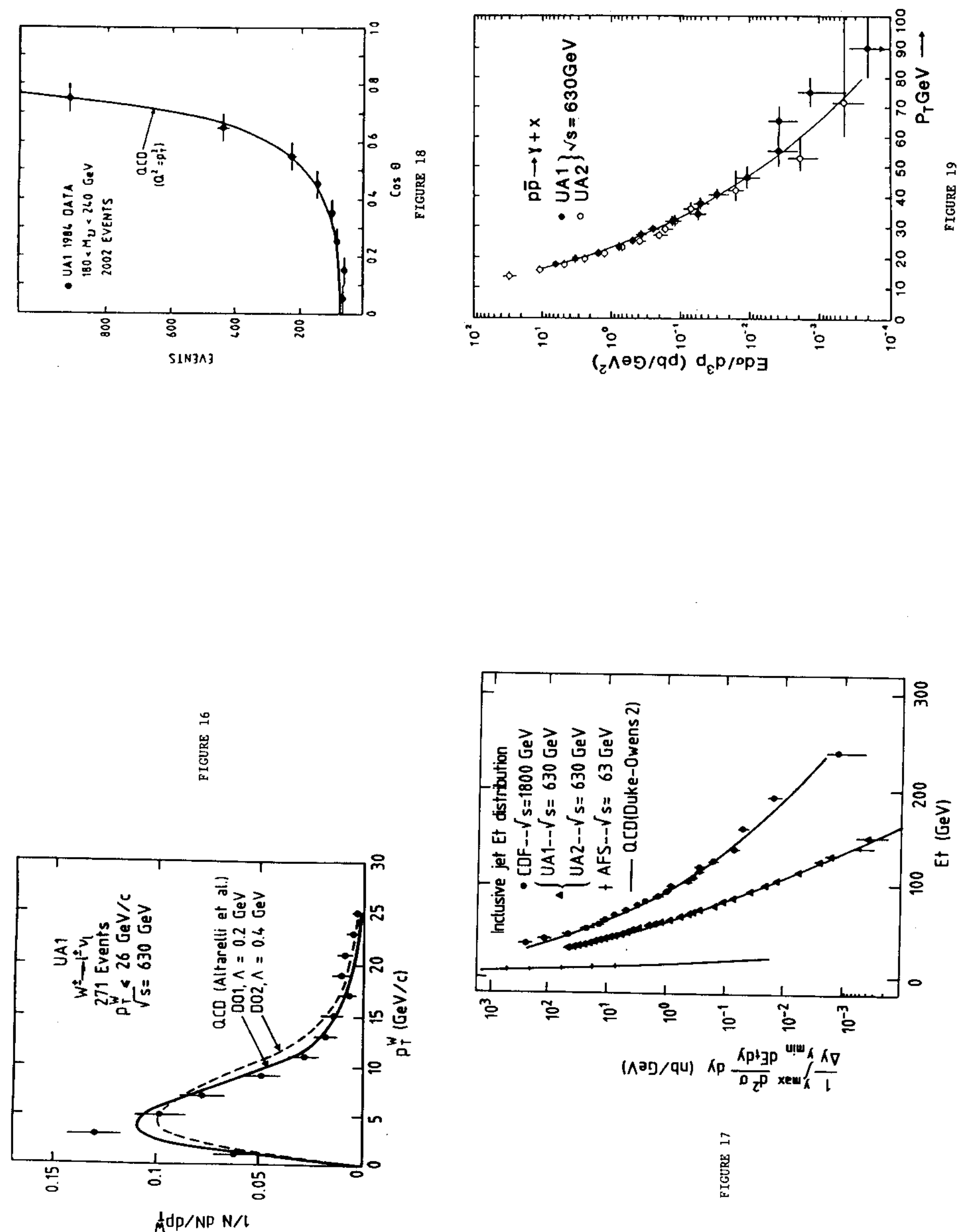